\title{
THE EFFECTS OF A UNIFORMLY WEIGHTED EXERCISE SUIT ON BIOMARKERS OF BONE TURNOVER IN RESPONSE TO AEROBIC EXERCISE IN POSTMENOPAUSAL WOMEN \\ WITH LOW BONE DENSITY
}

\author{
A Thesis \\ presented to \\ the Faculty of California Polytechnic State University, \\ San Luis Obispo \\ In Partial Fulfillment \\ of the Requirements for the Degree \\ Master of Science in Kinesiology
}

by

Haley Frances Terndrup

July 2016 
(C) 2016

Haley Frances Terndrup

ALL RIGHTS RESERVED 


\section{COMMITTEE MEMBERSHIP}

TITLE:

The Effects Of A Uniformly Weighted Exercise Suit On

Biomarkers Of Bone Turnover In Response To Aerobic

Exercise In Postmenopausal Women With Low Bone

Density

AUTHOR: $\quad$ Haley Frances Terndrup

DATE SUBMITTED: July 2016

COMMITTEE CHAIR: Alison K. Ventura, Ph.D.

Assistant Professor of Kinesiology

COMMITTEE MEMBER: Todd Hagobian, Ph.D.

Associate Professor of Kinesiology

COMMITTEE MEMBER: Scott Hazelwood, Ph.D.

Professor of Biomedical Engineering 


\begin{abstract}
The Effects Of A Uniformly Weighted Exercise Suit On Biomarkers Of Bone Turnover

In Response To Aerobic Exercise In Postmenopausal Women With Low Bone Density

Haley Frances Terndrup
\end{abstract}

Current options for maintaining or slowing aging-related bone mineral density (BMD) loss in postmenopausal women primarily include pharmaceutical agents. More recently, physical activity and exercise have been suggested as highly effective, low cost alternatives. Weighted aerobic exercise, utilizing load carriage systems (LCS), is known to increase the gravitational forces impacting bone, creating a higher osteogenic stimulus than standard aerobic exercise. In response to the positive research on aerobic exercise with well-designed LCS, Dr. Lawrence Petrakis, MD, developed a unique $5.44 \mathrm{~kg}$ uniformly weighted exercise suit. This study aimed to examine the effects of the uniformly weighted exercise suit on serum biochemical markers of bone formation (Amino-Terminal Propeptide of Type 1 Collagen [P1NP]; Carboxy-Terminal Propeptide of Type 1 Collagen [P1CP] and resorption (Carboxy-Terminal Telopeptide of Type 1 Collagen [CTX]) in response to submaximal aerobic exercise in postmenopausal women with low bone density. Nine volunteer, sedentary to lightly active, healthy postmenopausal women (Age: $58.7 \pm 1.1$ years, BMI: $28.2 \pm 1.0$, BMD T-score: $-1.2 \pm 0.5$ ) participated in this within-subjects study, wherein each participant exercised under two counterbalanced conditions (aerobic exercise with [ES] or without [NS] the exercise suit). During each condition, participants walked on a treadmill at $65 \%-75 \%$ of their agepredicted maximum heart rate until they reached their goal caloric expenditure $(400 \mathrm{kcal})$. There was a seven-day washout period between sessions. Serum was processed using ELISA protocols to investigate the change in biomarker at 24 and 72 hours post exercise, relative to baseline. The results indicated, when compared to the NS condition, the ES condition elicited a greater positive change in $\mathrm{P} 1 \mathrm{CP}$ at 24 hours $(\mathrm{P}<0.05)$. During the NS condition, CTX increased, relative to baseline, at 24 hours following exercise $(\mathrm{P}<0.05)$, while there was no significant variance in CTX following the ES condition ( $\mathrm{P}>0.05)$. There was no effect of condition on P1NP at any time point ( $\mathrm{P}>0.05)$. In sum, submaximal aerobic exercise while wearing the uniformly weighted exercise suit elicited an antiresorptive effect on bone collagen resorption with a simultaneous increase in bone collagen formation 24 hours post exercise.

Key Words: Weighted Exercise Suit, Biomarkers, Bone Turnover, Formation,

Resorption, Postmenopausal, Osteoporosis, Low Bone Density, Aerobic Exercise 


\section{ACKNOWLEDGMENTS}

I would like to express my sincerest gratitude to my committee chair, Alison Ventura, Ph.D., for her everlasting support, positive reinforcement, guidance, and encouragement, which pushed me to become a better student and researcher. Thank you to my other committee members, Todd Hagobian, Ph.D. and Scott Hazelwood, Ph.D., for their detailed insights regarding methodology and physiological processes. As a committee, your unwavering confidence, even in times when I doubted myself, was greatly appreciated.

Thank you to Dr. Lawrence Petrakis, for without you, the exercise suit would not have existed. Thank you for entrusting me with your suits, and allowing me to explore my own research ideas. Without your contributions, this project would not have been possible. Thank you to Dr. Schaffner for your assistance with my statistical analysis and interpretation. Everything seemed so simple when you explained it.

Thank you to my Assessment-Team (A-Team) students who assisted in the data collection process. You all streamlined my mornings and helped more than you can imagine. It was a pleasure working with you, and I hope this was a positive research experience for you.

Thank you to Kristina Wong and Casey Heaney for managing my budgets and answering my never-ending lists of questions. Thank you to my family for their steadfast support and encouragement. 


\section{TABLE OF CONTENTS}

LIST OF TABLES Ix

LIST OF FIGURES $\quad$ X

\section{CHAPTER}

I. INTRODUCTION 1

Statement of the Problem 1

Statement of the Purpose and Research Hypotheses 3

$\begin{array}{ll}\text { Delimitations } & 3\end{array}$

$\begin{array}{ll}\text { Assumptions } & 4\end{array}$

$\begin{array}{ll}\text { Limitations } & 4\end{array}$

Definition of Terms $\quad 4$

II. LITERATURE REVIEW 9

$\begin{array}{ll}\text { Bone Turnover Mechanisms } & 10\end{array}$

$\begin{array}{ll}\text { Wolff's Law } & 10\end{array}$

$\begin{array}{ll}\text { Bone Modeling } & 11\end{array}$

Bone Remodeling 12

Osteoporotic Bone Mechanisms/Pathologic Response 14

Assessment and Diagnosis of Osteoporosis 15

An Alternative Measure: Biochemical Markers of Metabolism 17

$\begin{array}{ll}\text { Biochemical Markers for Bone Formation } & 18\end{array}$

Biochemical Markers for Bone Resorption 20 
Treatment Interventions

Pharmacological

Physical Activity

Effects of High Intensity Impact Training on Bone

Density and Metabolism

Effects of Aerobic Exercise on Bone Density and

Metabolism

Load Carriage Systems During Exercise on Bone

Density and Metabolism

Influence of Aerobic Exercise with LCS on

Bone Density and Metabolism

Conclusions

III. METHODS

Overview

Participants

Screening and Informed Consent

Experimental Conditions

Experimental Protocol

Blood Measures

Sample Size Calculation

Statistical Methods

IV. RESULTS

Participants 
Changes in Biochemical Markers for Bone Turnover 55

$\begin{array}{lll}\text { V. DISCUSSION AND CONCLUSION } & 60\end{array}$

$\begin{array}{ll}\text { Discussion } & 60\end{array}$

$\begin{array}{ll}\text { Conclusion } & 66\end{array}$

$\begin{array}{lr}\text { REFERENCES } & 68\end{array}$

APPENDICES

$\begin{array}{lr}\text { A. Informed Consent Form } & 88\end{array}$

B. Canadian Society for Exercise Physiology’s Physical Activity

Readiness Questionnaire (PAR-Q) \& You 91

C. Health History Questionnaire 92

D. International Physical Activity Questionnaire (IPAQ) 95

E. Automated Self-Administered 24-hour (ASA24) Dietary

$\begin{array}{ll}\text { Recall System } & 101\end{array}$

F. Exercise Protocol Data Sheet 102

$\begin{array}{ll}\text { G. ELISA Kit Instructions } & 104\end{array}$

a. Amino-Terminal Propeptide of Type 1 Collagen (P1NP) 104

b. Carboxy-Terminal Propeptide of Type 1 Collagen (P1CP) 106

c. Carboxy-Terminal Telopeptide of Type 1 Collagen (CTX) 108 


\section{LIST OF TABLES}

Table

2.1 Side Effects of Fracture-Prevention Medication 24

3.1 Exercise Suit Jacket Measurements 43

3.2 Exercise Suit Pants Measurements 44

3.3 Example Schedule of Events for Two Different Participants 46

3.4 Timeline of Participant Action During Exercise Trial Duration $\begin{array}{ll}\text { By Minute } & 49\end{array}$

4.1 Participant Characteristics $(\mathrm{N}=9) \quad 54$

4.2 Comparison of Characteristics at Baseline for Each Condition 55

4.3 Measurements of Serum Amino-Terminal Propeptide of Type 1

Collagen (P1NP), Carboxy-Terminal Propeptide of Type 1 Collagen

(P1CP), and Carboxy-Terminal Telopeptide of Type 1 Collagen

(CTX) at Baseline, 24 hours, and 72 hours Post Exercise 


\section{LIST OF FIGURES}

Figure

Page

2.1 Normal and Osteoporotic Bone Remodeling and Biochemical

Markers

2.2 Diagnostic Criteria for Osteoporotic Women Based on the Distribution of BMD in a Young, Healthy Adult Population

2.3 Extracellular Events in the Synthesis of Collagen Fibril

3.1 Uniformly Weighted Exercise Suit

4.1 Effect of Condition (ES; exercise suit, NS; no suit) on Average Serum Level of Amino-Terminal Propeptide of Type 1 Collagen (P1NP) at Baseline, 24-hours and 72-hours Post Exercise Session

4.2 Effect of Condition (ES; exercise suit, NS; no suit) on Average Serum Levels of Carboxy-Terminal Propeptide of Type 1 Collagen (P1CP) at Baseline, 24 hours and 72 hours Post Exercise Session

4.3 Effect of Condition (ES; exercise suit, NS; no suit) on Average Serum Levels of Carboxy-Terminal Telopeptide of Type 1 Collagen (CTX) at Baseline, 24 hours and 72 hours Post Exercise Session 


\section{Chapter I}

\section{INTRODUCTION}

\section{Statement of the Problem}

As the human body ages, bones become more fragile and porous leading to osteoporosis. This decline in both density and quality compromises the structural integrity of bone, greatly increasing the risk for fracture (Clarke, 2008). Traditionally, pharmaceutical interventions have been the primary method in the treatment of osteoporosis. Studies have shown that modern antiresorptive and anabolic medicines effectively lower the risk of fracture by either stimulating new bone growth by increasing bone modeling, or by strengthening the already existing skeleton (Lindsay et al., 2006; Stepan, Alenfeld, Boivin, Feyen, \& Lakatos, 2003). While effective, these drugs have detrimental side effects, high costs, and provide inconsistent results when tested (Cosman et al., 2014).

More recently, physical activity and exercise have been suggested as effective, low cost alternatives to maintain and potentially increase bone mineral density (BMD) in postmenopausal women. Based on these findings, exercise is recommended as an alternative treatment modality. The most commonly prescribed exercise for strengthening bones is high intensity, high impact resistance training. Although effective, this type of training is associated with increased risk of fracture and decreased quality of life due to injury (Martyn-St James \& Carroll, 2006). Recently, aerobic exercise has been indicated as a lower risk alternative method of loading the skeleton when compared with high intensity impact training (Alghadir, Aly, \& Gabr, 2014; Block, Genant, \& Black, 1986; 
N. E. Lane et al., 1986; Nilsson, Andersson, Havdrup, \& Westlin, 1978; Rutherford, 1997; Talmage, Stinnett, Landwehr, Vincent, \& McCartney, 1986), but is not as effective. However, weighted aerobic exercise, utilizing load carriage systems (LCS), increases the gravitational forces impacting the bone creating a higher osteogenic stimulus than standard aerobic exercise. LCS also allow for the forces to be delivered in a more gradual manner, rather than at the higher rate produced by resistance training (Klentrou, Slack, Roy, \& Ladouceur, 2007; Kohrt, Ehsani, \& Birge, 1997; Milliken et al., 2003; Snow, Shaw, Winters, \& Witzke, 2000; Tosun, Bolukbasi, Cingi, Beyazova, \& Unlu, 2006). Currently, there are several LCS designs (backpacks, front packs, double packs, weighted vests, hand and ankle weights, etc.), which require users to carry larger weight amounts in singular locations around the body. These site-specific designs may prove to be problematic when utilized to enhance aerobic exercise (Knapik, Harman, \& Reynolds, 1996), and may result in reduced performance, such as imbalance, shoulder and back pain, and/or kyphosis. A more universal distribution of the weight around the whole body has the potential to enhance the likelihood of completing the exercises in a safe and effective manner (Curry et al., 2015).

In response to the positive research on aerobic exercise with well-designed LCS, Dr. Lawrence Petrakis, MD, developed a $5.44 \mathrm{~kg}$ uniformly weighted exercise suit, consisting of a front zip jacket and drawstring pants. The exercise suit is made from a flexible fabric, called Athlotex ${ }^{\mathrm{TM}}$, which combines biaxial stretching, breathability, and flexibility to accommodate different body compositions. 


\section{Statement of the Purpose and Research Hypotheses}

The purpose of this study was to examine the effects of a uniformly weighted exercise suit on biochemical markers of bone formation and resorption in response to aerobic exercise in postmenopausal women with osteoporosis. We hypothesized the following:

When compared to the non-suit condition, wearing the uniformly weighted exercise suit during submaximal aerobic exercise will elicit a greater:

1. Positive change in P1NP at 24 and 72 hours post exercise relative to baseline.

2. Positive change in $\mathrm{P} 1 \mathrm{CP}$ at 24 and 72 hours post exercise relative to baseline.

3. Negative change in CTX at 24 and 72 hours post exercise relative to baseline.

\section{$\underline{\text { Delimitations }}$}

This study was delimited to the following parameters:

1. Only 9, sedentary to lightly active, female members of the Cal Poly and San Luis Obispo communities between the ages of 45-65 years old and with low bone density as assessed by DXA, were recruited as participants.

2. Only participants who met the sizing measurement specifications of the uniformly weighted exercise suit were recruited for this study.

3. Physical activity during the duration of the study was self-reported using the International Physical Activity Questionnaire (IPAQ).

4. Nutritional information was gathered and self-reported using the Automated SelfAdministered 24-hour Dietary Recall (ASA24). 
5. Body composition, bone mineral density, $\mathrm{T}$-score, and Z-score were determined using Dual X-ray Absorptiometry (DXA).

\section{$\underline{\text { Assumptions }}$}

The study was based on the following assumptions:

1. It was assumed that all participants honestly self-reported medications and health history information so as to not avoid exclusion from this study.

2. It was assumed that research assistants followed every protocol outlined in this study.

\section{Limitations}

The study was limited by the following factors:

1. Psychological state and motivation may have affected the participant's activity level outside of testing sessions.

2. There was limited funding for this project.

3. Sizing measurements of the suit limited participant involvement and increased exclusion criteria.

\section{$\underline{\text { Definition of Terms }}$}

Aerobic exercise: a type of physical activity using large muscle groups and is maintained continuously in a rhythmic nature; this type of exercise overloads the heart and lungs to increase cardiorespiratory fitness 
Amino-terminal of the propeptides of type 1 collagen (PINP): biochemical marker of bone formation

Anabolic agent: a class of pharmacological medication that acts by directly stimulating bone formation, and reducing the risk of fracture

Antiresorptive agent: a class of pharmacological medication used in the prevention and treatment of osteoporosis

Biochemical markers of bone turnover: cellular and extracellular components of the skeletal matrix that can be measured in serum or urine; used to predict bone growth or loss and fracture risk

Bone: major structural connective tissue and support for the human body Bone mineral content (BMC): the mass of the mineral contained in an entire bone in grams $(\mathrm{g})$; the mass per unit bone length in grams per centimeter $(\mathrm{g} / \mathrm{cm})$ Bone mineral density $(B M D)$ : the amount of mineralized tissue; amount per volume of bone

Calcitonin: a polypeptide hormone that inhibits the resorptive activity of osteoclasts Calcium: an essential mineral that's major role is in the development and maintenance of the healthy skeleton Carboxy-terminal of the propeptides of type 1 collagen (P1CP): biochemical marker of bone formation Carboxy-terminal telopeptides of type 1 collagen (CTX): biochemical marker of bone resorption Collagen: the main structural protein found in human connective tissue 
Dual energy $x$-ray absorptiometry (DXA): a diagnostic test used to measure and assess BMD at various sites of the skeleton using a low dose radiation exposure Estrogen: steroid hormones controlling female sexual development; directly affects the level of bone mass via estrogen receptors in bone that reduce the rate of bone resorption and bone loss.

Exercise: a form of physical activity; pre-planned, structured, and repetitive bodily movement purposefully done to maintain or improve the physical fitness level of the participant

Formation: see osteogenesis

Fracture: the complete or incomplete breakage of bone

Heart rate: The number of heart beats per minute expressed as beats.minute ${ }^{-1}(\mathrm{bpm})$ Hormone/Estrogen therapy: a general term for all types of estrogen replacement therapy generally prescribed for women after menopause

Load carriage systems (LCS): systems used to enhance the comfort and efficiency of load carriage, such as backpacks and shoulder straps

Load training: physical training while wearing additional external load

Metabolism: the biochemical processes occurring within a living cell or organism that are necessary for the maintenance of life

Modeling: the skeletal process that occurs during the increased rate of bone mass

Normal bone mass: bone mineral density within $1 \mathrm{SD}$ of the mean for normal young adults

Osteoblasts: the cells responsible for secretion of the bone matrix

Osteoclasts: multinucleated cells that dissolve bone tissue 
Osteoid: unmineralized, organic part of the bone matrix that is formed prior to maturation of the bone tissue

Osteogenesis: the formation of bone tissue

Osteopenia: low bone mass; bone mineral density between -1.0 and $-2.5 \mathrm{SD}$ below the mean for young normal adults

Osteoporosis: a chronic, progressive disorder in which the bones become more porous, brittle, and are at an increased risk for fracture; characterized by deterioration of microarchitecture and bone strength; bone mineral density of -2.5 SD below the young normal mean

Peak bone mass: the total bone mass amassed during young adulthood Physical activity: any bodily movement produced by the contraction of skeletal muscle resulting in the increase of energy expenditure over resting expenditure Remodeling: the continuous coupled process of bone formation and resorption after the termination of growth

Resistance training: a form of physical activity designed to improve muscular fitness through the exercising of a muscle or muscle groups against an external resistance Resorption: the decrease in bone mass via pathological or physiological means Serum (blood): blood plasma from which the clotting factor has been removed Standard deviation $(S D)$ : a measure of the variation of the distribution T-score: (Measured BMD - Young adult mean BMD) / young adult standard deviation; the number of SD above or below the mean for young normal adults of the same sex Turnover: refers to the total volume of bone that is resorbed and formed over a period of time; can be estimated by measuring biochemical markers of bone formation 
Vitamin D: a fat-soluble compound that is ingested from plant and animal sources; when activated in the liver and kidney, vitamin D promotes calcium absorption and bone mass; when taken as a replacement, it may increase the muscular strength and decreases risks for falling

Wolff's Law: theory postulated by Julius Wolff in the $19^{\text {th }}$ century stating that bone will adapt to the load under which it is placed

Z-score: (Mean BMD - Age matched mean BMD) / age matched standard deviation; the number of SD above or below the mean for persons of the same age and sex 


\section{Chapter II}

\section{LITERATURE REVIEW}

With the average age of the world's population increasing at an exponential rate, the population of adults over the age of 65 years will double between 2008 and 2040 . This rise in population will lead to an increase in the number of individuals with osteoporosis and an increase in the number of fractures (Cauley, 2013). Osteoporosis, a disorder of the skeletal system, is characterized by progressive loss of bone mineral density (BMD), compromised microarchitecture, and an increased susceptibility to fracture (Shan, Xian, Li, Xiang, \& Yuan, 2013). Affecting nearly 50\% of women and $25 \%$ of men over the age of 50 , osteoporosis ranges from asymptomatic to debilitating and significantly decreasing the person's quality of life (Rosen, 2005). In the United States, there are 1.5 million osteoporotic fractures per year, which impose direct and indirect annual medical costs of nearly \$18 billion (Gabriel et al., 2002). Even if the fracture rate stabilizes, the greater aging population projects an increase in the number of fractures and associated costs (Burge et al., 2007).

Vertebral fractures are the most common osteoporotic fracture (Cauley, 2013), potentially causing pain, loss of height, kyphosis or lordosis. Multiple fractures to the vertebral column can lead to more debilitating problems, such as restrictive lung disease, alterations of the abdominal anatomy, and discomfort of the digestive system (Nieves, Mosner, \& Silverstein, 2012). Hip fractures, as well as radial fractures, are most often the result of a fall. Mortality rate following fracture is a major consequence of osteoporosis, with roughly $24 \%$ of patients with hip fracture dying within the first year. In addition, 
emotional morbidity in the form of reclusiveness, depression, and fear of additional fractures may accompany osteoporosis (Burge et al., 2007; Cauley, 2013; J. M. Lane, Riley, \& Wirganowicz, 1997; Nieves et al., 2012) and significantly reduce a patient's health related quality of life. Furthermore, osteoporosis related fracture impose a substantial burden of disability and cost (Cauley, 2013) on postmenopausal women and older men.

The decline in bone formation that is typically associated with aging is attributable to changes both in physical activity levels and estrogen reduction. To fully understand the effect of osteoporosis on bone metabolism, we have to first understand the mechanisms by which bone turnover occurs and second, understand how current treatment options affect these processes.

\section{$\underline{\text { Bone Turnover Mechanisms }}$}

Wolff's Law

Wolff's law, established in 1892, proposes that when a bone is subject to mechanical loading causing it to bend, bone structure is modified by the creation of new bone within the existing concave portion of the bone, and resorption in the existing convex region (Sinaki, 1989). Wolff suggested that bone growth and remodeling occur in response to the forces placed upon it, implying that bone mass reaches an equilibrium point, which is suited to the amount of loading routinely imposed upon it. While investigating the pathology of osteoporosis, several studies on animals and humans have illustrated that mechanical stress and strain on bones, resulting from increased muscle 
pressure rather than tension assist in the prevention of osteopenia and osteoporosis (Abramson, 1948; Gillespie, 1954; Whedon, Deitrick, \& Shorr, 1949).

\section{Bone Modeling}

Bone modeling is defined as bone formation by osteoblasts without prior bone resorption by osteoclasts, resulting in an increase in bone mass (Clarke, 2008).

Osteoblasts, which are responsible for synthesizing new bone matrix, respond differently to various hormonal, mechanical, or cytokine signals (Clarke, 2008; Hadjidakis \& Androulakis, 2006). These cells function in cluster groupings along the bony surface on which they are producing and rebuilding. They originate from undifferentiated stem cells, which have the potential to develop into a variety of mature cell types. Oftentimes, osteoblast cells that have finished laying down the bony matrix end up entrapped within this new bone matrix, further differentiating into osteocytes. Those that do not end up trapped, remain on the bone surface and become flat, lining cells (Hadjidakis \& Androulakis, 2006).

There are 3 phases of bone formation, which cumulate in the mineralization and hardening of the original bone matrix. First, osteoblasts produce osteoid by rapidly laying down collagen. Second, the mineralization rate increases to equal the synthesis of collagen. During the third stage, collagen synthesis declines while mineralization continues until the osteoid fully mineralizes. In healthy adult bone, production and maturation of the osteoid matrix occurs at the same rate as the mineralization process (Hadjidakis \& Androulakis, 2006). 


\section{Bone Remodeling}

Bone remodeling is the process by which bone is reintroduced in order to maintain and strengthen existing mineral homeostasis (Clarke, 2008). Osteoclasts are bone-lining cells responsible for bone resorption. By creating an acidic environment, osteoclasts dissolve the bone mineral content (BMC) and compromise the strength of the existing bone. To complete the process of resorption, osteoclasts release enzymes to remove the remaining collagen bone matrix. Osteoclast activity is highly regulated by a number of factors, predominantly by the receptor activator of NF- $\kappa$ B ligand (RANKL). This protein, produced by osteoblasts and their precursor cells, has been shown to exert its effects on osteoclasts and their precursors through an interaction with the surface receptor RANK. The interaction between RANKL and RANK triggers the formation of signaling pathways involved in differentiation, activation, and survival of osteoclasts, ultimately leading to an increase in the bone resorption rate. Osteoprotegerin (OPG) is secreted by osteoblasts and protects bone by helping balance the effect of RANKL/RANK interaction. OPG binds to RANKL preventing the ligand from interacting with and binding to its receptor on the surface of osteoclasts. Several homeostatic mechanisms, hormones and cytokines, balance and temperate the production of RANKL versus OPG (Boyce \& Xing, 2008). Parathyroid hormone (PTH) stimulates the production of RANKL while suppressing the effect of OPG, leading to increased osteoclast activity. In contrast, estrogen can increase the expression of OPG, and inhibit RANKL signals (Clarke, 2008).

After age 30, a normal skeleton experiences gradual loss in BMD, characterized by a decrease in the activity of osteoblasts compared to osteoclasts (Clarke, 2008). Many 
factors can accelerate or hinder this loss, including medication, proper nutrition, and physical activity. Osteocytes can sense increased workload in bone, changing the differentiation of osteoblasts to increase BMD. When bone experiences decreased loading, resorption occurs to eliminate the underutilized bone, leading to potential fragility fractures.

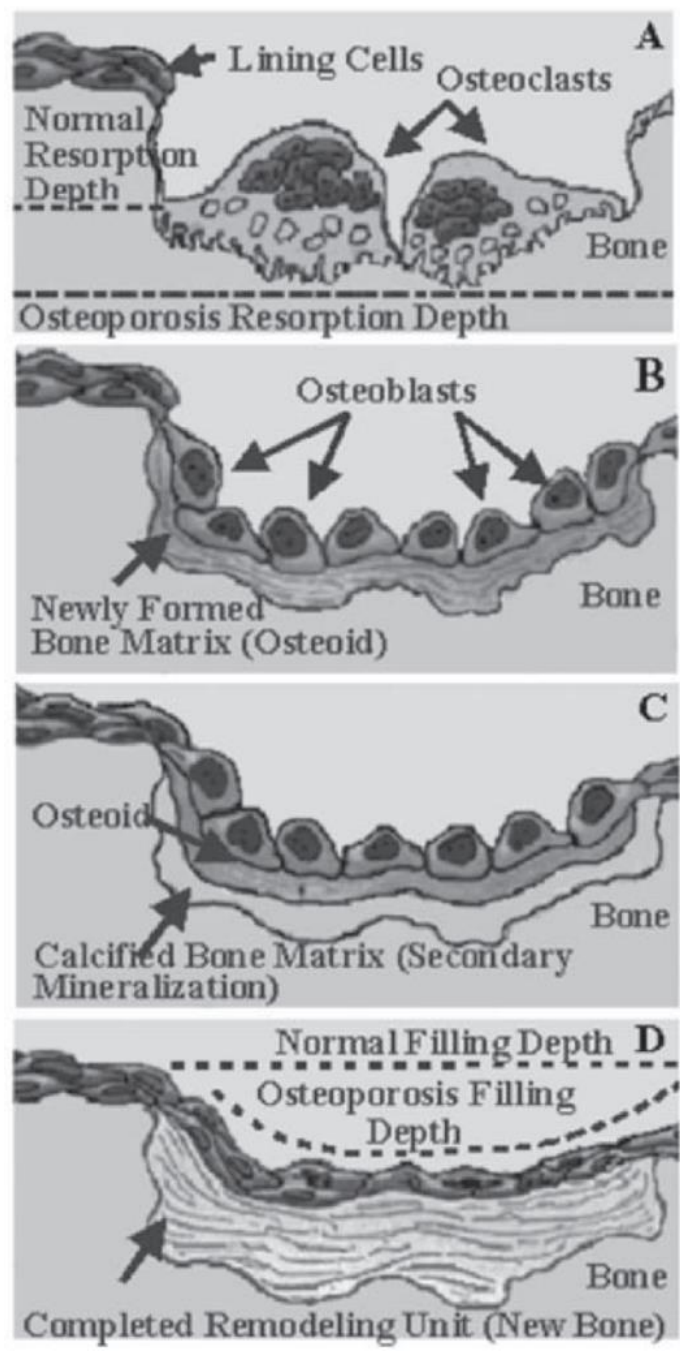

Figure 2.1: Normal and Osteoporotic Bone Remodeling and Biochemical

Markers (Srivastava et al., 2005) 


\section{Osteoporotic Bone Mechanisms/Pathologic Response}

Age-related bone loss is a natural occurrence, modulated primarily by the rapid decline in sex hormones. While the rate of bone mass lost varies on an individual basis, the postmenopausal osteoporotic period is marked by a more rapid rate of bone loss in women, as noted in Figure 2.1. After this period, the rate of loss returns to a more gradual decline (Mazess, 1987). Low, as well as high, bone turnover rates, with bone resorption greater than bone formation, lead to the accumulation of microfracture and microarchitectural deterioration respectively (Clarke, 2008).

Menopause is thought to be due to decreased ovarian function, leading to reduced estrogen secretion by $85-90 \%$ when compared to premenopausal levels (Khosla, Atkinson, Melton, \& Riggs, 1997). The assessment of bone resorption and bone formation markers in postmenopausal women suggests a rise by roughly $90 \%$ and $45 \%$, respectively (Garnero, Sornay-Rendu, Chapuy, \& Delmas, 1996). This imbalance primarily favors bone resorption, leading to accelerated post-menopause bone loss (Clarke \& Khosla, 2010). The cellular mechanisms by which estrogen withdrawal leads to bone loss are regulated in part by osteoclast development and apoptosis. It is believed that estrogen withdrawal increases the signaling processes of RANKL, when compared to pre-menopausal levels, in turn increasing osteoclast recruitment, and decreasing the rate of osteoclast apoptosis (Clarke \& Khosla, 2010). The pathophysiology of this disease alters the normal physiology of bone turnover by decreasing the expression of OPG, and increasing the RANKL/RANK signaling process, thereby increasing rate of resorption over formation.

In addition, postmenopausal bone loss is secondarily due to a decrease in bone 
formation rates when compared with premenopausal levels. Because estrogen directly stimulates bone formation, absence of estrogen may lead to impaired bone formation or increased bone loss (Heaney, Recker, \& Saville, 1978). Previous literature has thoroughly explored this causal relationship, providing thorough verification that estrogen can stimulate bone formation after the skeleton has reached peak bone mass (Khastgir et al., 2001; Tobias \& Compston, 1999), although not to a level to overcome resorption.

\section{Assessment and Diagnosis of Osteoporosis}

It has been demonstrated that osteoporosis primarily affects postmenopausal women (Yamazaki, Ichimura, Iwamoto, Takeda, \& Toyama, 2004), however one in four men over the age of 50 is diagnosed as well. There are several additional risk factors that cause someone to be more susceptible or prone to osteoporosis. These include but are not limited to: age ( $\geq 50)$, smoking, low body weight, genetics, physical inactivity, alcohol consumption ( $\geq 3$ drinks per day), low dietary calcium intake, vitamin D deficiency, and or long term use of seizure medication and steroids (Sugerman, 2014).

The primary diagnostic assessment for osteoporosis centers on measuring BMD because the disease is, in part, defined by low bone mass and increased bone fragility. Most often, BMD is quantified through the use of dual energy $\mathrm{x}$-ray absorptiometry (DXA), which scans the central or axial skeleton (spine and hip). Advantages to DXA include short scan times, high precision, and stable calibration techniques. The low dose radiation (Njeh, Fuerst, Hans, Blake, \& Genant, 1999) poses no threat larger than the average daily dose from everyday background radiation (Blake \& Fogelman, 2002). While the spine provides more metabolically active tissue for better monitoring of 
treatment responses, measurement of hip BMD has been shown to provide reliable and predictive indications of fracture risk (Blake \& Fogelman, 2002).

When compared with alternative methods that measure bone densitometry, central DXA scans provide results that can be interpreted using the World Health Organization (WHO) T-score classifications of osteoporosis (Kanis \& Gluer, 2000b; World Health Organization, 1994). As illustrated in Figure 2.2, diagnostics for osteoporosis in postmenopausal women is often defined by the reference values for Caucasian women: $\mathrm{BMD} \leq-2.5$ standard deviations $(\mathrm{SD})$ from the average value for premenopausal women (Blake \& Fogelman, 2007). This is represented by a T-score, which evaluates the participant's BMD compared to the young and healthy adult reference group.

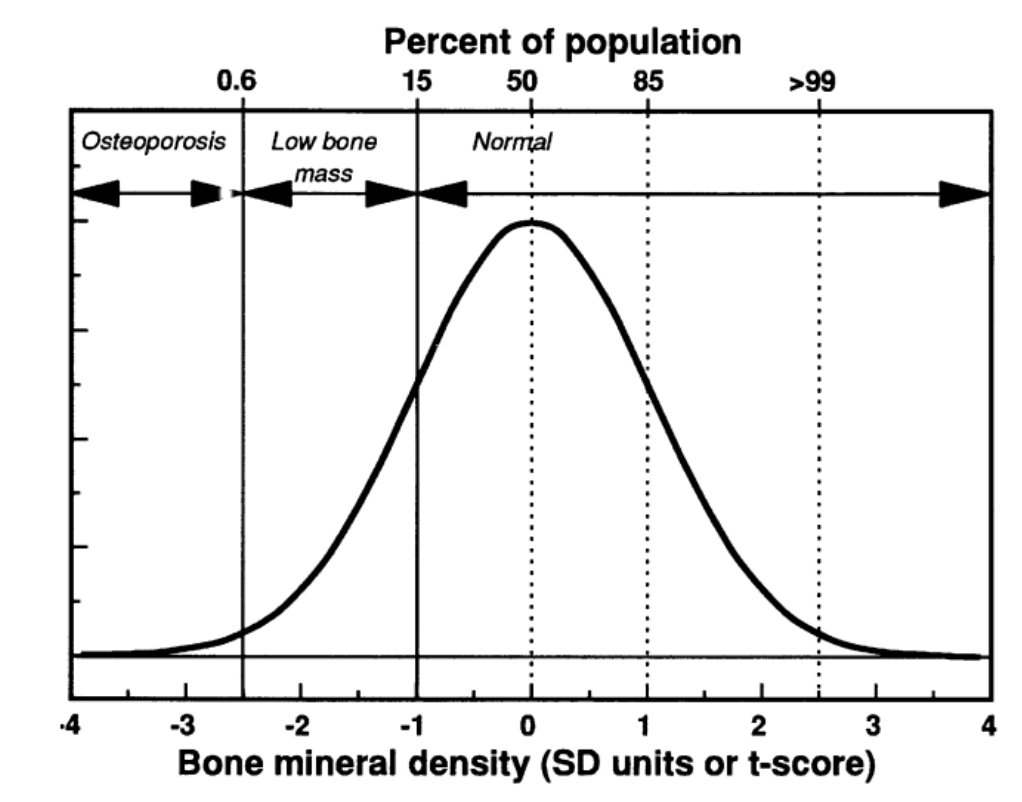

Figure 2.2: Diagnostic Criteria for Osteoporotic Women Based on the Distribution of BMD in a Young, Healthy Adult Population (Kanis \& Gluer 2000) 
Persons who have experienced marked bone loss, such as postmenopausal women, have a tendency to exhibit a negative T-score because they have less BMD when compared with the standard. A T-score between -1 to 1 suggests normal, healthy bones; 1 to -2.5 means the person has osteopenia, or low bone density; $\leq-2.5$ offers a diagnosis of osteoporosis (Kanis \& Gluer, 2000b).

While normal reference ranges exist for many countries (Arlot, Sornay-Rendu, Garnero, Vey-Marty, \& Delmas, 1997; Lehmann et al., 1995; Looker et al., 1998; Lunt et al., 1997; Ryan, Spector, Blake, Doyle, \& Fogelman, 1993; Shipman et al., 1999; SmeetsGoevaers et al., 1998), the difference in mean BMD, as well as the standard deviation, is minimal, suggesting the use of population specific reference ranges to be unnecessary. Variations in fracture risk appear to be substantially higher than variations in BMD across populations (Kanis \& Gluer, 2000a), suggesting BMD and fracture risk are not directly proportional. For example, in Asia, the risk of hip fracture is lower than in Northern Europe or the USA, but BMD is also lower (Looker et al., 1998; Melton, 1997).

\section{An Alternative Measure: Biochemical Markers of Metabolism}

Although BMD has proven useful for clinical diagnosis of osteoporosis, changes in bone mass occur slowly, causing static measurement of BMD, such as DXA, to be an inadequate measure of dynamic changes occurring as a result of prevention and treatment strategies. While DXA is mainly utilized in long term studies to set baseline and final BMD data, biochemical markers can be used during short-term ( $<6$ months) and long term research to monitor therapies during intervention or treatment to assess progress. For example, exercise elicits a skeletal response, measurable by analyzing urine and 
blood serum biomarkers to estimate the rate of bone remodeling (Franck, Beuker, \& Gurk, 1991). Biomarkers of bone metabolism can also be used to predict the rate of bone degradation and formation in postmenopausal women, and assess risk factors for fracture (Eastell \& Hannon, 2008).

The efficacy of biomarkers in assessing the rate of reduction in fracture risk has been illustrated in many clinical trials (Bonnick \& Shulman, 2006; Cummings et al., 2002; Hochberg et al., 2002; Wasnich \& Miller, 2000), resulting in the suggestion that biomarkers may be able to note changes in risk factors before any modifications in BMD become evident. In studies conducted by Bonnick and Schulman (2006) investigating the effects of monitoring biomarker response to antiresorptive therapies as a treatment for osteoporosis, the researchers discovered that benefits to the spine have been observed even among women who maintain rather than increase BMD during therapy. During these trials, the authors showed that suppression of bone remodeling markers could occur after as few as 3 months after the onset of therapy, and that this suppression is highly associated with decreased risk for fracture. These results suggest that biochemical markers may provide valuable data for assessing the progress of therapeutic agents, particularly during treatment or before fluctuations of BMD can be distinguished.

Biochemical Markers for Bone Formation. Significant developments in cell biology, metabolism, and pathology have led to advancements of assays for testing biochemical markers, making them more sensitive and marker-specific. Biochemical markers are classified according to the process by which products of osteoblasts and osteoclasts are created. Bone formation markers are the result of osteoblast activity, 
expressed during different stages of bone cell development, and reflect phases of bone formation. All bone formation markers are measured in blood serum or plasma (Delmas et al., 2000).

Osteoid forms during the early phases of bone formation, and is made up of nearly 90\% type 1 collagen (Naylor \& Eastell, 2012). Type 1 collagen, the most abundant form of collagen in bone, is expressed by osteoblasts, and requires the splitting off of the carboxy $(\mathrm{C}-)$ terminal $(\mathrm{P} 1 \mathrm{CP})$ and amino $(\mathrm{N}-)$ terminal $(\mathrm{P} 1 \mathrm{NP})$ of the propeptides of type 1 collagen (Melkko et al., 1996; Melkko, Niemi, Risteli, \& Risteli, 1990), as seen in Figure 2.3.

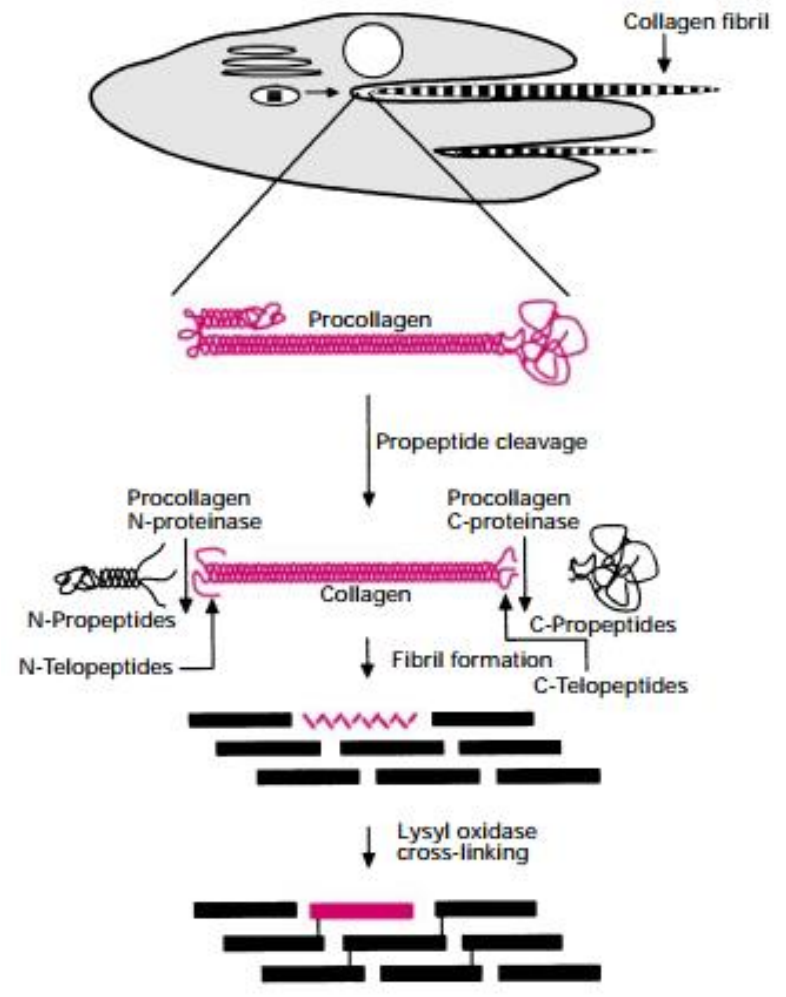

Figure 2.3: Extracellular Events in the Synthesis of Collagen Fibril (Kadler, Holmes, Trotter, \& Chapman, 1996). 
While type 1 collagen has been previously considered to turnover at a relatively low rate, recent studies have indicated that peritendinous connective tissue responds at a higher rate to metabolic and inflammatory activity than previously shown (Langberg, Skovgaard, Karamouzis, Bulow, \& Kjaer, 1999). These markers are then released into circulation, signifying bone collagen synthesis (Langberg, Skovgaard, Petersen, Bulow, \& Kjaer, 1999). Although Type 1 collagen is not specific to bone tissue, and is also produced by the skin and tendon, circulating levels of these markers are mainly derived from bone metabolism. Furthermore, most non-skeletal tissues experience a much slower rate of turnover when compared to bone, contributing minute amounts to the circulating pool of P1NP (Vasikaran, Eastell, et al., 2011).

Several studies have shown positive correlation between the rate of bone formation and serum P1CP levels (Adami, Bianchi, et al., 2008; Horowitz, 2010). In order to standardize the future biochemical bone turnover research, the International Osteoporosis Foundation (IOF) and the International Federation of Clinical Chemistry (IFCC) suggest the use of P1NP as the marker of bone formation to be used for reference analyses (Naylor \& Eastell, 2012; Vasikaran, Eastell, et al., 2011) due to its greater diagnostic validity.

Biochemical Markers for Bone Resorption. Most biochemical markers of bone resorption are products of bone collagen degradation (Pagani, Francucci, \& Moro, 2005). When type I collagen is degraded by osteoclasts, and amino- (NTX) and carboxy- (CTX) terminal telopeptides of type 1 collagen are released into circulation, increasing the concentration in the blood stream during the resorption process. Current literature 
suggests that, although the mechanism by which exercise positively effects bone turnover in postmenopausal women remains poorly understood, bone resorption markers, specifically serum CTX, were the most significant indicators for estimating the effects of intervention methods in early postmenopausal women (Chailurkit, Ongphiphadhanakul, Piaseu, Saetung, \& Rajatanavin, 2001). Furthermore, the authors suggested CTX to be the most significant predictor of long-term BMD change following therapeutic intervention, when compared to other clinical markers of both formation and resorption. Results from studies attempting to model osteoporotic conditions by utilizing ovariectomized rats, have supported this model, indicating that exercise can inhibit bone resorption, leading to further reduction of bone loss (Li et al., 2014). An increase in BMD through the suppression of bone resorption in response to short-term duration exercise has been reported previously in young growing rats as well (Hagihara et al., 2009). Therefore, the International Osteoporosis Foundation (IOF) has recommended that the serum CTX be used as the reference marker for bone resorption because of the adequate characterization of the marker, specificity to bone, and performance in previous clinical studies (Vasikaran, Cooper, et al., 2011; Vasikaran, Eastell, et al., 2011).

Blood serum markers of bone turnover have been established as good measures of progress during therapy interventions, and their direct correlation to the eventual calcification and mineralization, suggesting an increased BMD, has been extensively researched (Lester et al., 2009). Any inconsistency has been suggested to be due to the difficulty in predicting the mode, volume, and intensity needed to maximize the osteogenic response. Several studies have investigated both the appropriate age-specific reference intervals from global and national representative populations, as well as the 
relationship between bone turnover markers and BMD in postmenopausal women (Hu et al., 2013; Jenkins et al., 2013). After examining 2799 individuals aged 20-79 years in Shanhai, China, Hu, Z. Zhang, He, Fu, Wang, H. Zhang, Yue, Gu, and Z. L. Zhang (2013) established normal reference ranges for bone turnover markers (OC and CTX). They found these bone turnover markers correlated with BMD. In a subsequent study on Australian reference populations, data obtained from a large study offered reference intervals for amino-terminal of propeptides of type 1 collagen and CTX biomarkers in serum. Further research studying pharmacological treatments for osteoporosis, such as with Alendronate, Risedronate, and Raloxifene on bone turnover markers show a strong correlation with decreased fracture risk than BMD (Eastell \& Hannon, 2008). These findings suggest bone biomarkers rather than BMD should be monitored throughout interventions. Therefore, the use of biochemical markers of bone turnover may be a more effective skeletal health assessment during short-term observations of treatment interventions than pure densitometry.

\section{$\underline{\text { Treatment Interventions }}$}

\section{Pharmacological}

Osteoporosis is not an inevitable disease and its progress can be slowed through several treatment modalities. According to the US Surgeon General, osteoporosis responds to treatment (Office of the Surgeon General, 2004). The US Food and Drug Administration (FDA) has approved two classes of pharmaceutical treatments, anabolic and antiresorptive agents, in the treatment of osteoporosis. While anabolic medications, such as Teriparatide (Fortical), help lower the risk of fracture by stimulating new bone 
formation and increasing BMD through increased bone modeling (Lindsay et al., 2006; Stepan et al., 2003), antiresorptive agents (bisphosphonates, Denosumab, Raloxifene, hormone therapy/estrogen therapy, and calcitonin) focus on strengthening the existing skeleton, and preventing bone loss through ensuring adequate remodeling (Canalis, Giustina, \& Bilezikian, 2007; Meunier, 2001). Pharmacological agents have been shown effective, albeit concerns associated with potentially detrimental side effects on other body tissues leads many to non-adherence (McHorney, Schousboe, Cline, \& Weiss, 2007) as seen in Table 2.1 (Cosman et al., 2014). Because of the side effects associated with pharmacological therapies, physical activity has been recommended as a potential alternative, as well as an adjunct to other prevention and treatment strategies (Berard, Bravo, \& Gauthier, 1997; Kelley, 1998) 


\begin{tabular}{|c|c|c|c|}
\hline Medication & Classification & Side Effects & Other Notable Information \\
\hline Bisphosphonates & Antiresorptive & $\begin{array}{l}\text { - Diarrhea, nausea, vomiting, heartburn, esophageal } \\
\text { - } \text { irritation, gastric ulcer } \\
\text { - Pow calcium levels in the blood } \\
\text { - for }>5 \text { years } \\
\text { - } \text { Bone, joint, muscle pain } \\
\text { - Vermanent bone deterioration of the jaw } \\
\text { Visual disturbances }\end{array}$ & $\begin{array}{l}\text { Patients should follow label } \\
\text { instructions exactly to } \\
\text { decrease risk of esophageal } \\
\text { side effects }\end{array}$ \\
\hline Calcitonin & Antiresorptive & - Rhinitis, Epistaxis, Nose bleeds & \\
\hline \multirow[t]{2}{*}{$\begin{array}{l}\text { Estrogen/Hormone } \\
\text { Replacement Therapy } \\
\text { (ERT/HRT) }\end{array}$} & Antiresorptive & $\begin{array}{l}\text { ERT: } \\
\text { - Increased risk of developing endometrial cancer } \\
\text { - Breast swelling or discomfort, Breast cancer } \\
\text { - Bilateral swelling of the legs or feet; rapid weight gain } \\
\text { - Heart disease, blood clots } \\
\text { - Stroke }\end{array}$ & $\begin{array}{l}\text { - In studies of } \\
\text { postmenopausal women } \\
\text { who were diagnosed with } \\
\text { osteoporosis, estrogen did } \\
\text { not reduce the risk of } \\
\text { fractures }\end{array}$ \\
\hline & & $\begin{array}{l}\text { HRT: } \\
\text { - Chest pain, unexpected coughing, difficulty breathing } \\
\text { - Dizziness, change or loss of vision, fatigue } \\
\text { - Stroke, heart disease }\end{array}$ & $\begin{array}{l}\text { - Given the serious side } \\
\text { effects, it is generally not } \\
\text { used solely to treat } \\
\text { osteoporosis }\end{array}$ \\
\hline $\begin{array}{l}\text { Estrogen Agonist/antagonist } \\
\text { (SERMs) }\end{array}$ & Antiresorptive & $\begin{array}{l}\text { - Raloxifene may increase the risk of deep vein thrombosis } \\
\text { o Increases hot flashes }\end{array}$ & \\
\hline $\begin{array}{l}\text { Human Parathyroid } \\
\text { Hormone (PTH); } \\
\text { Teriparatide }\end{array}$ & Anabolic & - Leg cramps, dizziness & $\begin{array}{l}\text { - Not to be used for more } \\
\text { than } 2 \text { years }\end{array}$ \\
\hline
\end{tabular}




\section{Physical Activity}

The Surgeon General asserts that physical activity and proper nutrition should be the initial intervention methods for osteoporosis, prior to any pharmacological treatment (Office of the Surgeon General, 2004). While pharmaceutical intervention can increase bone mass, physical activity has the potential to both increase bone mass and improve bone strength. Additionally, physical activity can delay the deterioration of age related bone loss in older populations (Berard et al., 1997; Marcus, 1998; Umemura, Sogo, \& Honda, 2002). Physical exercise decreases risk factors for falling (Liu-Ambrose, Eng, Khan, Carter, \& McKay, 2003) and improves balance (Chien, Wu, Hsu, Yang, \& Lai, 2000; Jessup, Horne, Vishen, \& Wheeler, 2003; Madureira et al., 2007), making it an important primary prevention strategy. Law, Wald, and Meade (1991) evaluated the relationship between hip fracture occurrence and osteoporosis treatment modalities in a review of epidemiological studies, concluding that that physical activity was the most impactful measure in preventing hip fracture.

With respect to the mechanisms underlying the beneficial impact of physical activity on bone health, the mechanical loading provided by physical activity acts as a stress stimulus, producing physiological adaptations that, over time, lead to a variety of health benefits, including stronger bones, increased physical fitness, and cardiovascular health (Kemmler et al., 2004; Roghani et al., 2013). As previously illustrated by Wolff's law, physical activity increases the mechanical load placed on the skeleton, in an attempt to modify bone structure. These internal and external forces must be greater than normally exhibited by activities of daily living to stimulate the osteogenic response for bone formation (Lanyon, 1984; Umemura et al., 2002) Exercise's osteogenic effect 
occurs slowly and is site-specific (Adami, Gatti, et al., 2008); BMD only increases at the anatomic sites where the mechanical strain occurs (Haapasalo et al., 1994; Lanyon, 1996; Tommerup, Raab, Crenshaw, \& Smith, 1993). Despite our mechanistic understanding of the influence of exercise on BMD, findings have been conflicting regarding the impact of exercise interventions on BMD. Inconsistencies may be attributed to variations in the type, duration, frequency, and intensity of the exercise interventions tested (Gutin \& Kasper, 1992; Rutherford, 1997; Stewart et al., 2005).

\section{Effects of High Intensity Impact Training on Bone Density and Metabolism.}

Currently, the American College of Sports Medicine (ACSM) recommends a variety of exercise modes and intensities to effectively maintain bone mass in postmenopausal women (Kohrt, Bloomfield, Little, Nelson, \& Yingling, 2004). Traditionally, high impact and weight bearing activity has been shown to produce a greater osteogenic response (Yamazaki et al., 2004; Zehnacker \& Bemis-Dougherty, 2007), but such high-impact programs may be associated with increased fracture risk and injury in postmenopausal osteoporotic women (Martyn-St James \& Carroll, 2006; Roghani et al., 2013).

In a one year randomized, controlled trial investigating the effect of high-intensity resistance training on postmenopausal women, Nelson, Fiatarone, Morganti, Trice, Greenberg, and Evans (1994) found that women who participated in resistance training program 2 days per week increased their BMD by $1 \%$ at the hip and lumbar spine. The control group lost $2.5 \%$ and $1.8 \%$ at the hip and spine respectively. Furthermore, a study by Kerr, Morton, Dick, and Prince (1996) reported similar results, suggesting participating in a high intensity, low volume strength-training regimen can increase BMD 
more than a high volume, low intensity program.

A meta-analysis of high intensity resistance training and bone loss in postmenopausal women found that regular exercise at this level helps maintain BMD in the lumbar spine (Martyn-St James \& Carroll, 2006). While resistance training protects BMD in the spine, it seems additional physical activity modalities are necessary to elicit such improvements in the femoral neck of the hip. Kemmler and Engelke (2004) note that while the high impact exercise promotes a higher osteogenic response and increased bone formation, it may cause unfavorable effects on persons with osteoarthritis and/or lower back pain. The conclusions of the meta-analysis and related research suggest that high intensity resulting in overloading the skeleton is more important than the number of repetitions for increasing BMD in postmenopausal women, but that caution should be taken in prescribing these activities.

Although previous studies have used a wide variety of exercise prescriptions, current literature is in agreement that weight-bearing exercises involving gravitational stimulation, such as gymnastics, running, jumping activity, institute an escalation in BMD when compared to physical activity not directly affected by gravity, such as swimming (Creighton, Morgan, Boardley, \& Brolinson, 2001). Based on this research, a combined resistance training and weight bearing exercise program is recommended to older individuals attempting to increase or maintain their both bone density and strength to ensure safety to the individual.

While increased physical activity and exercise promote bone formation, a decline in physical activity decreases musculoskeletal loading and is associated with muscular atrophy and decreased strength, balance, and coordination, all of which increase risk for 
fracture (Roghani et al., 2013). Decreased muscle mass results in a loss of muscular tension, removing a degree of muscle contraction necessary for musculoskeletal health (Bogdanis, 2012). While several studies have thoroughly investigated the osteopenic effects of weightlessness in astronauts (Birge \& Whedon, 1968), the effects of inactivity in postmenopausal osteoporotic women has only been minimally addressed (Krolner \& Pors Nielsen, 1982; Krolner, Toft, Pors Nielsen, \& Tondevold, 1983).

Effects of Aerobic Exercise on Bone Density and Metabolism. The ability to use aerobic exercise to evaluate bone turnover rates has previously been explored utilizing a variety of populations and methodologies due to its potential as an alternative to pharmacological interventions. There is a large body of research investigating the difference between bone density measures of various athletic groups and matched sedentary controls. In general, results show difference (6-20\%) in BMD and BMC between exercisers and controls at different anatomical sites, over a wide range of physical activities (Rutherford, 1997). The type of activity can affect the degree of increase in BMD. Nilsson and associates compared the BMC of 24 male weight lifters and 21 professional ballet dancers (men and women) with age-matched healthy controls (Nilsson et al., 1978). The results indicated that BMC was higher in both dancers and weightlifters. Increased bone width was found predominantly in the dancers even though they were shorter and weighed less than the controls. This data suggests that, when controlling for nutrition, physical activity started early in life results in high BMC and increased bone dimensions.

Nilsson \& Westlin (1971) measured bone density in the distal femur in a variety 
of male athletic groups ranked by the load taken on the lower limb (weight-lifters, throwers, runners, soccer players, swimmers and controls). In this study, bone density was ranked in the same order, with no difference between the swimmers and the controls. Similar results have been seen in female athletic groups, showing that women regularly participating in sports associated with high impact loading, such as volleyball and gymnastics, have greater bone densities in the spine, femoral neck, and legs compared to swimmers and controls (Fehling, Alekel, Clasey, Rector, \& Stillman, 1995). Additional cross-sectional studies of young adults show greater bone mass in athletes than in age and sex matched non-exercising controls (Block et al., 1986; Talmage et al., 1986). Even competitive runners in their sixth decade and beyond have been reported to demonstrate $40 \%$ higher BMD than non-exercising controls (N. E. Lane et al., 1986).

A second study assessed the osteogenic effect and changes in bone markers in healthy subjects by 12 weeks of aerobic training (Alghadir et al., 2014). Sixty-five healthy subjects, ages 30-60 years participated in this study. Twelve weeks of moderate aerobic training, 3 times per week, produced significant improvements in all bone metabolism indices among subjects. The authors measured bone formation markers (osteocalcin (OC), and bone specific alkaline Phosphatase (BAP)) and the bone resorption marker Deoxypyridinoline (DPD), and serum calcium. Alghadir and colleagues (2014) concluded that moderate intensity aerobic exercise could exert significant positive effects on bone formation markers and bone density, while also significantly decreasing the rate of bone resorption. In this study, bone formation markers (OC, BAP) showed a significant increase in all subjects, while bone resorption markers (DPD) were significantly lower than when taken at baseline. These observations suggest 
that moderate aerobic exercise increased the rate of bone remodeling. The authors concluded that long term aerobic exercise could be associated with decelerated bone resorption and normal to elevated bone formation.

With respect to the impact of aerobic exercise training on the bone health of older adults, Blumenthal, Emery, Madden, George, Coleman, Riddle, McKee, Reasoner, and Williams (1989) evaluated the physiological adaptations to 4-months of aerobic exercise training on 101 older men and women. Subjects were randomly assigned to one of three groups: aerobic exercise, yoga and flexibility, or waitlist control. Prior to and after 4months of intervention, participants underwent physiological and psychological evaluations, including but not limited to bone density measurements. Measurement of BMD was by single photon absorptiometry with I-125 was performed using a bone densitometer (Norland Corporation, Fort Atkinson, WI). BMC $\left(\mathrm{mg} / \mathrm{cm}^{2}\right.$ ) was taken from the distal radius of the non-dominant arm. The authors discovered an increase in BMC for subjects at risk for bone fracture, suggesting that 4-months of aerobic exercise may increase $\mathrm{BMC}$ in individuals with low bone density and who are at risk for fracture. The authors concluded that, although the mechanism remains unclear, the results suggest exercise may increase bone density.

In response to recommendations for evaluating biomarkers over a longer duration, Yamazaki, Ichimura, Iwamoto, Takeda, and Toyama (2004) examined whether moderate walking exercise in postmenopausal women with osteoporosis would affect bone metabolism over the course of a year. Fifty postmenopausal women were assigned to either the exercise or control groups. The exercise consisted of 4 days per week of 1 hour per day of outdoor walking at 50\% maximal oxygen consumption. Participants were 
required to complete 8,000 or more steps during this time. Lumber BMD was measured using DXA in both groups. Serum bone-specific alkaline phosphatase (BAP) and urinary cross-linked amino-terminal telopeptides of type 1 collagen (NTX) levels were measured at baseline, 1, 3, 6, 9, and 12 months by enzyme-linked immunoassay (EIA) and enzymelinked immunosorbent assay (ELISA) respectively. Findings from this study support those of previous research, in that the mechanism for the positive response of lumbar BMD to moderate walking appears to be the suppression of bone turnover.

A study by Thorsen, Kristoffersson, and Lorentzon (1996) explored the effects of a single bout of brisk walking on bone and calcium metabolism markers in postmenopausal women. Twelve subjects participated in a single bout of brisk walking at $50 \% \mathrm{VO}_{2}$ max for 90 minutes. Calciotropic hormones, markers of type I collagen formation (P1CP) and degradation (ICTP), and the amino terminal propeptide of type III collagen in serum (PIIINP) were measured at baseline, 1-hour, 24-hours, and 72-hours post exercise. Total body BMD and BMC were measured by DXA. A significant increase in $\mathrm{P} 1 \mathrm{CP}$ was observed at 24- and 72-hours $(\mathrm{P}<0.01)$ after exercise, and there was a significant decrease in ICTP at one hour $(\mathrm{P}<0.05)$, followed by an increase at 72 hours $(\mathrm{P}<0.001)$. A significant increase from rest was also seen in PIIINP at 24 and 72 hours $(\mathrm{P}<0.05)$ post exercise. Results indicated a lack of correlation between P1CP and ICTP, suggesting an uncoupling between the bone resorption and formation processes. This uncoupling is consistent with the mechanism of bone loss during menopause, and further escalated by the onset of osteoporosis. Although no significant difference was found between P1CP and ICTP at 72 hours, the results of this study suggest that one bout of brisk walking altered bone collagen turnover. The author's findings suggest that an acute 
bout of exercise exhibits a change in biochemical bone turnover markers that may stimulate a cascade of response that continue once threshold stimulus levels are reached. The lack of significant change in levels of calciotrophic hormones was explained by inadequate exercise intensity, but contradicted by the altered concentrations of serum P1CP and ICTP (Thorsen et al., 1996). In order to increase exercise intensity, the addition of gravitational forces acting on the body via weighted load carriage, or increasing the rate of work would be necessary.

In sum, previous research has shown that when compared with their nonexercising control counterparts, individuals who exercise, whether it be young athletes or older individuals, increase their BMD and have a better chance of maintaining that BMD as they age. Despite this knowledge, the effects of aerobic exercise on bone metabolism are not well established or consistent, with some studies showing beneficial results for women with osteoporosis (Alghadir et al., 2014; Yamazaki et al., 2004), while others are uncertain (Blumenthal et al., 1989; Thorsen et al., 1996). The increased risk of fracture associated with postmenopausal osteoporotic women (Arlot et al., 1997; Cauley, 2013; Clarke \& Khosla, 2010) necessitates more studies to develop safe, prescribable exercise interventions that provide an adequate osteogenic response on the skeletal system.

Load Carriage Systems During Exercise on Bone Density and Metabolism. It has been proposed that the osteogenic response to aerobic exercise could be improved by adding additional external weight-bearing force via load carriage systems (LCS) to physical activity interventions. By utilizing LCS such as backpacks, weighted vests, ankle weights, etc., the load on the skeleton can be increased without increasing risk for 
injury (Burr, Martin, \& Martin, 1983; Kai, Anderson, \& Lau, 2003). Shaw and Witzke (1998) postulated that forces greater than those experienced by activities of daily living must impact bone mass to achieve the appropriate level of overload to activate the osteogenic response, suggesting that by externally increasing the forces acting upon the body, the osteogenic response could also be increased.

Research supports the positive relationship between increased vertical ground reaction forces via carrying additional load and the effects on skeletal bone formation (Kai et al., 2003), and osteogenesis. One study investigated the different effects of loading and unloading conditions on bone-on-bone forces in 7 healthy male participants (Simonsen et al., 1995). Results showed that 20kg loaded walking generated an additional $8.0 \%$ body weight compression force at the hip joint. Additional studies by Kinoshita (1985), Knapik (1996), Hsiang and Chang (2002) evaluated the relationship of loaded walking ground reaction forces with the completion of gait patterns when compared to the same unloaded conditions. Their results concluded that the amount of loading, if too heavy, produced negative effects on gait patterns, while moderate loads improve gait stability.

In a subsequent study on postmenopausal women with osteoporosis, Snow, Shaw, Winters, and Witzke (2000), found that participating in 9-months of exercise wearing a weighted vest (10-20\% BW), showed significant improvements in indices of fall risks, lower body muscular strength, and muscular power, when compared to the nonexercising control group. However, they found no significant change in hip BMD, likely due to the lack of exposure to sufficient stimulus over the short duration of the study. 
While current research has thoroughly explored the effects of LCS on vertical ground reaction forces and their impact on bone density and metabolism, less attention has been paid to the proper distribution of load on the body. The most effective and safe method of load distribution is to keep the load as close to the body's center of mass (COM), while allowing the larger muscle groups to move the load (Legg \& Mahanty, 1985). This configuration allows the body to work more efficiently against the added load, while maintaining proper upright posture (Harman, Frykman, Knapik, \& Han, 1994; Kinoshita, 1985). Weighted vests, which load the upper body, have been shown to produce balance improvements in postmenopausal women with osteoporosis (Roghani et al., 2013; J. M. Shaw \& Snow, 1998). However, poorly designed weight layout can lead to feelings of imbalance (Birrell \& Haslam, 2010), and back or shoulder pain. Further research into the design of LCS, recommends spreading the load around the trunk, focusing on both anterior and posterior load to increase economy and maintain normal gait patterns (Lloyd \& Cooke, 2011).

In summary, current literature suggests that increasing vertical ground reaction forces by utilization of LCS during walking activity may provide osteogenic stimuli by producing higher impact forces in the lower limbs. These increases further support the suggestion for physical activity while wearing properly designed LCS in the treatment of osteoporosis (Watanabe, Asaka, \& Wang, 2012).

\section{Influence of Aerobic Exercise with LCS on Bone Density and Metabolism.}

Externally loaded exercise has been shown to increase or maintain bone mass in younger and older populations, but the mechanisms by which mechanical loading stimulates bone 
metabolism are not well known. Current literature examining the effects of externally loaded aerobic exercise on bone turnover serum has produced conflicting results (Greendale, Hirsch, \& Hahn, 1993; Roghani et al., 2013; Tosun et al., 2006). To our knowledge, there have only been two studies investigating the effect of external load training during aerobic exercise on bone turnover biomarkers. A third study was found, utilizing DXA rather than biochemical markers.

One study, by Tosun, Bolukbasi, Cingi, Beyazova, and Unlu (2006), investigated the acute effects of brisk walking, with and without weight lifting, on bone turnover in healthy young women. The aim was to determine if external loading elicited a greater osteogenic response. Unlike previous studies, nine women performed both exercise bouts: brisk walking on a treadmill for 30 minutes, and an identical exercise but while carrying $5 \mathrm{~kg}$ of weight in a backpack. Intensity of submaximal aerobic exercise was determined by $60-85 \% \mathrm{HR}_{\max }$. The investigators measured and studied serum parathyroid hormone $(\mathrm{PTH})$, osteocalcin $(\mathrm{OC})$, calcitonin $(\mathrm{CT})$, carboxy-terminal propeptide of type 1 collagen (P1CP), amino-terminal propeptide of type 1 collagen (P1NP), type 1 collagen carboxy terminal telopeptide (ICTP), total alkaline phosphatase (ALP) and urine Deoxypyridinoline (DPD) at baseline, $30 \mathrm{~min}, 45 \mathrm{~min}$, and 1 hour post exercise. Testing produced statistically significant variance only in serum ALP and PTH values. ALP was found to be significantly decreased 24 hours after aerobic exercise, but significantly increased 24 hours post weighted aerobic exercise. Alkaline phosphatase is a bone formation marker, suggesting that the addition of external loading to brisk walking produced anabolic effects on bone metabolism. The decrease post non-weighted aerobic exercise suggests a decrease in bone formation (Tosun et al., 2006). It was concluded that 
brisk walking for 30 minutes had a stimulating effect on bone metabolism, without any significant effects of adding weight. The authors noted that their results are specific to healthy young women, and cannot be generalized to postmenopausal osteoporotic women due to the estrogen receptor response protecting against resorption (RANKL/RANK/OPG relationship). Thus, further studies aimed at postmenopausal osteoporotic women should be performed to evaluate the effects of external loading on bone metabolism.

A second study investigated the effect of aerobic exercise intervention using a weighted vest on perceived health status and BMD in older persons (Greendale et al., 1993). In this study, 36 seniors were recruited and randomly assigned to one of two groups: vest-use or discussion control. Both groups met for 1 hour per week for 20 weeks; the vest group wore a weighted vest while participating in a low-level exercise class and the discussion group met and reviewed topics relevant to aging, such as choosing a doctor, health insurance, or pharmacological interventions. The beginning weight load of the vest was $0.45 \mathrm{~kg}$, increasing over the duration of the study to a total of $3.6 \mathrm{~kg}$ maximum. At baseline and 20 weeks, participants completed a health status questionnaire and bone density was measured by DXA. The authors found that bone density was similar in both groups at baseline $\left(1.037 \mathrm{~g} / \mathrm{cm}^{2}\right.$ and $1.016 \mathrm{~g} / \mathrm{cm}^{2}$ respectively, $\mathrm{p}=0.75)$. At 20 weeks, the discussion group presented a $-0.59 \%\left(-0.0068 \mathrm{~g} / \mathrm{cm}^{2}\right)$

decrease in BMD, while the weighted vest groups BMD increased by $1.02 \%(0.0101$ $\mathrm{g} / \mathrm{cm}^{2}$ ) from baseline. Despite these promising results, the authors found no statistically significant difference between groups. The authors concluded that the use of a weighted vest provided gains in quality of life in elderly, but suggested using the weighted vest, as an osteogenic stimulus intervention, deserves further research. 
A subsequent study looked at the effect of short-term aerobic exercise with and without external loading on bone metabolism, found that after a 6-week exercise program, BALP increased and NTX decreased significantly in both exercise groups (Roghani et al., 2013). In this study, 36 sedentary, postmenopausal women with osteoporosis were randomly split into three groups: aerobic, weighted vest, and control. The exercise intervention for the aerobic exercise group consisted of 18 sessions of submaximal walking on a treadmill for 30 minutes per day, 3 times per week. The exercise intervention for the weighted vest group was identical to the aerobic exercise group, except for the addition of wearing the weighted vest (4-8\% of body weight). The authors concluded that simply walking on a treadmill, with or without the weighted vest, creates a satisfactory osteogenic stimulus, generated from both the participants' body weight and muscular contraction. The weighted vest additionally loads the pelvic and lumbar spine, stimulating further muscular when contractions compared to the same walking exercise without additional weight. Further results from this study suggest that submaximal walking, while wearing additional weight, helps maintains the homeostatic balance of bone turnover in osteoporotic postmenopausal women (Roghani et al., 2013).

While the previous studies all found that exercise positively stimulated bone turnover or maintenance of BMD, they could not differentiate significantly between aerobic exercise and weighted aerobic exercise groupings. Across all 3 studies, the authors noted that the lack of significant findings was most likely to do their study limitations. Tosun et al., (2006) tested a healthy young female population, whose bone metabolism is protected by the estrogen complex; Greendale et al., (1993) assessed both male and female older adults, and suggested their study was limited to the weight of the 
vest and duration of the exercise bout; Roghani et al., (2013) focused solely on postmenopausal women with osteoporosis, again picking a low vest weight, and short exercise bout duration. Research conducted by Snow et al., (2000) suggests a weight of $10-20 \%$ body weight is acceptable to be utilized during exercise interventions with postmenopausal osteoporotic women, with the recommendation that increasing from $10 \%$ to $20 \%$ should be done conservatively and over time. A secondary cause of lack of differentiation may be due to the intensity of exercise overpowering the low weight used during exercise.

While limitations of previous LCS designs have provided a substantial lack of evidentiary support, new developments in wearable technology, such as the uniformly weighted exercise suit, show promise in providing adequate weight bearing stimulus during exercise in a well-designed and safe manner (Curry et al., 2015). The design of the suit mimics the natural weight distribution of the human body, with the jacket slightly heavier than the pants, so as to not significantly alter the wearer's center of gravity. Furthermore, the whole body loading design allows for the increased forces to be more evenly distributed across all major muscle groups instead of simply the upper or lower body, allowing for a decrease in the likelihood of injury such as back, shoulder, or hip pain (Knapik et al., 1996).

In review, the available literature suggests:

- While BMD is the gold standard for evaluating long-term treatment, biochemical markers of bone turnover are a good measure of progress during treatment interventions. 
- The short-term increase in bone formation markers is correlated to long-term BMD change if the treatment is continued.

- Physical activity is a sufficient stimulus to produce increases in bone formation markers.

- Aerobic exercise may provide a safer alternative to high intensity impact training in postmenopausal women with low bone density or osteoporosis.

- Externally loaded aerobic exercise, through the use of a well-designed LCS, can increase the forces acting on the body, increasing bone formation markers.

- Research is needed to assess whether uniformly weighted LCS (e.g., an exercise suit) can overcome the limitations of existing LCS and have positive effects on bone formation and resorption biomarkers suggested by the IOF and IFCC.

\section{$\underline{\text { Conclusions }}$}

Although research shows pharmacological treatments are effective in increasing and maintaining BMD in postmenopausal women with osteoporosis, they are associated with potentially detrimental side effects. The non-adherence to such interventions has spurred the investigation into alternative treatment options, such as physical activity. The osteogenic effect of exercise provides a stimulus for bone formation, which can be monitored throughout treatment through the use of biochemical markers of bone turnover. While several studies have shown high intensity, high impact training to stimulate a greater osteogenic response, aerobic exercise has been deemed a sufficient and safer alternative, albeit not as good. To improve the effects of aerobic exercise, research has begun to investigate the effects of externally loading the body through the 
use of LCS. While there is evidence that aerobic exercise while wearing LCS positively affects bone formation and resorption serum markers, insignificant research results are, in part, due to the utilization of weight loads well below the recommended values that can be used safely in this population. If heavier, well-distributed LCS can increase biochemical markers of bone formation while decreasing markers of bone resorption, they have long-term positive effects on increasing and maintaining BMD. 


\section{Chapter III}

\section{METHODS}

\section{$\underline{\text { Overview and Design }}$}

The purpose of this study was to examine the effects of a uniformly weighted exercise suit on biochemical markers of bone formation (carboxy [C-] terminal [P1CP] and amino $[\mathrm{N}-]$ terminal [P1NP] of the propeptides) and resorption (carboxy- [CTX] terminal telopeptides of type 1 collagen) in response to aerobic exercise in postmenopausal women with osteoporosis. An experimental, crossover, within-subject study design was used where participants serve as their own control and complete both exercise conditions. Conditions were counterbalanced, with participants randomly assigned to start with one of the two conditions: 1) aerobic exercise while wearing the exercise suit (ES), or 2) aerobic exercise without the exercise suit (NS). Participants completed the different conditions on two different days, separated by a washout period of a minimum of 7 days. Biochemical markers of bone turnover, P1NP, P1CP, and CTX, were measured 15 minutes prior to the exercise bout, and at 24 and 72 hours post exercise.

\section{$\underline{\text { Participants }}$}

Participants were recruited from the faculty of California Polytechnic State University, San Luis Obispo (Cal Poly) and the surrounding communities. To determine eligibility, participants completed a brief telephone interview and the Canadian Society 
for Exercise Physiology's PAR-Q and YOU Physical Activity Readiness Questionnaire (Appendix B) to determine their ability to engage in exercise.

Inclusion criteria included: 1) 45-65 years of age, 2) BMI $\geq 18.5-30,3)$ good health, assessed by a health history questionnaire, 4) ability to participate in 90 minutes of walking activity without stopping assessed by PAR-Q, 5) menopause $\geq 6$ months, assessed by a health history questionnaire, 6) low bone density as assessed by a preliminary DXA scan, 7) the ability to carry a maximum of $12 \mathrm{lbs}$ assessed during preliminary testing, 8) classified as sedentary or lightly active in accordance with ACSM guidelines, assessed by self-reporting, and 9) fit within the confinements of the suit measurements (Table 3.1 and 3.2). Exclusion criteria included: 1) any history of osteoporotic fracture, 2) metabolic syndrome, 3) musculoskeletal or orthopedic disorder (Paget's disease), 4) history of cardiovascular or pulmonary disease, 5) currently taking antiresorptive agents or anabolic agents to treat osteoporosis, 6) currently receiving estrogen or hormone replacement therapy, 7) smoking tobacco, 8) regularly engage in over 300 minutes of moderate exercise per week or 150 minutes of vigorous exercise per week, and 9) diseases and conditions that may cause additional bone loss (Office of the Surgeon General, 2004), including:

- Autoimmune disorders (Rheumatoid Arthritis, Lupus, Multiple Sclerosis, Ankylosing spondylitis, Osteitis deformans, Osteochondroma, Osteosarcoma)

- Digestive and gastrointestinal disorders (Celiac disease, Inflammatory Bowel Disease, weight loss surgery, gastrectomy, gastrointestinal bypass procedures)

- Endocrine or hormonal disorders (diabetes, hyperparathyroidism, hyperthyroidism, Cushing's syndrome, Thyrotoxicosis) 
- Hematologic or blood disorders (Leukemia and lymphoma, multiple myeloma, Sickle Cell disease, blood and bone marrow disorders, Thalassemia)

- Neurological or nervous system disorders (Stroke, Parkinson's disease, spinal cord injuries)

- Mental illness (depression, eating disorders)

- Cancer or history of cancer (breast cancer and prostate cancer)

- $\mathrm{AIDS} / \mathrm{HIV}$

- Kidney or liver disease

- Organ transplants

- Polio and post-polio syndrome

Because males experience bone loss at a slower rate compared to females, this study only assessed women. All inclusion and exclusion criteria were be self-reported, assessed by a Premier Performance, Inc. Health History Questionnaire (Appendix C) and the PARQ \& YOU physical activity readiness questionnaire, or were objectively measured during preliminary measurements. Participants were informed of all risks, benefits, and requirements of the study, and gave verbal and written consent. All documentation and procedures were approved by the Human Subjects Committee at Cal Poly.

\begin{tabular}{lcc}
\hline \multicolumn{1}{l}{ Table 3.1: Exercise Suit Jacket Measurements } & \\
\hline Chest (in) & Medium & Large \\
Shoulder (in) & 17 & 18 \\
Length (in) & 16.5 & 17 \\
Sleeves (in) & 28 & 29 \\
\end{tabular}




\begin{tabular}{lcc}
\hline \multicolumn{2}{l}{ Table 3.2. Exercise Suit Pants Measurements } \\
\hline Inseam (in) & Medium & Large \\
Outseam (in) & 29 & 30 \\
Waist (in) & 37 & 37.5 \\
Hips (in) & 26 (relaxed) -34 (stretched) & 28 (relaxed) -35 (stretched) \\
\hline
\end{tabular}

\section{$\underline{\text { Screening and Informed Consent }}$}

Any woman who expressed interest in the study was given a general overview of the study and its requirements. To determine eligibility, interested women completed a brief telephone interview, which included a health history questionnaire and the PAR-Q $\&$ YOU, to screen for their ability to begin engaging in exercise.

Eligible participants were asked to schedule an in-person visit to the Webb Human Performance Laboratory in the Kinesiology Department at Cal Poly. During this visit, the participant was asked to confirm their answers on the PAR-Q \& YOU and healthy history questionnaires, as well as complete several objective assessments to further confirm eligibility. These assessments were designed to 1) determine if the participant is able to fit within the confines of the exercise suit, and 2) assess whether the participant could carry $12 \mathrm{lbs}$.

Finally, participants had their DXA (GE Lunar iDXA, GE Healthcare, Bucks, UK) scan scheduled by the primary researcher and completed to determine current $\mathrm{T}$ score, BMD, and body composition. DXA scans were completed in the Nutrition and Health Assessment Laboratory at Cal Poly by a certified technician.

Once participant eligibility was confirmed, the study was explained in detail, including the importance of fasting prior to exercise testing bouts, and attending all assessments and follow up blood draws. The study and consent forms were reviewed and 
informed consent was obtained both verbally and through an informed consent document (Appendix A).

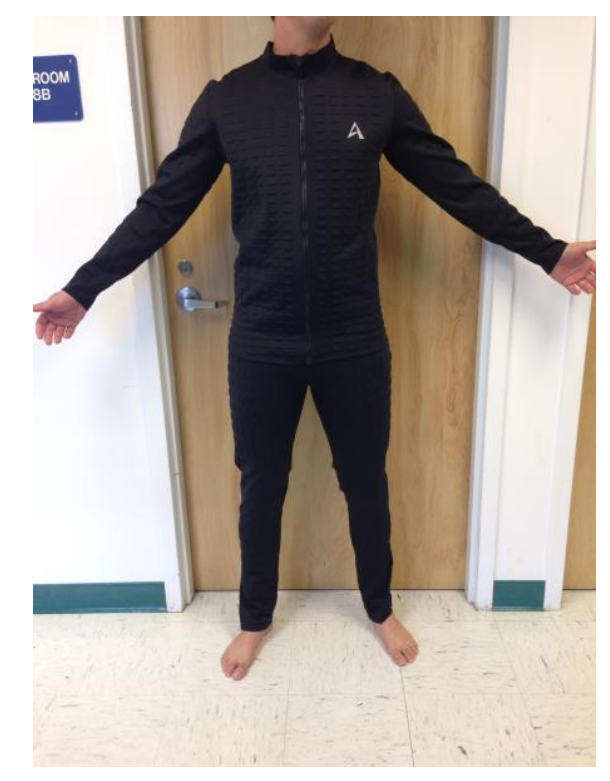

Figure 3.1: Uniformly Weighted Exercise Suit (Curry, Davis, Nazmi, \& Clegg, 2015)

\section{$\underline{\text { Experimental Conditions }}$}

Exercise Suit (ES) versus No Suit (NS)

The experimental conditions consisted of either 1) wearing the weighted exercise suit (ES) or 2) no suit (NS) during a bout of aerobic exercise. During both conditions participants wore clothes of their choice, preferably a t-shirt and athletic shorts with athletic shoes. During the ES condition, the participant additionally wore the uniformly weighted exercise suit designed by Dr. Lawrence Petrakis, MD, weighing 5.44kg (Figure 3.1). The exercise suit consisted of a front zip, full-sleeved jacket, and long, drawstring pants. The fabric, Athlotex ${ }^{\mathrm{TM}}$ is uniformly weighted, and combines flexibility and breathability for participant comfort as well as to accommodate various body 
compositions of the participants. Stainless steel beads are uniformly distributed and integrated throughout the fabric, which is composed of Spandex and other synthetic and natural fibers. A sample of two different participant timelines can be found in Table 3.3.

\begin{tabular}{|c|c|c|c|c|c|c|c|c|}
\hline & Preliminary & & & Experi & iental CoI & ditions & & \\
\hline & Visit 1 & $\begin{array}{c}\text { Visit } \\
2\end{array}$ & $\begin{array}{l}24 \mathrm{hr} \\
\text { post } \\
\text { test }\end{array}$ & $\begin{array}{c}72 \mathrm{hr} \\
\text { post } \\
\text { test }\end{array}$ & & $\begin{array}{c}\text { Visit } \\
3\end{array}$ & $\begin{array}{c}24 \mathrm{hr} \\
\text { post } \\
\text { test }\end{array}$ & $\begin{array}{c}72 \mathrm{hr} \\
\text { post } \\
\text { test }\end{array}$ \\
\hline $\begin{array}{l}\text { Participant } \\
1\end{array}$ & $\begin{array}{c}\text { Screening } \\
\text { and } \\
\text { Informed } \\
\text { Consent }\end{array}$ & $\begin{array}{l}\text { Blood } \\
\text { draw; } \\
\text { ES }\end{array}$ & $\begin{array}{c}\text { Blood } \\
\text { draw }\end{array}$ & $\begin{array}{c}\text { Blood } \\
\text { draw }\end{array}$ & $\begin{array}{c}7 \text { day } \\
\text { washout }\end{array}$ & $\begin{array}{c}\text { Blood } \\
\text { draw; } \\
\text { NS }\end{array}$ & $\begin{array}{l}\text { Blood } \\
\text { draw }\end{array}$ & $\begin{array}{l}\text { Blood } \\
\text { draw }\end{array}$ \\
\hline $\begin{array}{l}\text { Participant } \\
2\end{array}$ & $\begin{array}{c}\text { Screening } \\
\text { and } \\
\text { Informed } \\
\text { Consent }\end{array}$ & $\begin{array}{c}\text { Blood } \\
\text { draw; } \\
\text { NS }\end{array}$ & $\begin{array}{c}\text { Blood } \\
\text { draw }\end{array}$ & $\begin{array}{c}\text { Blood } \\
\text { draw }\end{array}$ & period & $\begin{array}{c}\text { Blood } \\
\text { draw; } \\
\text { ES }\end{array}$ & $\begin{array}{l}\text { Blood } \\
\text { draw }\end{array}$ & $\begin{array}{l}\text { Blood } \\
\text { draw }\end{array}$ \\
\hline
\end{tabular}

Exercise Suit (ES): exercise bout with suit, No Suit (NS): exercise bout without suit ${ }^{1}$ Note that conditions are counterbalanced across the $2^{\text {nd }}$ and $3^{\text {rd }}$ visit

\section{Experimental Protocol}

Participants completed two identical single-bout exercise trial protocols in a counterbalanced fashion, on two separate occasions separated by seven days (Tosun et al., 2006). The only difference between trials was the addition of the exercise suit. Participants were randomized to begin with one of the two conditions: 1) aerobic exercise while wearing the exercise suit, or 2) aerobic exercise without the exercise suit. Participants were asked to arrive at the Webb Human Performance Laboratory between 0700-1000 hours after an overnight fast, well rested, and well hydrated. Fasting status was required due to a feeding effect of serum CTX. CTX can decrease by as much as $20 \%$ following a meal (Vasikaran, Eastell, et al., 2011). Participants were asked to 
consume $16-20 \mathrm{oz}$ of water the night before to ensure adequate hydration. Furthermore, all participants were asked to refrain from exercise 72 hours prior to any and all sessions; and caffeine, drugs, and alcohol for 24 hours prior to any and all sessions.

Upon arrival, the participant had their baseline blood drawn by the on-site phlebotomist. Next, all physical activity, dietary, and hydration measures were assessed though the completion of the International Physical Activity Questionnaire (IPAQ) (Appendix D), and Automated Self-Administered 24-hour Dietary Recall (ASA24) (Appendix E). To ensure proper hydration during and post exercise, participants were given a $160 z$ water bottle to be consumed at will during their appointment. Participants remained fasted until the exercise bout had been terminated.

Following completion of both questionnaires, and prior to the exercise bout, participants had their resting heart rate, resting blood pressure, height, weight, BMI, and tympanic membrane temperature measured and recorded (Appendix F). Resting heart rate was measured using a Polar ${ }^{\mathrm{TM}} \mathrm{T} 31$ transmitter and receiver $\left(\right.$ Polar $^{\mathrm{TM}}$, model 94035939.02), and blood pressure was measured using sphygmomanometry. A portable stadiometer (SECA, Hamburg, Germany) was used to determine height to the nearest 0.1 centimeter and a digital scale (MedWeight digital scale, model MS-3200) was used to determine weight to the nearest 0.1 kilogram. BMI was calculated using the following equation: $\mathrm{BMI}=$ weight $[\mathrm{kg}] /$ height $[\mathrm{m}]^{2}$. Tympanic membrane temperature was recorded using the BRAUN ThermoScan tympanic thermometer. Prior to the exercise bout, each participant's maximal heart rate range was determined using the Age Predicted Maximum Heart Rate equation (220-age) in order to maintain the desired heart rate range (Tosun et al., 2006). 65-75\% $\mathrm{HR}_{\max }$ was chosen to approximate a workload greater than 
that of activities of daily living, but low enough so as to not overstress the participant (Moldover \& Bartels, 2000).

The participant was fitted with headgear and a mouthpiece hooked up to a 6-foot tube attached to the TrueOne 2400 metabolic measurement system (Parvo Medics, Sandy, Utah) using a Hans Rudolf 3813 (Kansas City, MO) pneumotachometer to measure ventilation during the first 15 minutes of the exercise bout. Before initializing the exercise bout, the gas analyzer was calibrated to the manufacturer's specifications, including a room air auto-calibration and a two-point gas calibration using a single gas tank. To calibrate the flow meter, a 3L Hans Rudolf 5530 series syringe was used, involving a series of flow rate stroke calibrations (Crouter, Antczak, Hudak, DellaValle, \& Haas, 2006).

Participants walked on a treadmill (Trackmaster, Full Vision Inc., Newton, Kansas; Q 65, Quinton Instrument Company, Seattle, Washington) with the necessary incline and grade to elicit the desired heart rate range. Gas analysis was performed using a computerized TrueOne 2400 metabolic measurement system (Parvo Medics, Sandy, Utah) using a Hans Rudolf 3813 (Kansas City, MO) pneumotachometer to measure ventilation. Participants wore a nose clip and headgear, which secure the 1-way Hans Rudolf valve to the rubber mouthpiece, during the first 15 minutes of the exercise bout to test for oxygen and carbon dioxide analysis. Additionally, the gas analysis allowed for the calculation of time necessary to reach caloric expenditure.

After the first 15-minutes, the participant was instructed to remove the nose clip and headgear, and to continue walking for the remainder of the trial. Total duration of the exercise session was calculated by averaging the caloric expenditure over minutes 10-15, 
during steady state, to determine the average caloric expenditure per minute. The total energy expended was subtracted from the goal expenditure (400kcal), to establish the remaining time necessary to burn the remaining calories. Heart rate was measured before and monitored during the trial, at 5-minute intervals until the cessation of the trial, to ensure the participant remains within the target heart rate range. Blood pressure was measured halfway through the exercise bout, and twice following the exercise bout to ensure adequate recovery. Tympanic membrane temperature was recorded prior to and during the exercise bout, at 25-minute intervals. The timeline of required action during the exercise bout can be referenced in Table 3.4. During both trials, the participant was cooled by a fan placed behind and to the left of the treadmill.

\begin{tabular}{ll}
\hline Table 3.4. Timeline of Participant Action During Exercise Trial Duration By Minute \\
\hline Minute & Participant Action \\
\hline $0-10$ & Walking to reach steady state \\
$10-15$ & $\begin{array}{l}\text { Steady state achieved; calculate calories per minute } \\
\text { expended during steady state to predict duration of trial } \\
15\end{array}$ \\
$\begin{array}{l}\text { Remove headgear and nose clip } \\
15-\text { termination of exercise }\end{array}$ & Continue walking at the same pace and incline \\
\hline
\end{tabular}

Criteria for terminating the exercise trial prematurely followed ACSM guidelines for general indications for stopping an exercise test in low-risk adults (American College of Sports Medicine, 2013): 1) onset of angina-like symptoms, 2) drop in systolic blood pressure of $>10 \mathrm{~mm} \mathrm{Hg}$ from baseline blood pressure (BP) despite an increase in workload, 3) excessive rise in BP: systolic pressure > $250 \mathrm{~mm} \mathrm{Hg}$ or diastolic pressure > $115 \mathrm{~mm} \mathrm{Hg}$, 4) shortness of breath, wheezing, leg cramps, or claudication, 5) signs of poor perfusion: light-headedness, confusion, ataxia, pallor, cyanosis, nausea, or cold and 
clammy skin, 6) failure of heart rate to increase with increased exercise intensity, 7) noticeable change in heart rhythm, 8) subject request to stop, 9) physical or verbal manifestations of severe fatigue, or 10) failure of testing equipment.

Following normal termination of the exercise bout, a post-weight was taken to assess hydration status of the participant, and she was again offered $16 \mathrm{oz}$ of water. The participant returned to Cal Poly 24 hours and 72 hours post exercise to have her follow up blood draws taken at the same time as the baseline blood draw. As stipulated previously, the participant was overnight fasted, well hydrated, and had not performed additional exercise within the last 24 hours.

One week later, the participant returned to the Webb Human Performance Laboratory at Cal Poly to complete the identical protocol following the subsequent experimental condition, including baseline blood draw, followed by the 24 hour and 72 hour follow up blood draws.

\section{$\underline{\text { Blood Measures }}$}

Blood was drawn by one of two trained phlebotomists at Cal Poly 15 minutes before the exercise session (baseline), 24 and 72 hours following the submaximal aerobic exercise. Blood was collected in a BD 367988 vacutainer Plus SST Plus Venous Blood Collection Serum Tube (BD Biosciences), and left to sit for 15-30 minutes at room temperature until the blood clotted. The clot was removed by centrifuging the sample at 2,000 x g for 15 minutes in a refrigerated centrifuge (Sorvall ST 40R Centrifuge, Thermo Fisher Scientific, 2012). Immediately following centrifugation, the serum was transferred into a clean polypropylene cryovial tube using a Pasteur pipette. Serum samples were 
stored at $-80^{\circ} \mathrm{C}$ for later simultaneous analyses. All calibrators, controls, and samples of P1NP, P1CP, and CTX were measured in triplicate samples of serum by enzyme-linked immunosorbent assay (NeoScientific, NeoGroup Inc, Cambridge, MA) according to manufacture specifications and instructions (Appendix G).

All serum samples and kit components were brought to room temperature prior to use. In order to prepare the reagents, $10 \mu 1$ of Balance Solution was dispensed into $100 \mu 1$ of the experimental samples. The following assay procedure was utilized with all samples. One hundred microliters of the sample or standard was dispensed into the appropriate number of wells in the NeoPlate, and $100 \mu 1$ of deionized water was added to the pre-determined blank wells. An enzyme solution $(50 \mu 1)$ was then dispensed into each well, except the blank wells. Following 1-hour of incubation, each well was washed 5 times with $300-400 \mu 1$ of $1 \mathrm{x}$ wash solution per well. Substrate A $(50 \mu 1)$ was added to each well, followed by an addition of 50 $\mathrm{\mu l}$ of Substrate B. Again, the plate was covered and incubated for 15 minutes. Finally, $50 \mu 1$ of stop solution was dispensed into each well and mixed well. Immediately following, the plate was read, using a Fisher Scientific Multiskan FC Microplate Reader (Fisher Scientific) to determine the optical density (O.D.) at 450nm. The mean blank value was subtracted from each sample or standard value, and the mean for triplicate wells was calculated. Standard curves were constructed using statistical software.

The primary investigator analyzed all serum samples to prevent interpretation errors. The degree to which the samples, in triplicate, differ can be explained by calculating the intra-assay Coefficient of Variability (CV). It was calculated as follows: 
Eq. 1

CV $(\%)=($ SD of triplicate sample/Mean of triplicate sample $) * 100$

Overall Plate Intra-assay CV $(\mathrm{N}=$ number of triplicate samples $)=$ Mean of all Intra-assay CVs

The corresponding concentrations of each biomarker were reported to reflect the range of results found within the sample specimens. Overall plate intra-assay CV is a measure of the mean of all the intra-assay CV's for each sample. A measure of less than $10 \%$ was acceptable (Chesher, 2008). The intra-assay CV was $8.64 \%$ at $1.7 \mathrm{ng} / \mathrm{L}, 6.79 \%$ at $4.4 \mu \mathrm{g} / \mathrm{L}$, and $7.28 \%$ at $1.4 \mu \mathrm{g} / \mathrm{L}$, for P1NP, P1CP, and CTX, respectively.

\section{Sample Size Calculation}

The sample size was based on Thorsen et al. (1996), which showed an increase in $\mathrm{P} 1 \mathrm{CP}$ as a result of exercise, at 24 hours and 72 hours, relative to baseline. With 9 participants, our within-subject, experimental, crossover design, using a two-sample, twosided t-test, $\alpha<0.05$ had $80.5 \%$ to detect a difference in P1CP serum levels between rest and 24 hours post exercise bout, and a 93.5\% power to detect a difference in P1CP serum levels between rest and 72 hours post exercise.

\section{$\underline{\text { Statistical Methods }}$}

All statistical analyses were performed using JMP Stats version 12 (SAS Institute, Cary, NC) statistical software. Descriptive statistics were calculated for participant characteristics, including means and standard deviations (SD). Dependent t-tests were used to compare the means of the differences of the baseline participant characteristics 
for each condition. Repeated Measures Analysis of Variance (ANOVA) was used to assess the independent effects of time (the effect of exercise), condition order (which condition participants experienced first), and condition $\mathrm{x}$ time interactions for P1NP, P1CP, and CTX. Exploratory analyses were utilized to evaluate biomarker changes separately within each condition. Given the equal sample sizes per comparison group, Tukey's post hoc analysis was used to determine any differences in biomarker changes from baseline, and between time points. A significance level of $\mathrm{P}<0.05$ was used for all comparisons. 


\section{Chapter IV}

RESULTS

\section{$\underline{\text { Participants }}$}

Participant characteristics for age (years), height $(\mathrm{cm})$, body weight $(\mathrm{kg})$, body mass index (BMI), BMD T-score, and BMD Z-score were reported in means and standard errors in Table 4.1. All participants presented with low BMD as characterized by a negative $\mathrm{T}$-score.

\begin{tabular}{lcc}
\hline \multicolumn{2}{l}{ Table 4.1. Participant Characteristics $(\mathrm{N}=9)$} & Range \\
\hline Age (years) & Mean & $52.0-63.0$ \\
Height $(\mathrm{cm})$ & $165.7(3.4)$ & $154.9-180.3$ \\
Weight $(\mathrm{kg})$ & $77.7(9.3)$ & $64.6-89.8$ \\
BMI $\left(\mathrm{kg} \cdot \mathrm{m}^{-2}\right)$ & $28.2(3.1)$ & $23.4-32.3$ \\
BMD T-score & $-1.2(1.0)$ & $-2.7--0.5$ \\
BMD Z-score & $0.3(1.6)$ & $-2.3-2.7$
\end{tabular}

Note: Values are Mean (SD)

A comparison of the mean of the difference of the baseline characteristics for participants prior to the start of each exercise condition were analyzed (Table 4.2). Dependent t-tests revealed there was no significant difference between the means for caloric intake 24 hours prior to the exercise session, resting systolic blood pressure, resting diastolic blood pressure, height, weight, tympanic membrane temperature, or time to goal expenditure of 400kcal. There was, however, a significant difference for resting heart rate $(\mathrm{P}=0.04)$. These results indicate that participants presented with higher resting heart rates, on average, prior to the exercise session without the suit. 


\begin{tabular}{lccccc}
\hline Table 4.2. Comparison of Characteristics at & $\begin{array}{c}\text { Exercine for Each Condition } \\
\text { Suit (ES) }\end{array}$ & $\begin{array}{c}\text { No Suit } \\
\text { (NS) }\end{array}$ & Range & $\begin{array}{c}\text { t- } \\
\text { value }\end{array}$ & p-value \\
\hline Caloric Intake 24 hours & 1518.2 & 1520.2 & $994.6-2521.6$ & 0.01 & 0.99 \\
prior & $(732.6)$ & $(546.4)$ & & & \\
Resting Heart Rate (bpm) & 70.2 & 78.7 & $60.0-87.0$ & 2.28 & 0.04 \\
& $(7.1)$ & $(8.5)$ & & & \\
Resting Systolic Blood & 125.8 & 125.4 & $118.0-138.0$ & -0.10 & 0.90 \\
Pressure (mmHg) & $(3.5)$ & $(6.6)$ & & & \\
Resting Diastolic Blood & 78.0 & 77.8 & $60.0-92.0$ & -0.06 & 0.90 \\
Pressure (mmHg) & $(9.4)$ & $(3.2)$ & & & \\
Weight (kg) & 165.6 & 166.1 & $64.5-92.2$ & -0.06 & 0.99 \\
& $(9.9)$ & $(9.7)$ & & & \\
Body Mass Index (BMI) & 28.9 & 28.6 & $23.4-32.3$ & -0.20 & 0.80 \\
& $(3.1)$ & $(2.9)$ & & & \\
Tympanic Membrane & 97.8 & 97.5 & $96.2-98.7$ & -0.80 & 0.40 \\
Temperature (F) & $(0.5)$ & $(0.9)$ & & & \\
Time to Goal Expenditure & 52.5 & 55.6 & $42.0-62.0$ & 1.30 & 0.20 \\
(min) & $(4.8)$ & $(5.9)$ & & & \\
Final Speed & 3.1 & 3.1 & $2.1-3.6$ & 0.00 & 0.99 \\
& $(0.5)$ & $(0.5)$ & & & \\
Final Incline & 2.4 & 2.4 & $0.5-4.0$ & 0.00 & 0.99 \\
& $(1.1)$ & $(1.1)$ & & & \\
\hline Note: Values are Mean (SD) & & & & & \\
\hline
\end{tabular}

Changes in Biochemical Markers for Bone Turnover

It was hypothesized that, when compared to the non-suit condition, wearing the $5.44 \mathrm{~kg}$ weighted exercise suit during submaximal aerobic exercise to goal expenditure (400kcal), would elicit a greater positive change in P1NP and P1CP, and a greater negative change in CTX at both 24 and 72 hours post-exercise relative to baseline. The changes in biochemical markers of bone turnover over time are shown in Table 4.3 and Figures 4.1-4.3. 
Table 4.3. Measurements of Serum Amino-Terminal Propeptide of Type 1 Collagen (P1NP), Carboxy-Terminal Propeptide of Type 1 Collagen (P1CP), and CarboxyTerminal Telopeptide of Type 1 Collagen (CTX) at Baseline, 24 hours, and 72 hours Post Exercise

\begin{tabular}{lllllll}
\hline & \multicolumn{3}{c}{ Exercise Suit } & \multicolumn{3}{c}{ No Suit } \\
& Baseline & $24 \mathrm{hrs}$ & $72 \mathrm{hrs}$ & Baseline & $24 \mathrm{hrs}$ & $72 \mathrm{hrs}$ \\
\hline P1NP & 10.6 & 12.1 & 10.9 & 10.5 & 12.4 & 11.0 \\
$(\mathrm{ng} / \mathrm{L})$ & $(2.1)$ & $(3.6)$ & $(2.4)$ & $(2.3)$ & $(5.1)$ & $(2.6)$ \\
$\mathrm{P} 1 \mathrm{CP}$ & 10.5 & $13.3^{*}$ & 9.9 & 10.2 & 10.4 & 9.3 \\
$(\mu \mathrm{g} / \mathrm{L})$ & $(2.1)$ & $(3.4)$ & $(2.1)$ & $(4.1)$ & $(4.3)$ & $(3.9)$ \\
$\mathrm{CTX}$ & 8.5 & 8.9 & 8.7 & 8.8 & $12.7 *$ & 9.9 \\
$(\mu \mathrm{g} / \mathrm{L})$ & $(2.4)$ & $(2.4)$ & $(2.6)$ & $(2.3)$ & $(5.1)$ & $(1.9)$ \\
\hline
\end{tabular}

Values are Mean (SD)

Significantly different from baseline: ${ }^{*} \mathrm{P}<0.05$

NS, aerobic exercise without the exercise suit;

ES, aerobic exercise while wearing the exercise suit

P1NP, Amino-Terminal Propeptide of Type 1 Collagen; P1CP, Carboxy-Terminal Propeptide of Type 1 Collagen; CTX, Carboxy-Terminal Telopeptide of Type 1 Collagen

There was no effect of time ( $\mathrm{P}=0.26)$, order of experimental condition $(\mathrm{P}=0.89)$, or condition $(\mathrm{P}=0.96)$ on change in serum levels of $\mathrm{P} 1 \mathrm{NP}$ at any time point relative to baseline (Figure 4.1). Moreover, there was no effect of an interaction between condition and time $(\mathrm{P}=0.99)$ on $\mathrm{P} 1 \mathrm{NP}$ levels at any given time point. Post hoc analysis revealed no difference between conditions $(\mathrm{P}=0.98)$. These finding suggests there was no significant effect of this type of submaximal aerobic exercise on serum levels of P1NP. 


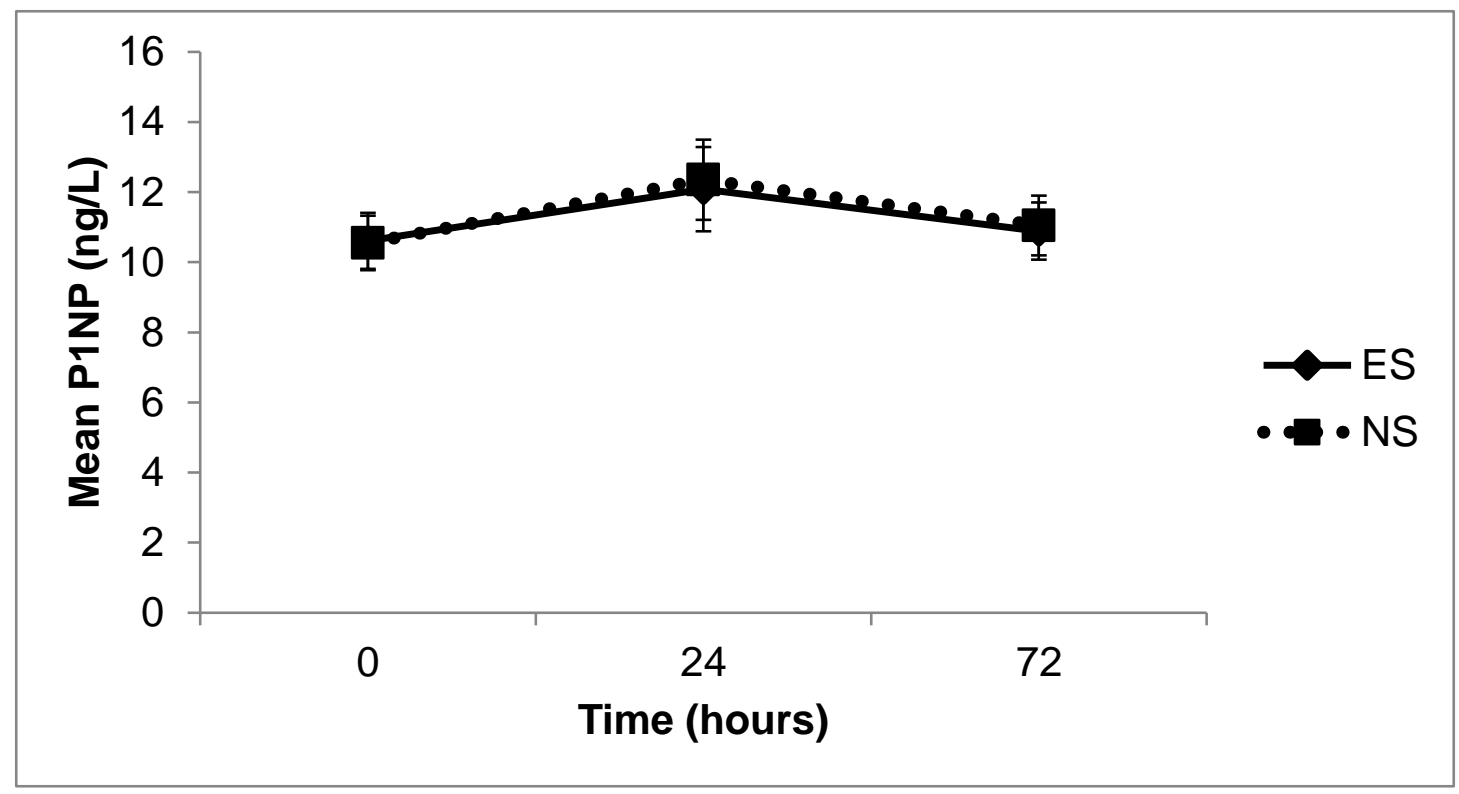

Figure 4.1: Effect of Condition (ES; exercise suit, NS; no suit) on Average Serum Level of Amino-Terminal Propeptide of Type 1 Collagen (P1NP) at Baseline, 24hours and 72-hours Post Exercise Session. Values are Mean \pm SE.

A statistically significant effect of time $(\mathrm{P}=0.01)$ on $\mathrm{P} 1 \mathrm{CP}$ levels was observed. Participants' serum P1CP values increased at 24 hours post exercise $(\mathrm{P}=0.01)$, but returned to baseline levels at 72 hours $(\mathrm{P}=0.58)$. There was no observable effect of order of trial condition $(\mathrm{P}=0.35)$. A statistically significant effect of condition on $\mathrm{P} 1 \mathrm{CP}$ levels was observed $(\mathrm{P}=0.04)$. ES caused a significant increase in serum $\mathrm{P} 1 \mathrm{CP}$ values $(\mathrm{P}=0.01)$, while NS caused no significant change $(\mathrm{P}=0.59)$. There was no effect of an interaction between condition and time $(\mathrm{P}=0.19)$. However, further exploratory analysis, when the effects of time were analyzed by condition, revealed a significant increase in serum P1CP values from 0-24 hours was seen during the ES condition, but not during the NS condition.

The mean increase in $\mathrm{P} 1 \mathrm{CP}$ at 24 hours post exercise, compared to baseline levels was $27.2 \%$ and $2.30 \%$ for ES and NS, respectively (Figure 4.2). These findings indicate 
that this type of exercise was substantial enough to elicit a significant response in serum levels of P1CP only while wearing the weighted exercise suit.

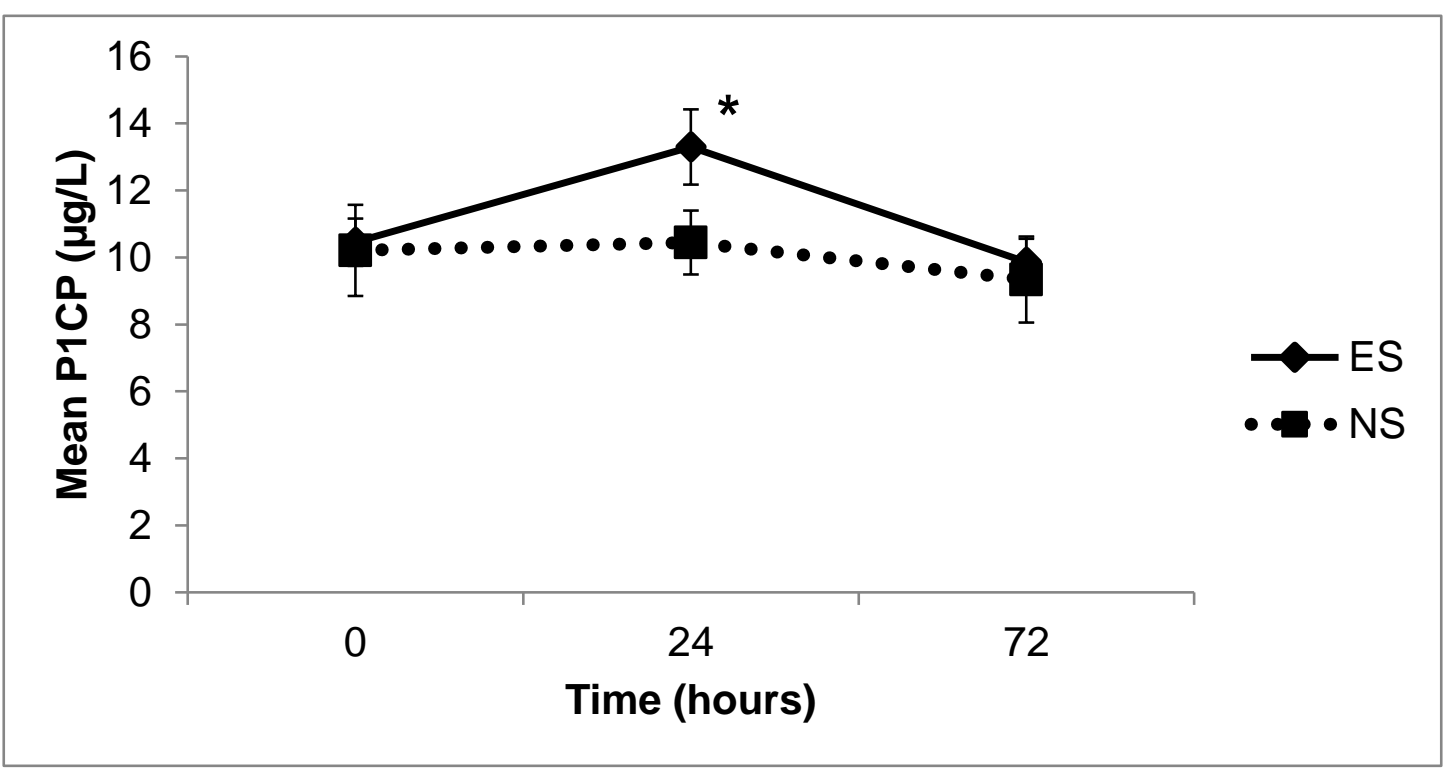

Figure 4.2: Effect of Condition (ES; exercise suit, NS; no suit) on Average Serum Levels of Carboxy-Terminal Propeptide of Type 1 Collagen (P1CP) at Baseline, 24 hours and 72 hours Post Exercise Session. All values are Mean \pm SE. *Significant change from baseline to 24 hours during ES condition: $\mathrm{P}<0.05$.

There was no effect of time $(\mathrm{P}=0.89)$ or of order of condition $(\mathrm{P}=0.29)$ on serum levels of CTX in response to this type of exercise. Statistically significant variances due to condition were observed in levels of CTX $(\mathrm{P}=0.001)$. There was evidence of a significant interaction between condition and time $(\mathrm{P}=0.02)$. Tukey's post hoc analysis revealed a significant difference between conditions at 24 hours following exercise $(\mathrm{P}=0.001)$. A significant increase in CTX values was seen after the NS condition $(\mathrm{P}=0.0003)$, but not after the ES condition $(\mathrm{P}=0.89)$. The mean increase in CTX at 24 hours, compared to basal levels, was $5.3 \%$ and $44.7 \%$ for ES and NS, respectively 
(Figure 4.3). These findings suggest an antiresorptive effect of wearing the weighted exercise suit on markers of bone resorption.

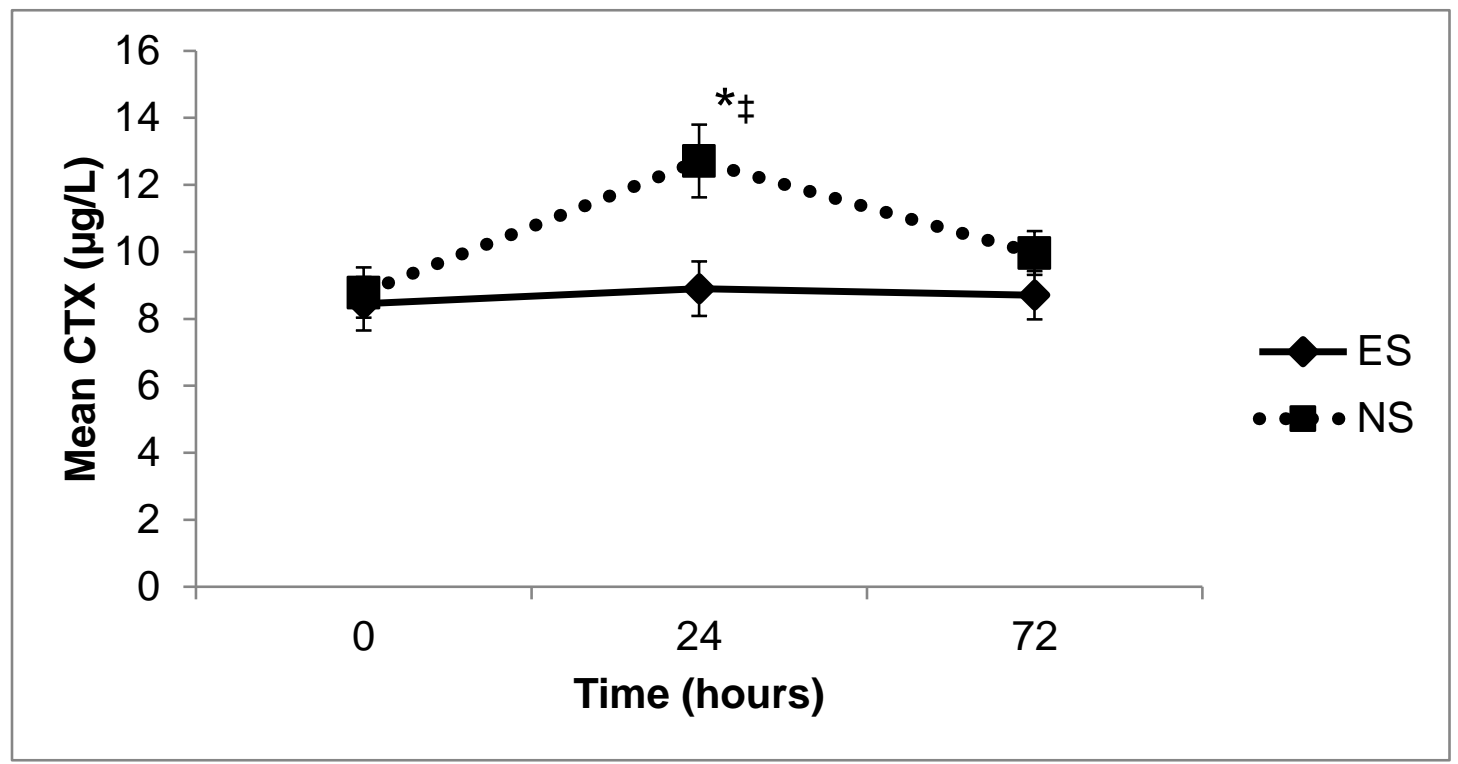

Figure 4.3: Effect of Condition (ES; exercise suit, NS; no suit) on Average Serum Levels of Carboxy-Terminal Telopeptide of Type 1 Collagen (CTX) at Baseline, 24 hours and 72 hours Post Exercise Session. Values are Mean \pm SE. * Significant change from baseline to 24 hours during NS condition: $\mathrm{P}<0.05$. $¥$ Significant difference between ES and NS conditions at 24 hours: $\mathrm{P}<0.05$. 


\section{Chapter V \\ DISCUSSION AND CONCLUSION}

\section{$\underline{\text { Discussion }}$}

The purpose of the present study was to examine the effects of a uniformly weighted exercise suit on serum biochemical markers of bone formation (P1NP, P1CP) and resorption (CTX) in response to submaximal aerobic exercise in postmenopausal women with low bone density. It was hypothesized that, when compared to the non-suit condition (NS), wearing the uniformly weighted exercise suit (ES) during submaximal aerobic exercise would elicit a greater: positive change in P1NP at 24 and 72 hours post exercise relative to baseline; positive change in $\mathrm{P} 1 \mathrm{CP}$ at 24 and 72 hours post exercise relative to baseline; and negative change in CTX at 24 and 72 hours post exercise relative to baseline. Results suggest that submaximal aerobic exercise under ES conditions may be beneficial for bone health, as the ES condition provided a significant stimulatory effect on P1CP combined with an antiresorptive effect on levels of CTX when compared to the NS condition. No effect of exercise or condition on P1NP was seen at any time point.

Fibrillar collagen synthesis, characterized by the cleavage of P1NP and P1CP from the procollagen molecule during bone matrix formation (Kadler et al., 1996), indicates an increase in the circulation of these biomarkers. Previously literature suggests a significant association between fracture risk and bone formation markers, showing lower circulating levels of $\mathrm{P} 1 \mathrm{CP}$ were associated with higher fracture rates (Akesson et al., 1995; Vasikaran, Eastell, et al., 2011). Our findings show that, 24 hours following exercise during the ES condition, there were increased levels of $\mathrm{P} 1 \mathrm{CP}$, indicating an 
increase in this formation process. The lack of similar results following the NS condition, suggests the stimulatory effect on collagen synthesis results only while wearing the weighted exercise suit. Our findings suggest that wearing the weighted exercise suit during submaximal aerobic exercise may have the potential to decrease risk for fracture within this population.

Possibly the most impactful results of the present study were those associated with variance in serum levels of CTX. During bone resorption, collagen peptide fragments are secreted into circulation, and a rise in CTX is expected. Our findings indicated a significant within-person increase in CTX levels during exercise in the NS condition, and a distinct lack of variance during the ES condition. The lack of increase in collagen resorption during the ES condition, when compared to the NS condition, suggest an acute antiresorptive effect of weighted aerobic exercise on bone collagen due to the increased loading on the musculoskeletal system (Knapik et al., 1996; Kohrt, 2001).

To our knowledge, no other study has investigated the effects of short-term, low impact aerobic exercise on variance in CTX. However, many have investigated the effects of exercise on the amino-terminal telopeptide of type 1 collagen (NTX). Significant decreases in NTX, due to submaximal treadmill walking exercise, have been observed in several studies (Roghani et al., 2013; Yamazaki et al., 2004). However, previous research suggests NTX, when compared to CTX, may lack specificity to bone due to the smaller response to intervention therapy (Vasikaran, Eastell, et al., 2011).

There appears to be a more significant association between fracture risk and markers of bone resorption, when compared with bone formation (Vasikaran, Eastell, et al., 2011). When data from six previous publications (Bauer et al., 2009; Chapurlat, 
Garnero, Breart, Meunier, \& Delmas, 2000; Dobnig et al., 2007; Garnero, Sornay-Rendu, Claustrat, \& Delmas, 2000; Gerdhem et al., 2004; Meier, Nguyen, Center, Seibel, \& Eisman, 2005) investigating the association between serum levels of CTX and fracture risk in olden men and women were merged, the results indicated that a 1 SD increase of CTX was equivocal to an 18\% increase in risk for fracture (Johansson et al., 2014). If the reverse of this association holds as expected, it would suggest that decreasing levels of CTX should, in turn, decrease fracture risk in the same population.

The increase in markers of bone formation in response to low impact aerobic exercise seen in the current and previous studies may be attributable to the additional load placed on the musculoskeletal system by the exercise suit. As Wolff's law suggests, bone growth and remodeling occur in response to the forces placed upon it (Sinaki, 1989), so loading the skeleton with the additional weight provided by the exercise suit would be expected to cause a physiological reaction favoring bone formation to support the new load. Furthermore, the uniform design of the weighted suit allows for weight to be distributed over a greater surface area of the body, increasing the regions that can be affected by the external load. Biomarkers of bone formation and resorption are systemic, not site specific, suggesting the greater affected surface area could cause a more widespread effect. Although the systemic nature of biomarkers is advantageous in the present study, it doubles as a limitation. It is unclear as to where the formation and resorption are occurring within the body. Previously research suggests interventions have focused primarily on increasing BMD in the lumbar spine and hip to prevent fracture. Future research utilizing both DXA and biomarkers of bone turnover should investigate 
locations of bone modeling or resorption in response to externally loaded aerobic exercise.

The beneficial effects of the weighted suit seen in the present study have various physical and psychosocial health related implications for the target population. The combination of increased formation and decreased resorption, if maintained over time, have the potential to slow the rate of BMD loss, thus decreasing fracture risk amongst postmenopausal women with low bone density, even before changes in BMD occur (Bonnick \& Shulman, 2006). Further possible benefits, which should be explored in future research, include improved balance (Roghani et al., 2013; J. M. Shaw \& Snow, 1998), better posture (Harman et al., 1994; Kinoshita, 1985), improved indices of fall risks, lower body muscular strength, and muscular power (Snow et al., 2000), and maintenance of normal gait patters, which can be negatively affected by BMD loss (Lloyd \& Cooke, 2011).

It remains unclear as to why significant variance was observed in $\mathrm{P} 1 \mathrm{CP}$ but not P1NP, as we would have expected to see the same variance, or lack thereof, in both collagen metabolites. During the type 1 collagen formation, P1CP and P1NP are cleaved from the ends of the pro-collagen molecule in equimolar concentrations (Kadler et al., 1996) (Figure 2.3). This process occurs prior to formation of the collagen fibril, suggesting the production of serum $\mathrm{P} 1 \mathrm{CP}$ and P1NP reflect the rate of collagen formation on a stoichiometric basis (Adler, 2009; Delmas et al., 2000; Eriksen et al., 1993). While no international reference standard currently exists for P1CP, our P1NP data falls within normal reference intervals for healthy postmenopausal women (Eastell, Krege, Chen, Glass, \& Reginster, 2006; Vasikaran, Eastell, et al., 2011). Research should regularly 
monitor levels of P1NP, as an increase greater than or equal to $21 \%$ from baseline indicates an adequate response due to intervention therapy (Eastell et al., 2006).

Research by Thorsen et al. (1996) investigated the effects of non-weighted brisk walking on the amino-terminal propeptide of type III collagen in serum (PIIINP) and found brisk walking also increased levels of PIIINP at 24 and 72 hours post-exercise. Although change was observed in this variant of P1NP, PIIINP and P1NP are indicative of different metabolic processes, suggesting inferences cannot be made between the observed increase in one to the other. Type III (PIIINP) collagen is derived from type III procollagen, a much larger protein when compared with type 1 procollagen.

Concentrations of PIIINP increase in response to the accumulation or breakdown of connective tissue, most often related to fibroproliferative, endocrinological, malignant, and hematological diseases (Ehlers \& Leary, 2008). While neither type I nor type III collagen are exclusively specific to bone, roughly $90 \%$ of the organic matrix and $35 \%$ of bones dry weight is made up of type 1 collagen (Vasikaran, Eastell, et al., 2011). Thus, the IOF and IFCC have recommended that variance of bone turnover should be measured utilizing type 1 collagen metabolites (P1NP, P1CP).

Due to the inconsistency in both variance between P1NP and P1CP, and the lack of findings at 72 hours, future studies should explore the duration of stimulated physiological effects, and should strongly consider measuring serum P1NP and P1CP at a time interval between 24 and 72 hours post exercise to better understand patterns of P1NP and P1CP variance after exercise. In order to utilize the exercise suit to maximize osteogenic response during exercise, determining the greatest window of physiological stimuli would be vital to determine the optimal timing for multi-session interventions. 
Future research investigating the effects of the weighted exercise suit should also address the limitations of the present study. Inconsistency in measures of bone formation and lack of evidence of variance in any biomarker at the 72 hour time point suggest limitations of the current study in terms of frequency, intensity, type of exercise, duration, or limitations imposed by the exercise suit. Future research investigating biomarkers of bone turnover should also include measuring intensity levels via serum cortisol, to accurately determine the levels of physical stress experienced, due to exercise, at all time points. This would allow for a more comprehensive analysis of the effects of duration versus intensity on variance in biomarkers. The findings from this analysis would be beneficial for exercise prescription for persons concerned with bone health. Additional study design limitations include the lack of objectively measuring physical activity levels throughout the entirety of the study duration. Future studies should consider utilizing pedometers or accelerometers to monitor participant physical activity levels to ensure similar patterns throughout the study. Increased physical activity levels during the washout period have the potential to affect both baseline measurements for the second trial and follow up measures depending on the intensity of the activity, as seen by alterations in biomarker levels as early as 24 hours post exercise.

Moreover, the participant's psychological states or motivations may have affected her physical activity levels or nutritional intake pattern outside of testing sessions. The Hawthorne effect has been well documented and suggests that participants in an experiment may change their behavior simply because they are being monitored (Bravata et al., 2007; Campbell, Maxey, \& Watson, 1995; Katz, 2008). Participating in a health related study could cause the participant to want to change their behavior. Further 
research should consider having participants keep a nutritional journal to ensure no major deviations are made from their normal eating patterns.

The present study was powered only for $\mathrm{P} 1 \mathrm{CP}$, due to the lack of previous data on the new standard set of biomarkers (P1NP, CTX) during short-term exercise, disallowing for this analysis to be done for each. Although the study was powered at greater than $80 \%$ for the given sample size, a greater sample size in future research may result in understanding the effects of submaximal aerobic exercise, under both conditions, on serum levels of P1NP across all time points. Additionally, the greater sample size could provide further information regarding the trend of decline in all markers back to baselinelike values from 24 hours to 72 hours post exercise. Future research should strongly consider recruiting a greater number of participants to explore these trends.

Finally, our study design was limited by the standard weight of the exercise suit. Future research utilizing the weighted exercise suit should consider weighting each participant by a standard percent of their body weight, rather than loading all participants with a constant weight. Loading by percent body weight would provide the same external loading stimulus. It is possible that while the $5.44 \mathrm{~kg}$ suit provided enough of an osteogenic stimulus for some participants, it was not heavy enough to produce the same effect in others. As noted previously, the lack of sufficient load could have affected biomarker data, leading to findings of no variance.

\section{Conclusion}

In conclusion, wearing the uniformly weighted exercise suit during submaximal aerobic exercise (65\%-75\% age predicted maximum heart rate) to goal expenditure of 
400kcal, increased serum biochemical markers of bone formation (P1CP), while simultaneously providing an antiresorptive effect on biochemical markers of bone resorption (CTX) at 24 hours following exercise. The identical exercise protocol, completed without the exercise suit, did not elicit the same response; CTX was increased significantly in the non-suit condition, while P1CP showed no variation. From a clinical perspective, increasing formation, while limiting resorption, may provide significant benefits to postmenopausal women with low bone density in terms of decreased risk for fracture. 


\section{REFERENCES}

Abramson, A. S. (1948). Atrophy of disuse; a definition. Archives of Physical Medicine and Rehabilitation, 29(9), 562-570.

Adami, S., Bianchi, G., Brandi, M. L., Giannini, S., Ortolani, S., DiMunno, O., . . group, B. s. (2008). Determinants of bone turnover markers in healthy premenopausal women. Calcified Tissue International, 82(5), 341-347.

Adami, S., Gatti, D., Viapiana, O., Fiore, C. E., Nuti, R., Luisetto, G., . . Group, B. S. (2008). Physical activity and bone turnover markers: a cross-sectional and a longitudinal study. Calcified Tissue International, 83(6), 388-392.

Adler, R. A. (2009). Osteoporosis: pathophysiology and clinical management: Springer Science \& Business Media.

Akesson, K., Ljunghall, S., Jonsson, B., Sernbo, I., Johnell, O., Gardsell, P., \& Obrant, K. J. (1995). Assessment of biochemical markers of bone metabolism in relation to the occurrence of fracture: a retrospective and prospective population-based study of women. J Bone Miner Res, 10(11), 1823-1829. doi:10.1002/jbmr.5650101127

Alghadir, A. H., Aly, F. A., \& Gabr, S. A. (2014). Effect of Moderate Aerobic Training on Bone Metabolism Indices among Adult Humans. Pakistan Journal of Medical Sciences, 30(4), 840-844.

American College of Sports Medicine. (2013). ACSM's guidelines for exercise testing and prescription: Lippincott Williams \& Wilkins.

Arlot, M. E., Sornay - Rendu, E., Garnero, P., Vey - Marty, B., \& Delmas, P. D. (1997). Apparent Pre - and Postmenopausal Bone Loss Evaluated by DXA at Different 
Skeletal Sites in Women: The OFELY Cohort. Journal of bone and mineral research, 12(4), 683-690.

Bauer, D. C., Garnero, P., Harrison, S. L., Cauley, J. A., Eastell, R., Ensrud, K. E., . . . Osteoporotic Fractures in Men Research, G. (2009). Biochemical markers of bone turnover, hip bone loss, and fracture in older men: the MrOS study. Journal of Bone Mineral Research, 24(12), 2032-2038.

Berard, A., Bravo, G., \& Gauthier, P. (1997). Meta-analysis of the effectiveness of physical activity for the prevention of bone loss in postmenopausal women. Osteoporosis International, 7(4), 331-337.

Birge, S. J., \& Whedon, G. D. (1968). Hypodynamics \& Hypogravics. In M. McCally (Ed.), The Physiology of Inactivity and Weightlessness (pp. 213). New York: Academic Press.

Birrell, S. A., \& Haslam, R. A. (2010). The effect of load distribution within military load carriage systems on the kinetics of human gait. Applied ergonomics, 41(4), 585590.

Blake, G. M., \& Fogelman, I. (2002). Dual energy x-ray absorptiometry and its clinical applications. Seminars in Musculoskeletal Radiology, 6(3), 207-218.

Blake, G. M., \& Fogelman, I. (2007). The role of DXA bone density scans in the diagnosis and treatment of osteoporosis. Postgraduate Medical Journal, 83(982), $509-517$

Block, J. E., Genant, H. K., \& Black, D. (1986). Greater vertebral bone mineral mass in exercising young men. Western Journal of Medicine, 145(1), 39-42. 
Blumenthal, J. A., Emery, C. F., Madden, D. J., George, L. K., Coleman, R. E., Riddle, M. W., . . Williams, R. S. (1989). Cardiovascular and behavioral effects of aerobic exercise training in healthy older men and women. The Journals of Gerontology Series A: Biological Sciences and Medical Sciences, 44(5), M147157.

Bogdanis, G. C. (2012). Effects of physical activity and inactivity on muscle fatigue. Frontiers in physiology, 3.

Bonnick, S. L., \& Shulman, L. (2006). Monitoring osteoporosis therapy: bone mineral density, bone turnover markers, or both? American Journal of Medicine, 119(4 Suppl 1), S25-31.

Boyce, B. F., \& Xing, L. (2008). Functions of RANKL/RANK/OPG in bone modeling and remodeling. Archives Biochemistry Biophysics, 473(2), 139-146.

Bravata, D. M., Smith-Spangler, C., Sundaram, V., Gienger, A. L., Lin, N., Lewis, R., . . . Sirard, J. R. (2007). Using Pedometers to Increase Physical Activity and Improve Health. The Journal of the American Medical Association, 298(19), 2296-2304.

Burge, R., Dawson-Hughes, B., Solomon, D. H., Wong, J. B., King, A., \& Tosteson, A. (2007). Incidence and economic burden of osteoporosis-related fractures in the United States, 2005-2025. Journal of bone and mineral research, 22(3), 465-475.

Burr, D. B., Martin, R. B., \& Martin, P. A. (1983). Lower extremity loads stimulate bone formation in the vertebral column: implications for osteoporosis. Spine (1976), $8(7), 681-686$.

Campbell, J. P., Maxey, V. A., \& Watson, W. A. (1995). Hawthorne effect: implications for prehospital research. Annals of Emergency Medicine, 26(5), 590-594. 
Canalis, E., Giustina, A., \& Bilezikian, J. P. (2007). Mechanisms of anabolic therapies for osteoporosis. The New England Journal of Medicine, 357(9), 905-916.

Cauley, J. A. (2013). Public health impact of osteoporosis. The Journals of Gerontology Series A: Biological Sciences and Medical Sciences, 68(10), 1243-1251.

Chailurkit, L. O., Ongphiphadhanakul, B., Piaseu, N., Saetung, S., \& Rajatanavin, R. (2001). Biochemical markers of bone turnover and response of bone mineral density to intervention in early postmenopausal women: an experience in a clinical laboratory. Clinical Chemistry, 47(6), 1083-1088.

Chapurlat, R. D., Garnero, P., Breart, G., Meunier, P. J., \& Delmas, P. D. (2000). Serum type I collagen breakdown product (serum CTX) predicts hip fracture risk in elderly women: the EPIDOS study. Bone, 27(2), 283-286.

Chesher, D. (2008). Evaluating assay precision. The Clinical Biochemist Reviews, 29 Suppl 1, S23-26.

Chien, M. Y., Wu, Y. T., Hsu, A. T., Yang, R. S., \& Lai, J. S. (2000). Efficacy of a 24week aerobic exercise program for osteopenic postmenopausal women. Calcified Tissue International, 67(6), 443-448.

Clarke, B. (2008). Normal bone anatomy and physiology. Clinical Journal of the American Society of Nephrology, 3 Suppl 3, S131-139.

Clarke, B., \& Khosla, S. (2010). Physiology of bone loss. Radiologic Clinics of North America, 48(3), 483-495.

Cosman, F., de Beur, S. J., LeBoff, M. S., Lewiecki, E. M., Tanner, B., Randall, S., . . . National Osteoporosis, F. (2014). Clinician's Guide to Prevention and Treatment of Osteoporosis. Osteoporosis International, 25(10), 2359-2381. 
Creighton, D. L., Morgan, A. L., Boardley, D., \& Brolinson, P. G. (2001). Weightbearing exercise and markers of bone turnover in female athletes. Journal of Applied Physiology (1985), 90(2), 565-570.

Crouter, S. E., Antczak, A., Hudak, J. R., DellaValle, D. M., \& Haas, J. D. (2006). Accuracy and reliability of the ParvoMedics TrueOne 2400 and MedGraphics VO2000 metabolic systems. European journal of applied physiology, 98(2), 139151.

Cummings, S. R., Karpf, D. B., Harris, F., Genant, H. K., Ensrud, K., LaCroix, A. Z., \& Black, D. M. (2002). Improvement in spine bone density and reduction in risk of vertebral fractures during treatment with antiresorptive drugs. American Journal of Medicine, 112(4), 281-289.

Curry, T., Davis, S., Nazmi, A., \& Clegg, D. (2015). The Effects of a Novel Exercise Suit on Cardiorespiratory Fitness. Manuscript in Progress.

Delmas, P. D., Eastell, R., Garnero, P., Seibel, M. J., Stepan, J., \& Committee of Scientific Advisors of the International Osteoporosis, F. (2000). The use of biochemical markers of bone turnover in osteoporosis. Committee of Scientific Advisors of the International Osteoporosis Foundation. Osteoporosis International, 11 Suppl 6, S2-17.

Dobnig, H., Piswanger-Solkner, J. C., Obermayer-Pietsch, B., Tiran, A., Strele, A., Maier, E., . . . Fahrleitner-Pammer, A. (2007). Hip and nonvertebral fracture prediction in nursing home patients: role of bone ultrasound and bone marker measurements. The Journal of Clinical Endocrinology \& Metabolism, 92(5), 1678-1686. 
Eastell, R., \& Hannon, R. A. (2008). Biomarkers of bone health and osteoporosis risk. Proceedings Of The Nutrition Society, 67(2), 157-162.

Eastell, R., Krege, J., Chen, P., Glass, E., \& Reginster, J. (2006). Development of an algorithm for using PINP to monitor treatment of patients with teriparatide. Current Medical Research and Opinion, 22(1), 61-66.

Ehlers, M. R., \& Leary, E. T. (2008). Biochemical markers of rheumatoid arthritis and osteoarthritis: Clinical utility and practical considerations Clinical Trials in Rheumatoid Arthritis and Osteoarthritis (pp. 151-169): Springer.

Eriksen, E. F., Charles, P., Melsen, F., Mosekilde, L., Risteli, L., \& Risteli, J. (1993). Serum markers of type I collagen formation and degradation in metabolic bone disease: correlation with bone histomorphometry. Journal of bone and mineral research, 8(2), 127-132.

Fehling, P. C., Alekel, L., Clasey, J., Rector, A., \& Stillman, R. J. (1995). A comparison of bone mineral densities among female athletes in impact loading and active loading sports. Bone, 17(3), 205-210.

Franck, H., Beuker, F., \& Gurk, S. (1991). The effect of physical activity on bone turnover in young adults. Experimental and Clinical Endocrinology \& Diabetes, 98(1), 42-46.

Gabriel, S. E., Tosteson, A. N., Leibson, C. L., Crowson, C. S., Pond, G. R., Hammond, C. S., \& Melton, L. J., 3rd. (2002). Direct medical costs attributable to osteoporotic fractures. Osteoporosis International, 13(4), 323-330. 
Garnero, P., Sornay-Rendu, E., Chapuy, M. C., \& Delmas, P. D. (1996). Increased bone turnover in late postmenopausal women is a major determinant of osteoporosis. Journal of bone and mineral research, 11(3), 337-349.

Garnero, P., Sornay-Rendu, E., Claustrat, B., \& Delmas, P. D. (2000). Biochemical markers of bone turnover, endogenous hormones and the risk of fractures in postmenopausal women: the OFELY study. Journal of Bone Mineral Research, 15(8), 1526-1536.

Gerdhem, P., Ivaska, K. K., Alatalo, S. L., Halleen, J. M., Hellman, J., Isaksson, A., . . . Obrant, K. J. (2004). Biochemical markers of bone metabolism and prediction of fracture in elderly women. Journal of Bone Mineral Research, 19(3), 386-393.

Gillespie, J. (1954). The nature of the bone changes associated with nerve injuries and disuse. Journal of Bone \& Joint Surgery, British Volume, 36(3), 464-473.

Greendale, G. A., Hirsch, S. H., \& Hahn, T. J. (1993). The effect of a weighted vest on perceived health status and bone density in older persons. Quality of Life Research, 2(2), 141-152.

Gutin, B., \& Kasper, M. (1992). Can vigorous exercise play a role in osteoporosis prevention? A review. Osteoporosis International, 2(2), 55-69.

Haapasalo, H., Kannus, P., Sievanen, H., Heinonen, A., Oja, P., \& Vuori, I. (1994). Long-term unilateral loading and bone mineral density and content in female squash players. Calcified Tissue International, 54(4), 249-255.

Hadjidakis, D. J., \& Androulakis, II. (2006). Bone remodeling. Annals of the New York Academy of Sciences, 1092, 385-396. 
Hagihara, Y., Nakajima, A., Fukuda, S., Goto, S., Iida, H., \& Yamazaki, M. (2009). Running exercise for short duration increases bone mineral density of loaded long bones in young growing rats. The Tohoku Journal of Experimental Medicine, 219(2), 139-143.

Harman, E. A., Frykman, P. N., Knapik, J., \& Han, K.-H. (1994). Backpack vs. frontpack: Differential effects of fatigue on loaded walking posture. Medicine \& Science in Sports \& Exercise, 26(5), S140.

Heaney, R. P., Recker, R. R., \& Saville, P. D. (1978). Menopausal changes in calcium balance performance. Journal of Laboratory and Clinical Medicine, 92(6), 953963.

Hochberg, M. C., Greenspan, S., Wasnich, R. D., Miller, P., Thompson, D. E., \& Ross, P. D. (2002). Changes in bone density and turnover explain the reductions in incidence of nonvertebral fractures that occur during treatment with antiresorptive agents. The Journal of Clinical Endocrinology \& Metabolism, 87(4), 1586-1592.

Horowitz, G. L. (2010). Estimating reference intervals. American Journal of Clinical Pathology, 133(2), 175-177.

Hsiang, S. M., \& Chang, C. (2002). The effect of gait speed and load carrying on the reliability of ground reaction forces. Safety Science, 40(7), 639-657.

Hu, W. W., Zhang, Z., He, J. W., Fu, W. Z., Wang, C., Zhang, H., . . Zhang, Z. L. (2013). Establishing reference intervals for bone turnover markers in the healthy shanghai population and the relationship with bone mineral density in postmenopausal women. International Journal of Endocrinology, 2013, 513925. 
Jenkins, N., Black, M., Paul, E., Pasco, J. A., Kotowicz, M. A., \& Schneider, H. G. (2013). Age-related reference intervals for bone turnover markers from an Australian reference population. Bone, 55(2), 271-276.

Jessup, J. V., Horne, C., Vishen, R. K., \& Wheeler, D. (2003). Effects of exercise on bone density, balance, and self-efficacy in older women. Biological Research For Nursing, 4(3), 171-180.

Johansson, H., Oden, A., Kanis, J. A., McCloskey, E. V., Morris, H. A., Cooper, C., .. . Turnover, I.-I. J. W. G. o. S. o. B. M. o. B. (2014). A meta-analysis of reference markers of bone turnover for prediction of fracture. Calcified Tissue International, 94(5), 560-567.

Kadler, K. E., Holmes, D. F., Trotter, J. A., \& Chapman, J. A. (1996). Collagen fibril formation. Biochemical Journal, 316 ( Pt 1), 1-11.

Kai, M. C., Anderson, M., \& Lau, E. M. (2003). Exercise interventions: defusing the world's osteoporosis time bomb. Bulletin of the World Health Organization, 81(11), 827-830.

Kanis, J. A., \& Gluer, C. C. (2000a). An update on the diagnosis and assessment of osteoporosis with densitometry. Committee of Scientific Advisors, International Osteoporosis Foundation. Osteoporos International, 11(3), 192-202.

Kanis, J. A., \& Gluer, C. C. (2000b). An update on the diagnosis and assessment of osteoporosis with densitometry. Committee of Scientific Advisors, International Osteoporosis Foundation. Osteoporosis International, 11(3), 192-202.

Katz, A. R. (2008). Reduced falls in the elderly: tai chi or placebo or Hawthorne effect? Journal of the American Geriatrics Society, 56(4), 776-777; author reply 777. 
Kelley, G. (1998). Aerobic exercise and lumbar spine bone mineral density in postmenopausal women: a meta-analysis. Journal of the American Geriatrics Society, 46(2), 143-152.

Kemmler, W., \& Engelke, K. (2004). A critical review of exercise training effects on bone mineral density (BMD) in early postmenopausal women: article review. International SportMed Journal, 5(1), 67-77.

Kemmler, W., Lauber, D., Weineck, J., Hensen, J., Kalender, W., \& Engelke, K. (2004). Benefits of 2 years of intense exercise on bone density, physical fitness, and blood lipids in early postmenopausal osteopenic women: results of the Erlangen Fitness Osteoporosis Prevention Study (EFOPS). Archives of Internal Medicine, 164(10), 1084-1091.

Kerr, D., Morton, A., Dick, I., \& Prince, R. (1996). Exercise effects on bone mass in postmenopausal women are site-specific and load-dependent. Journal of bone and mineral research, 11(2), 218-225.

Khastgir, G., Studd, J., Holland, N., Alaghband-Zadeh, J., Fox, S., \& Chow, J. (2001). Anabolic effect of estrogen replacement on bone in postmenopausal women with osteoporosis: histomorphometric evidence in a longitudinal study. The Journal of Clinical Endocrinology and Metabolism, 86(1), 289-295.

Khosla, S., Atkinson, E. J., Melton, L. J., 3rd, \& Riggs, B. L. (1997). Effects of age and estrogen status on serum parathyroid hormone levels and biochemical markers of bone turnover in women: a population-based study. The Journal of Clinical Endocrinology and Metabolism, 82(5), 1522-1527. 
Kinoshita, H. (1985). Effects of different loads and carrying systems on selected biomechanical parameters describing walking gait. Ergonomics, 28(9), 13471362.

Klentrou, P., Slack, J., Roy, B., \& Ladouceur, M. (2007). Effects of exercise training with weighted vests on bone turnover and isokinetic strength in postmenopausal women. Journal of Aging and Physical Activity, 15(3), 287-299.

Knapik, J., Harman, E., \& Reynolds, K. (1996). Load carriage using packs: a review of physiological, biomechanical and medical aspects. Applied ergonomics, 27(3), 207-216.

Kohrt, W. M. (2001). Aging and the osteogenic response to mechanical loading. International journal of sport nutrition and exercise metabolism, 11, 137-142.

Kohrt, W. M., Bloomfield, S., Little, K., Nelson, M., \& Yingling, V. (2004). Physical activity and bone health. Position stand of the American College of Sports Medicine. Medicine \& Science in Sports \& Exercise, 36, 1985-1996.

Kohrt, W. M., Ehsani, A. A., \& Birge, S. J., Jr. (1997). Effects of exercise involving predominantly either joint-reaction or ground-reaction forces on bone mineral density in older women. Journal of Bone Mineral Research, 12(8), 1253-1261.

Krolner, B., \& Pors Nielsen, S. (1982). Bone mineral content of the lumbar spine in normal and osteoporotic women: cross-sectional and longitudinal studies. Clinical Science (London), 62(3), 329-336.

Krolner, B., Toft, B., Pors Nielsen, S., \& Tondevold, E. (1983). Physical exercise as prophylaxis against involutional vertebral bone loss: a controlled trial. Clinical Science (London), 64(5), 541-546. 
Lane, J. M., Riley, E. H., \& Wirganowicz, P. Z. (1997). Osteoporosis: diagnosis and treatment. Instructional Course Lecture, 46, 445-458.

Lane, N. E., Bloch, D. A., Jones, H. H., Marshall, W. H., Jr., Wood, P. D., \& Fries, J. F. (1986). Long-distance running, bone density, and osteoarthritis. The Journal of the American Medical Association, 255(9), 1147-1151.

Langberg, H., Skovgaard, D., Karamouzis, M., Bulow, J., \& Kjaer, M. (1999).

Metabolism and inflammatory mediators in the peritendinous space measured by microdialysis during intermittent isometric exercise in humans. The Journal of Physiology, 515 ( Pt 3), 919-927.

Langberg, H., Skovgaard, D., Petersen, L. J., Bulow, J., \& Kjaer, M. (1999). Type I collagen synthesis and degradation in peritendinous tissue after exercise determined by microdialysis in humans. The Journal of Physiology, 521 Pt 1, 299-306.

Lanyon, L. E. (1984). Functional strain as a determinant for bone remodeling. Calcified Tissue International, 36 Suppl 1, S56-61.

Lanyon, L. E. (1996). Using functional loading to influence bone mass and architecture: objectives, mechanisms, and relationship with estrogen of the mechanically adaptive process in bone. Bone, 18(1 Suppl), 37S-43S.

Law, M. R., Wald, N. J., \& Meade, T. W. (1991). Strategies for prevention of osteoporosis and hip fracture. British Medical Journal, 303(6800), 453-459.

Legg, S. J., \& Mahanty, A. (1985). Comparison of five modes of carrying a load close to the trunk. Ergonomics, 28(12), 1653-1660. 
Lehmann, R., Wapniarz, M., Randerath, O., Kvasnicka, H. M., John, W., Reincke, M., . . . Allolio, B. (1995). Dual-energy X-ray absorptiometry at the lumbar spine in German men and women: a cross-sectional study. Calcified Tissue International, 56(5), 350-354.

Lester, M. E., Urso, M. L., Evans, R. K., Pierce, J. R., Spiering, B. A., Maresh, C. M., .. . Nindl, B. C. (2009). Influence of exercise mode and osteogenic index on bone biomarker responses during short-term physical training. Bone, 45(4), 768-776.

Lindsay, R., Cosman, F., Zhou, H., Bostrom, M. P., Shen, V. W., Cruz, J. D., . . .

Dempster, D. W. (2006). A novel tetracycline labeling schedule for longitudinal evaluation of the short-term effects of anabolic therapy with a single iliac crest bone biopsy: early actions of teriparatide. Journal of bone and mineral research, $21(3), 366-373$.

Liu-Ambrose, T., Eng, J. J., Khan, K. M., Carter, N. D., \& McKay, H. A. (2003). Older women with osteoporosis have increased postural sway and weaker quadriceps strength than counterparts with normal bone mass: overlooked determinants of fracture risk? The Journals of Gerontology Series A: Biological Sciences and Medical Sciences, 58(9), M862-866.

Lloyd, R., \& Cooke, C. (2011). Biomechanical differences associated with two different load carriage systems and their relationship to economy. Human Movement, 12(1), 65-74.

Looker, A. C., Wahner, H. W., Dunn, W. L., Calvo, M. S., Harris, T. B., Heyse, S. P., . . Lindsay, R. (1998). Updated data on proximal femur bone mineral levels of US adults. Osteoporosis International, 8(5), 468-489. 
Lunt, M., Felsenberg, D., Adams, J., Benevolenskaya, L., Cannata, J., Dequeker, J., . . . Reeve, J. (1997). Population-based geographic variations in DXA bone density in Europe: the EVOS Study. European Vertebral Osteoporosis. Osteoporosis International, 7(3), 175-189.

Madureira, M. M., Takayama, L., Gallinaro, A. L., Caparbo, V. F., Costa, R. A., \& Pereira, R. M. (2007). Balance training program is highly effective in improving functional status and reducing the risk of falls in elderly women with osteoporosis: a randomized controlled trial. Osteoporosis International, 18(4), 419-425.

Marcus, R. (1998). Exercise: moving in the right direction. Journal of Bone Mineral Research, 13(12), 1793-1796.

Martyn-St James, M., \& Carroll, S. (2006). High-intensity resistance training and postmenopausal bone loss: a meta-analysis. Osteoporosis International, 17(8), $1225-1240$.

Mazess, R. B. (1987). Bone mineral content in early-postmenopausal and postmenopausal osteoporotic women. Radiology, 165(1), 289-291.

McHorney, C. A., Schousboe, J. T., Cline, R. R., \& Weiss, T. W. (2007). The impact of osteoporosis medication beliefs and side-effect experiences on non-adherence to oral bisphosphonates*. Current Medical Research and Opinion, 23(12), 31373152.

Meier, C., Nguyen, T. V., Center, J. R., Seibel, M. J., \& Eisman, J. A. (2005). Bone resorption and osteoporotic fractures in elderly men: the dubbo osteoporosis epidemiology study. Journal of Bone Mineral Research, 20(4), 579-587. 
Melkko, J., Kauppila, S., Niemi, S., Risteli, L., Haukipuro, K., Jukkola, A., \& Risteli, J. (1996). Immunoassay for intact amino-terminal propeptide of human type I procollagen. Clinical Chemistry, 42(6 Pt 1), 947-954.

Melkko, J., Niemi, S., Risteli, L., \& Risteli, J. (1990). Radioimmunoassay of the carboxyterminal propeptide of human type I procollagen. Clinical Chemistry, 36(7), 1328-1332.

Melton, L. J., 3rd. (1997). The prevalence of osteoporosis. Journal of Bone Mineral Research, 12(11), 1769-1771.

Meunier, P. J. (2001). Anabolic agents for treating postmenopausal osteoporosis. Joint Bone Spine, 68(6), 576-581.

Milliken, L. A., Going, S. B., Houtkooper, L. B., Flint-Wagner, H. G., Figueroa, A., Metcalfe, L. L., . . Lohman, T. G. (2003). Effects of exercise training on bone remodeling, insulin-like growth factors, and bone mineral density in postmenopausal women with and without hormone replacement therapy. Calcified Tissue International, 72(4), 478-484.

Moldover, J., \& Bartels, M. (2000). Cardiac Rehabilitation. In R. Branddom (Ed.), Physical medicine and rehabilitation (2 ed., pp. 665-686). Philadelphia: Saunders.

Naylor, K., \& Eastell, R. (2012). Bone turnover markers: use in osteoporosis. Nature Reviews Rheumatology, 8(7), 379-389.

Nelson, M. E., Fiatarone, M. A., Morganti, C. M., Trice, I., Greenberg, R. A., \& Evans, W. J. (1994). Effects of high-intensity strength training on multiple risk factors for osteoporotic fractures. A randomized controlled trial. The Journal of the American Medical Association, 272(24), 1909-1914. 
Nieves, J. W., Mosner, M., \& Silverstein, S. (2012). Osteoporosis. New York State Dental Journal, 78(4), 30-35.

Nilsson, B. E., Andersson, S. M., Havdrup, T., \& Westlin, N. E. (1978). Ballet-dancing and weight-lifting-effects on BMC. Paper presented at the American Journal of Roentgenology.

Nilsson, B. E., \& Westlin, N. E. (1971). Bone density in athletes. Clinical Orthopaedics and Related Research, 77, 179-182.

Njeh, C. F., Fuerst, T., Hans, D., Blake, G. M., \& Genant, H. K. (1999). Radiation exposure in bone mineral density assessment. Applied Radiation and Isotopes, $50(1), 215-236$.

Office of the Surgeon General. (2004). Bone Health and Osteoporosis.

Pagani, F., Francucci, C. M., \& Moro, L. (2005). Markers of bone turnover: biochemical and clinical perspectives. Journal of Endocrinological Investigation, 28(10 Suppl), 8-13.

Roghani, T., Torkaman, G., Movasseghe, S., Hedayati, M., Goosheh, B., \& Bayat, N. (2013). Effects of short-term aerobic exercise with and without external loading on bone metabolism and balance in postmenopausal women with osteoporosis. Rheumatology International, 33(2), 291-298.

Rosen, C. J. (2005). Clinical practice. Postmenopausal osteoporosis. The New England Journal of Medicine, 353(6), 595-603.

Rutherford, O. M. (1997). Bone density and physical activity. Proceedings Of The Nutrition Society, 56(3), 967-975. 
Ryan, P. J., Spector, T. P., Blake, G. M., Doyle, D. V., \& Fogelman, I. (1993). A comparison of reference bone mineral density measurements derived from two sources: referred and population based. The British Journal of Radiology, 66(792), 1138-1141.

Shan, P. F., Xian, C. J., Li, M., Xiang, G. D., \& Yuan, L. Q. (2013). Osteoporosis. International Journal of Endocrinology, 2013, 952858.

Shaw, J., \& Witzke, K. (1998). Exercise for skeletal health and osteoporosis prevention. In R. JL (Ed.), ACSM's resource manual for guidelines for exercise testing and prescription (pp. 288-293). Baltimore: Williams and Wilkins.

Shaw, J. M., \& Snow, C. M. (1998). Weighted vest exercise improves indices of fall risk in older women. Journals of Gerontology Series A: Biological Sciences and Medical Sciences, 53(1), M53-58.

Shipman, A. J., Guy, G. W., Smith, I., Ostlere, S., Greer, W., \& Smith, R. (1999). Vertebral bone mineral density, content and area in 8789 normal women aged 3373 years who have never had hormone replacement therapy. Osteoporosis International, 9(5), 420-426.

Simonsen, E. B., Dyhre-Poulsen, P., Voigt, M., Aagaard, P., Sjogaard, G., \& BojsenMoller, F. (1995). Bone-on-bone forces during loaded and unloaded walking. Acta Anatomica, 152(2), 133-142.

Sinaki, M. (1989). Exercise and osteoporosis. Archives of Physical Medicine and Rehabilitation, 70(3), 220-229.

Smeets-Goevaers, C. G., Lesusink, G. L., Papapoulos, S. E., Maartens, L. W., Keyzer, J. J., Weerdenburg, J. P., . . Pop, V. J. (1998). The prevalence of low bone mineral 
density in Dutch perimenopausal women: the Eindhoven perimenopausal osteoporosis study. Osteoporosis International, 8(5), 404-409.

Snow, C. M., Shaw, J. M., Winters, K. M., \& Witzke, K. A. (2000). Long-term exercise using weighted vests prevents hip bone loss in postmenopausal women. The Journals of Gerontology Series A: Biological Sciences and Medical Sciences, 55(9), M489-M491.

Srivastava, A. K., Vliet, E. L., Michael Lewiecki, E., Maricic, M., Abdelmalek, A., Gluck, O., \& Baylink, D. J. (2005). Clinical use of serum and urine bone markers in the management of osteoporosis. Current Medical Research and Opinion, 2l(7), 1015-1026.

Stepan, J. J., Alenfeld, F., Boivin, G., Feyen, J. H., \& Lakatos, P. (2003). Mechanisms of action of antiresorptive therapies of postmenopausal osteoporosis. Endocrine Regulations, 37(4), 225-238.

Stewart, K. J., Bacher, A. C., Hees, P. S., Tayback, M., Ouyang, P., \& Jan de Beur, S. (2005). Exercise effects on bone mineral density relationships to changes in fitness and fatness. American Journal of Preventive Medicine, 28(5), 453-460.

Sugerman, D. T. (2014). JAMA patient page. Osteoporosis. The Journal of the American Medical Association, 311(1), 104.

Talmage, R. V., Stinnett, S. S., Landwehr, J. T., Vincent, L. M., \& McCartney, W. H. (1986). Age-related loss of bone mineral density in non-athletic and athletic women. Journal of bone and mineral research, 1(2), 115-125. 
Thorsen, K., Kristoffersson, A., \& Lorentzon, R. (1996). The effects of brisk walking on markers of bone and calcium metabolism in postmenopausal women. Calcified Tissue International, 58(4), 221-225.

Tobias, J., \& Compston, J. (1999). Does estrogen stimulate osteoblast function in postmenopausal women? Bone, 24(2), 121-124.

Tommerup, L. J., Raab, D. M., Crenshaw, T. D., \& Smith, E. L. (1993). Does weightbearing exercise affect non-weight-bearing bone? Journal of bone and mineral research, 8(9), 1053-1058.

Tosun, A., Bolukbasi, N., Cingi, E., Beyazova, M., \& Unlu, M. (2006). Acute effects of a single session of aerobic exercise with or without weight-lifting on bone turnover in healthy young women. Modern Rheumatology, 16(5), 300-304.

Umemura, Y., Sogo, N., \& Honda, A. (2002). Effects of intervals between jumps or bouts on osteogenic response to loading. Journal of Applied Physiology (1985), 93(4), $1345-1348$.

Vasikaran, S., Cooper, C., Eastell, R., Griesmacher, A., Morris, H. A., Trenti, T., \& Kanis, J. A. (2011). International Osteoporosis Foundation and International Federation of Clinical Chemistry and Laboratory Medicine position on bone marker standards in osteoporosis. Clinical Chemistry and Laboratory Medicine, 49(8), 1271-1274.

Vasikaran, S., Eastell, R., Bruyere, O., Foldes, A. J., Garnero, P., Griesmacher, A., . . . Group, I.-I. B. M. S. W. (2011). Markers of bone turnover for the prediction of fracture risk and monitoring of osteoporosis treatment: a need for international reference standards. Osteoporosis International, 22(2), 391-420. 
Wasnich, R. D., \& Miller, P. D. (2000). Antifracture efficacy of antiresorptive agents are related to changes in bone density. The Journal of Clinical Endocrinology and Metabolism, 85(1), 231-236.

Watanabe, K., Asaka, T., \& Wang, Y. (2012). Effects of Backpack Load and Gait Speed on Plantar Force During Treadmill Walking. International Proceedings of Chemical, Biological and Environmental Engineering, 29.

Whedon, G. D., Deitrick, J. E., \& Shorr, E. (1949). Modification of the effects of immobilization upon metabolic and physiologic functions of normal men by the use of an oscillating bed. American Journal of Medicine, 6(6), 684-711.

World Health Organization. (1994). Assessment of fracture risk and its application to screening for postmenopausal osteoporosis. Report of a WHO Study Group. World Health Organization Technical Report Series, 843, 1-129.

Yamazaki, S., Ichimura, S., Iwamoto, J., Takeda, T., \& Toyama, Y. (2004). Effect of walking exercise on bone metabolism in postmenopausal women with osteopenia/osteoporosis. Journal of bone and mineral metabolism, 22(5), 500508.

Zehnacker, C. H., \& Bemis-Dougherty, A. (2007). Effect of weighted exercises on bone mineral density in post menopausal women. A systematic review. Journal of Geriatric Physical Therapy, 30(2), 79-88. 
Appendix A

Informed Consent Form

INFORMED CONSENT TO PARTICIPATE IN A RESEARCH PROJECT, “The Effects of a Uniformly Weighted Exercise Suit on Biomarkers of Bone Turnover in Response to Aerobic Exercise in Postmenopausal Women with Low Bone Density"

\section{Who is conducting this study and what is the purpose?}

A research project on bone metabolism is being conducted by Haley Terndrup, Dr. Alison K. Ventura, and Dr. Todd Hagobian, from the Department of Kinesiology at Cal Poly San Luis Obispo, and Dr. Scott Hazelwood from the Department of Biomedical Engineering at Cal Poly. The purpose of this study is to examine the effects of wearing a weighted exercise suit on bone metabolism biomarkers in response to aerobic exercise in a sample of postmenopausal women.

\section{What are you being asked to do, and where?}

You are being asked to take part in this study by visiting our laboratory for two experimental trials, and four follow up blood draws. First, you will have baseline measurements taken, including your height and weight, resting heart rate, resting blood pressure, and temperature. Per the two exercise trials, the condition you start with will be determined purely by chance. The two conditions are 1) aerobic exercise while wearing the weighted exercise suit, or 2) aerobic exercise without the weighted exercise suit. The protocol is as follows:

- 1 baseline blood draw

- Fill out two questionnaires (International Physical Activity Questionnaire and Automated Self-administered 24-hour Recall)

- Short-term exercise bout

All events will take place in the Webb Human Performance Lab of the Kinesiology Building (43A-250) on Cal Poly Campus. Twenty-four and 72 hours after your exercise, you will be asked to return to Cal Poly for successive blood draws. The second trial will follow an identical protocol, but your exercise condition will be opposite. Prior to the first exercise trial, you will complete a body composition and bone mineral density (Dual Energy X-ray Absorptiometry) scan.

\section{What occurs during the exercise trial?}

You should wear shorts and a t-shirt for both exercise trials and you should arrive having not eaten yet that day. You will be asked to walk on a treadmill at an incline and speed necessary to maintain working at $65-75 \%$ of your calculated maximum heart rate. The exercise trial will end once you have expended 400 calories. You will be exercising for roughly 60-90 minutes. This exercise will consist of a 15 minute warm up period to establish a constant rate of work, followed by roughly 45-75 minutes of walking at the same pace until the goal has been reached. .

\section{How long will the study last?}

The expected total amount of time required to participate in this study is approximately 7 8 hours maximum, a period of two weeks. Please be aware that you are not required to 
participate in this research and you may discontinue your participation at any time without penalty.

\section{What are the possible risks?}

The risk involved in this study is minimal. The possible risks associated with participation in this study include physical and psychological risks. Physical risks include those that are inherent to participating in any type of low-intensity exercise: falling, pain, discomfort, muscle soreness, injury, dizziness, dehydration, hunger, headache, tingling, hyperthermia, and in rare cases, nausea, vomiting, or heart attack. The possible psychological risks include: potential discomfort during different aspects of the exercise trial (dislike of wearing the weighted suit; awkwardness of wearing the headgear and mouthpiece). You may also experience psychological discomfort from having to exercise in front of the experimenter, getting weighed and measured, answering questions about your current and past health, and/or prematurely requesting termination of the exercise trial. Additionally, they may result from persons being uncomfortable with blood. If you should experience any of the negative physical, emotional, or social outcomes as described above, please be aware that you may contact Haley Terndrup at (650) 353-0677 or hterndru@calpoly.edu for assistance. If you are a Cal Poly employee, you may also contact the Cal Poly Health and Counseling Services at (805) 756-2511. There will be at least two certified CPR, AED, and First Aid certified researchers or assistants present during your assessments and exercise sessions in case of injury or emergency.

\section{What are the possible benefits?}

We cannot promise any benefits to from taking part in this research. However, potential benefits associated with the study include acute physical and psychological outcomes. Physical benefits may involve increased muscle strength, endurance, and metabolism. Psychological benefits may involve increased confidence, motivation, satisfaction, and heightened social interaction. Furthermore, you will be testing new exercise technology that has potential to enhance the benefits associated with physical activity and/or exercise. Participating in this study will allow the researchers to receive a better understanding of how the exercise suit influences one's blood serum bone turnover markers.

\section{What happens to the information we collect?}

The primary investigator has attended Data Security Training, and has been familiarized with CSU guidelines, and rules on saving and transporting data. Your confidentiality will be protected by removing any questionnaire face sheets containing identifying information; code numbers will be used in place of names; the individuals with access to data containing identifiers will be limited to the researchers identified on this form; and data will be stored in locked cabinets and password protected devices.

\section{What should you do if you have additional questions?}

If you have questions regarding this study or would like to be informed of the results when the study is completed, please feel free to contact Haley Terndrup at (650) 3530677 or hterndru@ calpoly.edu. You may also contact Dr. Alison K. Ventura at akventur@calpoly.edu. If you have concerns regarding the manner in which the study is 
conducted, you may contact Dr. Michael Black, Chair of the Cal Poly Human Subjects Committee, at (805) 756-2894, mblack@ calpoly.edu, or Dr. Dean Wendt, Dean of Research, at (805) 756-1508, dwendt@ calpoly.edu.

If you agree to voluntarily participate in this research project as described, please indicate your agreement by signing below. Please indicate if you agree to have your picture taken during exercise sessions for research purposes by signing below. These pictures will be displayed for the exercise suit manufacturer and poster board presentations. Lastly, please keep one copy of this form for your reference, and thank you for your participation in this research.

\section{Signature of Volunteer}

Signature of Researcher

I agree to have my picture taken

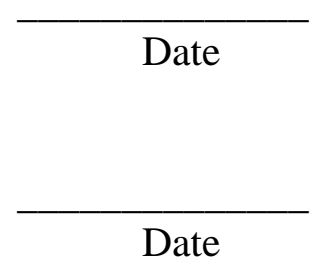

Yes

No 


\title{
Appendix B
}

Canadian Society for Exercise Physiology's Physical Activity Readiness Questionnaire

\author{
(PAR-Q) and YOU
}

\section{Appendix I \\ Physical Activity Readiness Questionnaire - PAR-Q \\ (revised 2002)

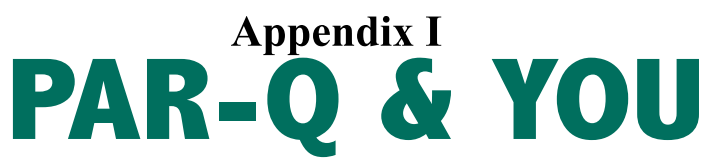 \\ (A Questionnaire for People Aged 15 to 69)}

Regular physical activity is fun and healthy, and increasingly more people are starting to become more active every day. Being more active is very safe for most people. However, some people should check with their doctor before they start becoming much more physically active.

If you are planning to become much more physically active than you are now, start by answering the seven questions in the box below. If you are between the ages of 15 and 69 , the PAR-Q will tell you if you should check with your doctor before you start. If you are over 69 years of age, and you are not used to being very active, check with your doctor.

Common sense is your best guide when you answer these questions. Please read the questions carefully and answer each one honestly: check YES or NO.

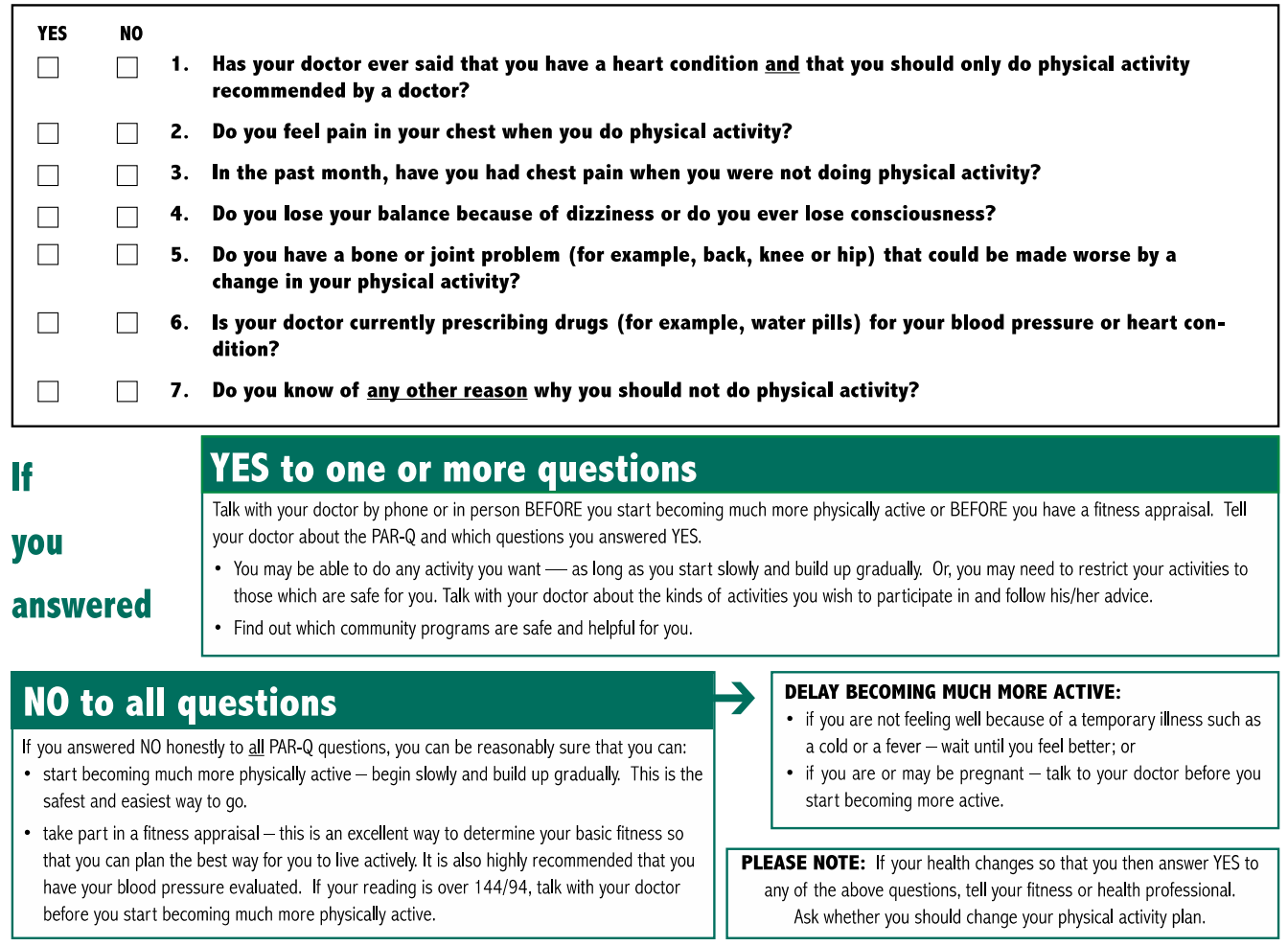

Informed Use of the PAR-Q: The Canadian Society for Exercise Physiology, Health Canada, and their agents assume no liability for per sons who undertake physical activity, and if in doubt after completing this questionnaire, consult your doctor prior to physical activity.

No changes permitted. You are encouraged to photocopy the PAR-Q but only if you use the entire form.

NOTE: If the PAR-Q is being given to a person before he or she participates in a physical activity program or a fitness appraisal, this section may be used for legal or administrative purposes.

"I have read, understood and completed this questionnaire. Any questions I had were answered to my full satisfaction."

NAME

SIGNATURE

SIGNATURE OF PARENT

or GUARDIAN (for participants under the age of majority)

DATE

WITNES Note: This physical activity clearance is valid for a maximum of 12 months from the date it is completed and
becomes invalid if your condition changes so that you would answer YES to any of the seven questions.

1DCSEP | SCPE C Canadian Society for Exercise Physiology www.csep.ca/forms 


\title{
Appendix C
}

\author{
Health History Questionnaire
}

\section{Health History Questionnaire}

Please answer the following questions to the best of your ability. For the following questions, unless otherwise indicated, circle the single best choice for each question. As is customary, all of your responses are completely confidential and may only be used in group summaries and/or reports. All information collected is subject to the Privacy Act of 1974. If you have any physical handicaps or limitations that would require special assistance with this questionnaire, please let your trainer know. This form is in accordance with the American College of Sports Medicine guidelines for risk stratification when followed correctly by your trainer. Your trainer should be certified with a national organization in order to use these forms correctly.

Name:

Ht:

Wt::

Gender: Age: Birthdate:

Address:

City: State: ZIP: Phone:

Emergency Contact: Phone:

Personal Physician: Phone:

E-mail:

1. Have you ever had a definite or suspected heart attack or stroke? Yes

2. Have you ever had coronary bypass surgery or any other type of heart surgery? .......... Yes

3. Do you have any other cardiovascular or pulmonary (lung) disease (other than asthma, allergies, or mitral valve prolapse)? .................... Yes

4. Do you have a history of: diabetes, thyroid, kidney, liver disease. . Yes (circle all that apply)

5. Have you ever been told by a health professional that you have had an abnormal resting or exercise (treadmill) electrocardiogram (EKG)? Yes

6. If you answered YES to any of Questions 1 through 5, please describe: 
7. Do you currently have any of the following:

a. pain or discomfort in the chest or surrounding areas that occurs when you engage in physical activity? . . . . . . . . . . . . . . . . . . . .

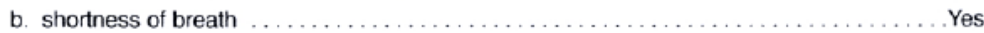

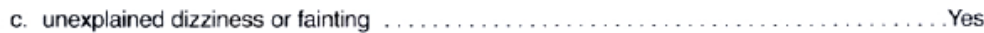

d. difficulty breathing at night except in upright position $\ldots \ldots \ldots \ldots \ldots \ldots \ldots \ldots \ldots$ Yes

e. swelling of the ankles (recurrent and unrelated to injury) . . . . . . . . . . . . . Yes

f. heart palpitations (irregularity or racing of the heart on more than one occasion) ........ Yes

g. pain in the legs that causes you to stop walking (claudication) $\ldots \ldots \ldots \ldots \ldots \ldots$. . . . .

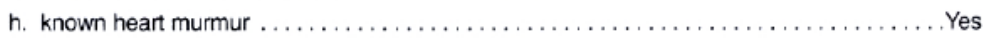

Have you discussed any of the above with your personal physician? $\ldots \ldots \ldots \ldots \ldots \ldots$. Yes

8. Are you pregnant or is it likely that you could be pregnant at this time? . . . . . . . . . . Yes If yes, what is your expected due date?

9. Have you had surgery or been diagnosed with any disease in the past 3 months? ........ Yes If yes, please list date and surgery/disease

10. Have you had high blood cholesterol or abnormal lipids within the past 12 months or are you taking medication to control your lipids? . . . . . . . . . . . . . . . . . .

11. Do you currently smoke cigarettes or have quit within the past 6 months? $\ldots \ldots \ldots \ldots$ Yes

12. Have your father or brother(s) had heart disease prior to age 55 OR mother or sister(s) had heart disease prior to age 65 ? . . . . . . . . . . . . . . . Yes

13. Within the past 12 months, has a health professional told you that you have high blood pressure (systolic $\geq 140$ OR diastolic $\geq 90$ )?

14. Currently, do you have high blood pressure or within the past 12 months, have you taken any medicines to control your blood pressure? . . . . . . . . . . . . . . . . Yes

15. Have you ever been told by a health professional that you have a fasting blood glucose greater than or equal to $110 \mathrm{mg} / \mathrm{dl}$ ? Yes

16. Describe your regular physical activity or exercise program:

type: frequency: ___ days per week

duration: minutes

intensity: low moderate high (circle one)

BMI:

17. If you have answered YES to any of questions $7-16$, please describe: 
18. Are you currently under any treatment for any blood clots? $\ldots \ldots \ldots \ldots \ldots \ldots \ldots \ldots \ldots \ldots \ldots$ Yes

19. Do you have problems with bones, joints, or muscles that may be aggravated with exercise? .........Yes

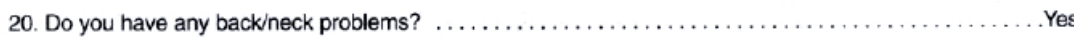

21 Have you been told by a health professional that you should not exercise? $\ldots \ldots \ldots \ldots \ldots \ldots \ldots$. Yes

23. Are there any other conditions (mitral valve prolapse, epilepsy, history of rheumatic fever, asthma, cancer, anemia, hepatitis, etc.) that may hinder your ability to exercise? ............. Yes

24. During the past six months, have you experienced any unexplained weight loss or gain (greater than ten pounds for no known reason)? . . . . . . . . . . . . . . . . . . . . . . . . . . . . .

25. If you have answered YES to any of questions $18-24$, please describe:

26. Please list below all prescription and over-the-counter medications you are currently taking:

Medicine:

Reason for taking:

Dosage:

Amount/Frequency:
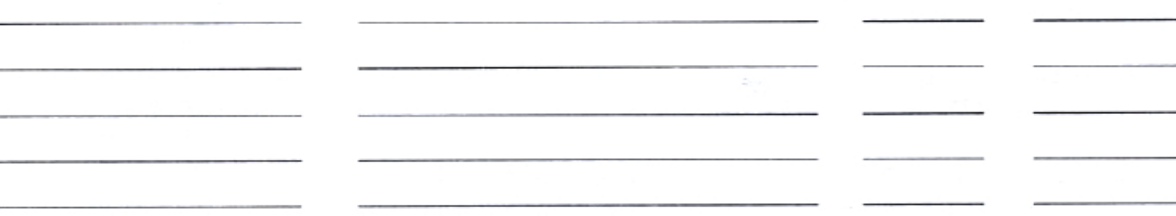

27. Are there any medicines that your physician has prescribed to you in the past

12 months which you are currently not taking? . . . . . . . . . . . . .

I have answered the Health History Questionnaire questions accurately and completely. I understand that my medical history is a very important factor in the development of my fitness/wellness program. I understand that certain medical or physical conditions which are known to me, but that I do not disclose to my trainer, may result in serious injury to me. If any of the above conditions change, I will immediately inform my trainer of those changes. I, knowingly and willingly, assume all risks of injury resulting from my failure to disclose accurate, complete, and updated information in accordance with the attached questionnaire. I also understand that in order to properly risk stratify my Health History Questionnaire, my trainer should have a minimum of a national certification as a personal trainer. My trainer also verbally explained this statement to me to my understanding.

Client's Signature: Date:

Trainer's Signature: Date: 
Appendix D

International Physical Activity Questionnaire (IPAQ)

\title{
INTERNATIONAL PHYSICAL ACTIVITY QUESTIONNAIRE (October 2002)
}

\section{LONG LAST 7 DAYS SELF-ADMINISTERED FORMAT}

\author{
FOR USE WITH YOUNG AND MIDDLE-AGED ADULTS (15-69 years)
}

The International Physical Activity Questionnaires (IPAQ) comprises a set of 4 questionnaires. Long ( 5 activity domains asked independently) and short (4 generic items) versions for use by either telephone or self-administered methods are available. The purpose of the questionnaires is to provide common instruments that can be used to obtain internationally comparable data on health-related physical activity.

\section{Background on IPAQ}

The development of an international measure for physical activity commenced in Geneva in 1998 and was followed by extensive reliability and validity testing undertaken across 12 countries (14 sites) during 2000 . The final results suggest that these measures have acceptable measurement properties for use in many settings and in different languages, and are suitable for national population-based prevalence studies of participation in physical activity.

\section{Using IPAQ}

Use of the IPAQ instruments for monitoring and research purposes is encouraged. It is recommended that no changes be made to the order or wording of the questions as this will affect the psychometric properties of the instruments.

Translation from English and Cultural Adaptation

Translation from English is encouraged to facilitate worldwide use of IPAQ. Information on the availability of IPAQ in different languages can be obtained at www.ipaq.ki.se. If a new translation is undertaken we highly recommend using the prescribed back translation methods available on the IPAQ website. If possible please consider making your translated version of IPAQ available to others by contributing it to the IPAQ website. Further details on translation and cultural adaptation can be downloaded from the website.

Further Developments of IPAQ

International collaboration on IPAQ is on-going and an International Physical Activity

Prevalence Study is in progress. For further information see the IPAQ website.

More Information

More detailed information on the IPAQ process and the research methods used in the development of IPAQ instruments is available at www.ipaq.ki.se and Booth, M.L. (2000).

Assessment of Physical Activity: An International Perspective. Research Quarterly for Exercise and Sport, 71 (2): s114-20. Other scientific publications and presentations on the use of IPAQ are summarized on the website. 


\section{INTERNATIONAL PHYSICAL ACTIVITY QUESTIONNAIRE}

We are interested in finding out about the kinds of physical activities that people do as part of their everyday lives. The questions will ask you about the time you spent being physically active in the last 7 days. Please answer each question even if you do not consider yourself to be an active person. Please think about the activities you do at work, as part of your house and yard work, to get from place to place, and in your spare time for recreation, exercise or sport.

Think about all the vigorous and moderate activities that you did in the last 7 days. Vigorous physical activities refer to activities that take hard physical effort and make you breathe much harder than normal. Moderate activities refer to activities that take moderate physical effort and make you breathe somewhat harder than normal.

\section{PART 1: JOB-RELATED PHYSICAL ACTIVITY}

The first section is about your work. This includes paid jobs, farming, volunteer work, course work, and any other unpaid work that you did outside your home. Do not include unpaid work you might do around your home, like housework, yard work, general maintenance, and caring for your family. These are asked in Part 3.

1. Do you currently have a job or do any unpaid work outside your home?

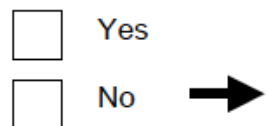

Skip to PART 2: TRANSPORTATION

The next questions are about all the physical activity you did in the last 7 days as part of your paid or unpaid work. This does not include traveling to and from work.

2. During the last $\mathbf{7}$ days, on how many days did you do vigorous physical activities like heavy lifting, digging, heavy construction, or climbing up stairs as part of your work? Think about only those physical activities that you did for at least 10 minutes at a time.

days per week

No vigorous job-related physical activity

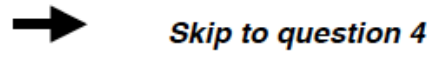

3. How much time did you usually spend on one of those days doing vigorous physical activities as part of your work?

\section{hours per day}

minutes per day

4. Again, think about only those physical activities that you did for at least 10 minutes at a time. During the last 7 days, on how many days did you do moderate physical activities like carrying light loads as part of your work? Please do not include walking.

\section{days per week}

No moderate job-related physical activity

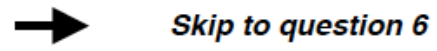


5. How much time did you usually spend on one of those days doing moderate physical activities as part of your work?

$$
\begin{aligned}
& \text { hours per day } \\
& \text { minutes per day }
\end{aligned}
$$

6. During the last $\mathbf{7}$ days, on how many days did you walk for at least 10 minutes at a time as part of your work? Please do not count any walking you did to travel to or from work.

days per week

No job-related walking

Skip to PART 2: TRANSPORTATION

7. How much time did you usually spend on one of those days walking as part of your work?

hours per day

minutes per day

PART 2: TRANSPORTATION PHYSICAL ACTIVITY

These questions are about how you traveled from place to place, including to places like work, stores, movies, and so on.

8. During the last 7 days, on how many days did you travel in a motor vehicle like a train, bus, car, or tram?

\section{days per week}

No traveling in a motor vehicle

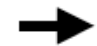

Skip to question 10

9. How much time did you usually spend on one of those days traveling in a train, bus, car, tram, or other kind of motor vehicle?

\section{hours per day}

minutes per day

Now think only about the bicycling and walking you might have done to travel to and from work, to do errands, or to go from place to place.

10. During the last 7 days, on how many days did you bicycle for at least 10 minutes at a time to go from place to place?

days per week

No bicycling from place to place

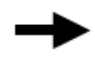

Skip to question 12

LONG LAST 7 DAYS SELF-ADMINISTERED version of the IPAQ. Revised October 2002. 
11. How much time did you usually spend on one of those days to bicycle from place to place?

hours per day

minutes per day

12. During the last 7 days, on how many days did you walk for at least 10 minutes at a time to go from place to place?

days per week

No walking from place to place

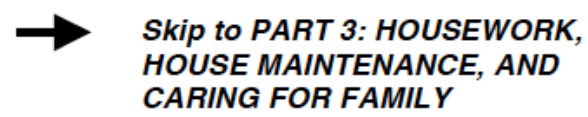

13. How much time did you usually spend on one of those days walking from place to place?

hours per day

minutes per day

\section{PART 3: HOUSEWORK, HOUSE MAINTENANCE, AND CARING FOR FAMILY}

This section is about some of the physical activities you might have done in the last $\mathbf{7}$ days in and around your home, like housework, gardening, yard work, general maintenance work, and caring for your family.

14. Think about only those physical activities that you did for at least 10 minutes at a time. During the last 7 days, on how many days did you do vigorous physical activities like heavy lifting, chopping wood, shoveling snow, or digging in the garden or yard?

\section{days per week}

No vigorous activity in garden or yard

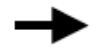

Skip to question 16

15. How much time did you usually spend on one of those days doing vigorous physical activities in the garden or yard?

hours per day minutes per day

16. Again, think about only those physical activities that you did for at least 10 minutes at a time. During the last $\mathbf{7}$ days, on how many days did you do moderate activities like carrying light loads, sweeping, washing windows, and raking in the garden or yard?

days per week

No moderate activity in garden or yard

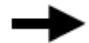

Skip to question 18

LONG LAST 7 DAYS SELF-ADMINISTERED version of the IPAQ. Revised October 2002. 
17. How much time did you usually spend on one of those days doing moderate physical activities in the garden or yard?

$$
\begin{aligned}
& \text { hours per day } \\
& \text { minutes per day }
\end{aligned}
$$

18. Once again, think about only those physical activities that you did for at least 10 minutes at a time. During the last 7 days, on how many days did you do moderate activities like carrying light loads, washing windows, scrubbing floors and sweeping inside your home?

\section{days per week}

No moderate activity inside home $\longrightarrow$ Skip to PART 4: RECREATION, SPORT AND LEISURE-TIME PHYSICAL ACTIVITY

19. How much time did you usually spend on one of those days doing moderate physical activities inside your home?

$$
\begin{aligned}
& \text { hours per day } \\
& \text { minutes per day }
\end{aligned}
$$

\section{PART 4: RECREATION, SPORT, AND LEISURE-TIME PHYSICAL ACTIVITY}

This section is about all the physical activities that you did in the last $\mathbf{7}$ days solely for recreation, sport, exercise or leisure. Please do not include any activities you have already mentioned.

20. Not counting any walking you have already mentioned, during the last 7 days, on how many days did you walk for at least 10 minutes at a time in your leisure time?

\section{days per week}

No walking in leisure time

Skip to question 22

21. How much time did you usually spend on one of those days walking in your leisure time?

\section{hours per day}

minutes per day

22. Think about only those physical activities that you did for at least 10 minutes at a time During the last 7 days, on how many days did you do vigorous physical activities like aerobics, running, fast bicycling, or fast swimming in your leisure time?

\section{days per week}

No vigorous activity in leisure time

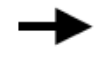

Skip to question 24

LONG LAST 7 DAYS SELF-ADMINISTERED version of the IPAQ. Revised October 2002. 
23. How much time did you usually spend on one of those days doing vigorous physical activities in your leisure time?

$$
\text { hours per day }
$$
minutes per day

24. Again, think about only those physical activities that you did for at least 10 minutes at a time. During the last 7 days, on how many days did you do moderate physical activities like bicycling at a regular pace, swimming at a regular pace, and doubles tennis in your leisure time?

\section{days per week}

No moderate activity in leisure time $\rightarrow$ Skip to PART 5: TIME SPENT SITTING

25. How much time did you usually spend on one of those days doing moderate physical activities in your leisure time? hours per day minutes per day

\section{PART 5: TIME SPENT SITTING}

The last questions are about the time you spend sitting while at work, at home, while doing course work and during leisure time. This may include time spent sitting at a desk, visiting friends, reading or sitting or lying down to watch television. Do not include any time spent sitting in a motor vehicle that you have already told me about.

26. During the last 7 days, how much time did you usually spend sitting on a weekday? hours per day minutes per day

27. During the last 7 days, how much time did you usually spend sitting on a weekend day?

hours per day minutes per day

This is the end of the questionnaire, thank you for participating. 


\section{Appendix E}

\section{Automated Self-Administered 24-hour (ASA24) Dietary Recall System}

Description from the ASA24 website: http:// asa24.nci.nih.gov

Extensive evidence has demonstrated that 24-hour dietary recalls provide the highest quality, least biased dietary data. Traditional 24-hour recalls, however, are expensive and impractical for large-scale research because they rely on trained interviewers and multiple administrations to estimate usual intakes. As a result, researchers often make use of food frequency questionnaires, which are less expensive but contain substantial error.

To address this challenge, investigators at NCI created the Automated Self-administered 24-hour Recall (ASA24) system, a web-based tool that enables multiple automated selfadministered 24-hour recalls. ASA24 was developed under contract with Westat, a social science research firm located in Rockville, MD, and builds on the Food Intake Recording Software System (FIRSSt) developed by Dr. Tom Baranowski of the Baylor College of Medicine. An External Working Group provided advice about the needs and interests of potential users.

ASA24 consists of a Respondent Web site used to collect recall data and a Researcher Web site used to manage study logistics and obtain data analyses. A Beta version released in August 2009 and supported through June 2012 was used by more than 200 researchers to collect more than 45,000 recalls. ASA24-2011 (released in September 2011) and ASA24-Kids-2012 (released in September 2012) continue to be available for currently registered studies but are no longer available for use to register new studies. The current versions, ASA24-2014, ASA24-Kids-2014, and ASA24-Canada-2014 are now freely available for use by researchers, clinicians, and teachers.

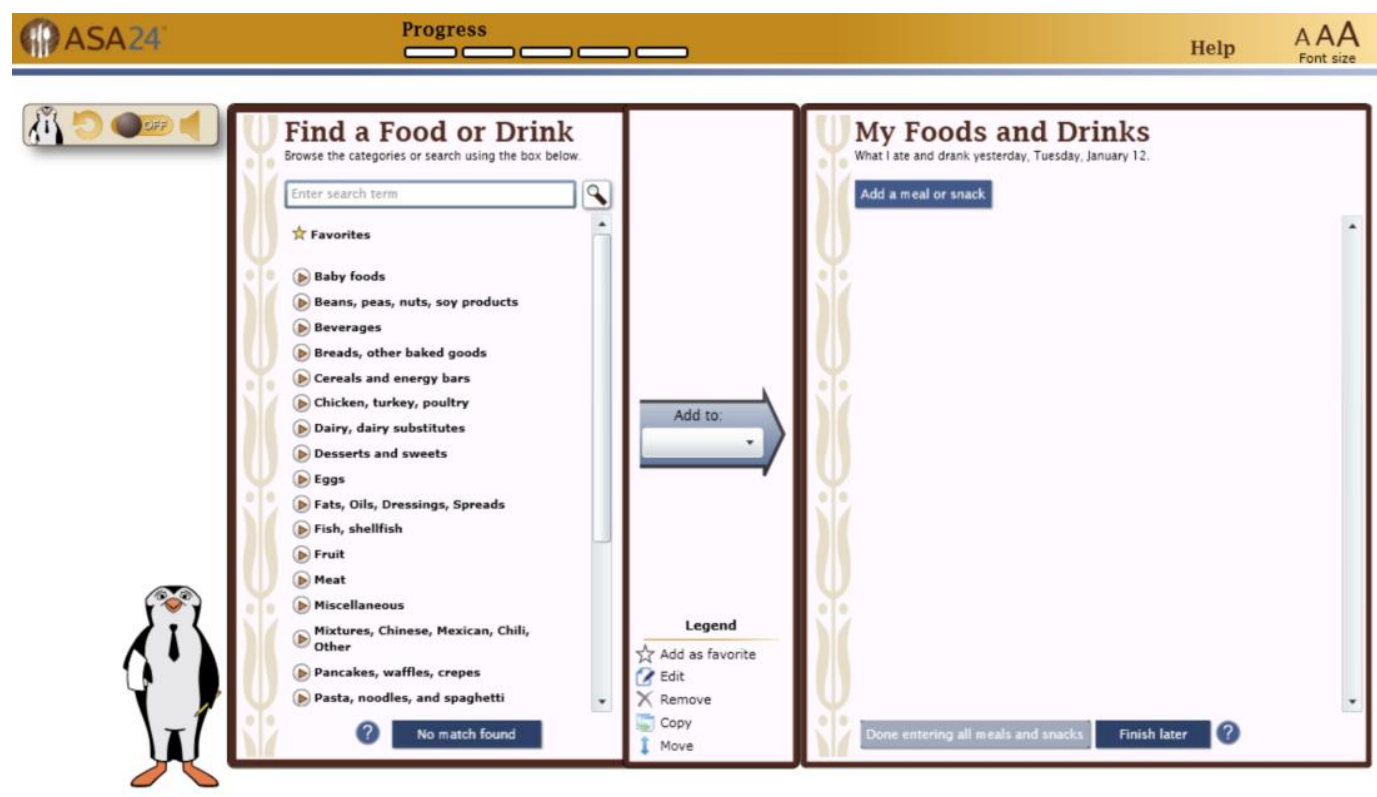

Figure 2: Prompt screen 1 from ASA24 


\section{Appendix F}

Exercise Protocol Data Sheet

\section{Participant ID\#}

Date:

Exercise Condition (ES/NS):

Age Predicted HR max (220-age):

Baseline blood draw (date/time):

\begin{tabular}{|l|l|l|l|}
\hline & Height $(\mathrm{cm})$ & Weight $(\mathrm{kg})$ & Temperature $(\mathrm{F})$ \\
\hline Pre-test & & & \\
\hline & & & \\
Post-test & & & \\
\hline
\end{tabular}

\begin{tabular}{|l|l|l|l|l|l|}
\hline Minute & $\begin{array}{l}\text { Heart Rate } \\
(\mathrm{bpm})\end{array}$ & $\begin{array}{l}\text { Blood Pressure } \\
(\mathrm{mmHg})\end{array}$ & Temperature (F) & $\begin{array}{l}\text { Incline } \\
(\%)\end{array}$ & $\begin{array}{l}\text { Speed } \\
(\mathrm{mph})\end{array}$ \\
\hline Resting & & & & & \\
\hline 5 & & & & & \\
\hline 10 & & & & & \\
\hline 15 & & & & & \\
\hline 20 & & & & & \\
\hline 25 & & & & & \\
\hline 50 & & & & & \\
\hline 75 & & & & & \\
\hline 100 & & & & & \\
\hline 125 & & & & & \\
\hline POST 2 & & & & & \\
\hline
\end{tabular}




\section{Exercise Trial Comments:}

24 hour follow up blood draw (date/time):

72 hour follow up blood draw (date/time): 


\section{Appendix G}

\section{ELISA Kit Instructions}

\section{Amino-Terminal Propeptide of Type 1 Collagen (P1NP)}

Human PINP ELISA KIT

Procollagen I N-terminal peptide ELISA Ki
Catalog Number: HP0670 (96 Tests)

Compatible samples: Cell culture fluid, body fluid, tissue homogenate, serum or blood plasm
Store all reagents at $2-8^{\circ} \mathrm{C}$

FOR RESEARCH USE ONLY. NOT FOR THERAPEUTIC OR

DIAGNOSTICAPPLEATIONS. READ THROUGHALCT

PROCEDURES BEFORE USE.

ASSAY PRINCIPL

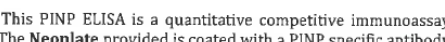
Standards or experimental samples are co-incubated in well. along with a PINP conjugate. PINP in standards or samples bound antibody. Higher levels of PINP from standards samples leads to decreased PINP-HRP conjugate binding an by incubation with HRP substrates s solutuions $A$ and $B$ ) Binding of the PINP-HRP is visualized by production of colorimetric reaction products that can be quantitatively measured

MATERIALS
All reagents must be stored at $2-8^{\circ} \mathrm{C}$. Refer to the expiration

\begin{tabular}{|c|c|c|c|}
\hline 1 & NeoPlate & 96 strip wells & \\
\hline & Enzyme Solution & $6.0 \mathrm{~mL}$ & 1 vial \\
\hline $3^{3}$ & Standard A & $0 \mathrm{pg} / \mathrm{mL}$ & 1 vial \\
\hline 4 & Standard B & $250 \mathrm{pg} / \mathrm{mL}$ & 1 vial \\
\hline 5 & Standard C & $500 \mathrm{pg} / \mathrm{mL}$ & 1 vial \\
\hline 6 & Standard D & $1000 \mathrm{pg} / \mathrm{mL}$ & 1 vial \\
\hline & Standard E & $2500 \mathrm{pg} / \mathrm{mL}$ & 1 vial \\
\hline 8 & Standard $\mathrm{F}$ & $5000 \mathrm{pg} / \mathrm{mL}$ & 1 vial \\
\hline & Substrate A & $6 \mathrm{~mL}$ & 1 vial \\
\hline 10 & Substrate B & $6 \mathrm{~mL}$ & 1 vial \\
\hline 11 & Stop Solution & $6 \mathrm{~mL}$ & \\
\hline 12 & Wash Solution (25x) & $50 \mathrm{~mL}$ & 1 vial \\
\hline & Balance Solution & $3 \mathrm{~mL}$ & 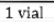 \\
\hline
\end{tabular}

GENERAL CONSIDERATION

Samples should be handled following standard practices freeze-thaw cycles or high temperaturures. For long term
storage, maintain samples at temperatures that minimize
2. Wegradation or denaturation. determining the amount of sample required for rob

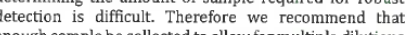
to be assayed. Experimental variation between wells is to be expected
We recommend assays be performed using at teast two wells for every sample or standard. Readings of duplicate wells should be averaged.
Two blank wells containing PBS or water should be
included to determine background.

REAGENT PREPARATION

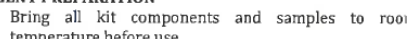

Bring Neoplate to room temperature before opening

3. Dispense $10 \mathrm{\mu L}$ of Balance Solution into 100

NOTE: This step is required only when the sample is cell cultur

spernotant, body fluid or tissue homogenate

4. Dilute $40 \mathrm{~mL}$ of Wash Solution concentrate $(25 x)$ with $960 \mathrm{~mL}$ of deionized or distilled water. If crystals have
formed in the concentrate warm to room temperature and mix to dissolve.

ASSAY PROCEDUR

Add $100 \mu \mathrm{L}$ of sample or standard to the appropriase
number of wells in the sun have been pre-blocked and no additional blocking ste, Add 50 ㄴ. of Enzyme Solutiontoeach well(NOT blank Wash each well 5 times with $300-400$ ul $1 \mathrm{x}$ wa Solutionperwell: After the last wash invert the plate and sides of the plate frame firmly when washing to assue that all strips remain securely in the frame. Complete
removal of the liquid at each step is essential for good

performance.
Add $50 \mu \mathrm{LL}$ Substrate A to each well followed by additio of 50 L S Substrate B. Cover and incubate 10-15 minutis out of direct sunlight or cover with foil
ond

6. Add $50 \mu$ of Stop Solution to each well and mix well.
8. Subtract the mean blank value from each sample or
standard value and calculate the mean for duplicate for greater) wells. Enstruct the standad cure using graph paper statistical software.
Note: Blank well must NOT have Enzyme Solution.

SENSITIVTTY AND SPECIFIITY

1. The sensitivity of this assay should be approximately $1.0 \mathrm{peg} / \mathrm{mL}$.
2. This assay high sensitivity and excellent specificity for the detection of PINP. No significant cross-reactivity or interference between PINP and any homologous proteins
assayed has been observed. Species cross-reactivity has not been specifically det

ADDITIONAL SUGGESTIONS

All reagents should be warned to roon trigerate before use.

3. When possible, avoid use of hemolyzed or lipemic sera.
Centrifuge or filter samples if particulate matter is

it is reconmended that all stonderds controls, atd samples be run at least in duplicate.

order of addition from well-to-well when pipenting reagents.

6. Cover or cap all reagents when not in use
Do not mix or interchange different 5 .

agent lots from 8. Do not use reagents after the kitexpiration date.
9. Determine absorbance within 2 hours of assay

10. Substrate $B$ is light sensitive. Avoid prolonged exposur

11. Incomplete washing will adversely affect the test outcome. All washing must be performed with the

12. Washing can be performed using a squirt bottle and $\mathrm{fll}$

13. Doll wells to the top

Do not mix reagents from different lots. It is
recommended that assays be performed at least in ecommended that assays be performed at least in
duplicate. Standards and samples must be assayed at the 


\section{neo}

\section{SAFETY NOTES}

1. This kit contains 3, 3', 5, 5'-Tetramethylbenzidine (TMB) in Substrate B. TMB, present at levels greater than equal to $0.1 \%$ is NOT identfied as a carchogen to skin and eyes. Please wear appropriate personal protective equipment, including gloves, safety glasses, and lab coats when handling.

2. The Stop Solution provided in the kit is an acidic solution Please wear appropriate personal protective equipme all kit components.

3. All blood components and biological materials should be handled as potentially hazardous. Follow univers precautions as established by the Centers for Disease and Health Administration when handling and disposing of infectious agents. 4. All waste must be disposed of in accordance with all

Calculation of competitive ELISA results

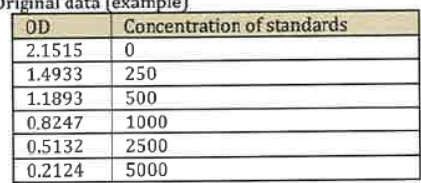

Data processing 0 . : $\log$ (base 10 or other) of (concentration of standards)

\begin{tabular}{|l|l|}
\hline$X$ & $Y$ \\
\hline 100 & 0 \\
\hline 69.407 & 1.698970004100 \\
\hline 55.277 & 2 \\
\hline 38.331 & 2.397940009 \\
\hline 23.853 & 2.698970004 \\
\hline 9.872 & 3 \\
\hline
\end{tabular}

The standard curve is generated using some curve software. (standard 0 is not used)

Linear Fit: $y=a+b x \quad$ CoefficientData: 0.998

5. Calculation of results
1) To process the sample 0.D:: 0. D.of samples divided by that of Standard 0, then multiplied by 100;
3) To get the concentration of samples: 10 to the power of

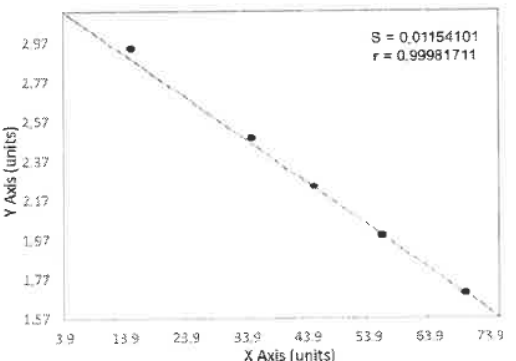

\section{Featured Products:}

Species: Human, Mouse, Rat, Rabbit, Guinea Pig, Goat, Porcine, Canine, Bovine, Anserine, etc.

Subcategories: Cytokine, Globulins, CD \& AM, Innate Immune, Immunodulator, Transplantation, Autoimmunity, Apoptosis Tumor Immune, Hypersensitivity, himminty, Infectious Disease ar, Respiratory. Digestive, Urinary System, Aristogenesis, Endocrine, Metabolism, Enzyme, Kinase, Hormone, etc

Proteins and Antibodies $(>5,000)$ :

cytokines, Growth Factors, Chemokines, Hormones, Enzymes and Viral Antigens

\section{Technical Seivices}

Custom ELISA Kits servic

Neoscientific is your premier partner in ELISA. We can make Our ELISA assays are designed for minimal manipulation an rapid use. This service from Neoscientific allows you to focus o Jestearch rather than of the arduous work of designing and building ELISA assay.

Antibodies are critical research reagents. Neoscientific has extensive experience generating high quality monoclonal an polyclonal antisera to native and recombinant proteins as well immunization protocols we have had areat success eenerating high-titer, high-affinity custom antibodies against a diverse set of antigens from numerous species.

Tel: +1(888) 754-5670 (Toll Free) or +1 (857) 259-4898 Fax: +1(888) 754-5670 Email:info@Neobiolab.com

\section{Peptide Synthesis} Services from peptide sequence design advice to peptaid
modifications. Our emphasis is on providing high quality peptides at a competitive price. All peptides synthesized are provided with a complete quality control package, which to confirm identity.

Custom Protein Expression and Purification

Neoscientific's custom recombinant protein services provide a comprehensive portfolio of protein expression systems, mammalian cells. With our proprietary optimization technology the expression level can be significantly increased. We also offer a full spectrum of protein purification methods to achieve the ideal level of protein purity. We work in partnership with our clients to ensure efcient and high quality reagent protel and proprietary technologies. We can also provide process development and scale-up production of biologics for researc purposes.

\section{Innovative Technology}

We offer our customers a novel technology platform for development of Post Translationally Modified (PTM) peptides for diagnostics, epitope mapping, companion drug blomarkers, enzymes \& methods for production of these glycosylated PTMpeptides and biomarkers. We can provide our customers wi custom made glycosylated peptides to meet their research needs.

MassAb $\mathrm{b}^{\text {tw: }}$ Low Cost-High Quality Monoclonal Antibodies We This system has been used in over thousands projects deliverin high quality monoclonal antibodies at the lowest cost available.

Promotion: 12 Custom Monoclonal Antib

- Customer gets $0.5 \mathrm{mg}$ of each antibody

More antibodiesavaila

Cells lines of your choice available at additional char
NeoPeptide offers a comprehensive range of Peptide Synthesis

- A set of 12 independent custom mAbs
NEO Group InC., 86 Cummings Park, Wobum, Massachusetts, US 0180 


\section{Carboxy-Terminal Propeptide of Type 1 Collagen (P1CP)}

\section{Human PICP ELISA KIT}

Carboxyterminal propeptide of type [ procollagen ELISA Kit Catalog Number: HP0584 (96 Tests)

Compatible samples: Cell culture fluid, body fluid, tissue homogenate, serum or blood plasm

FOR RESEARCH USE ONLY. NOT FOR THERAPEUTIC O PROCEDURES BEFORE USE

\section{ASSAY PRINCIPLE}

This PICP ELISA is a quantitative competitive immunoassay. The Neoplate provided is coated with a $\mathrm{ACP}$ specific antibody. along with a PICP conjugate. PICP in standards or samples competes with PICP-HRP conjugate for binding to the plate bound antibody. Higher levels of PICP from standards samples leads to decreased Pi.P-HRP conjugate binding an incubation with HRP substrates (solutions $A$ and B). Binding of the PICP-HRP is visualized by production of colorimetri reaction products that can be quantitatively measured by

\section{MATERIALS} All reagents must
date on the label.

\begin{tabular}{|l|l|l|l|}
\hline 1 & NeoPlate & $96 \mathrm{strip}$ wells & \\
\hline 2 & Enzyme Solution & $6.0 \mathrm{~mL}$ & 1 vial \\
\hline 3 & Standard A & $0 \mathrm{ng} / \mathrm{mL}$ & 1 vial \\
\hline 4 & Standard B & $0.5 \mathrm{ng} / \mathrm{mL}$ & 1 vial \\
\hline 5 & Standard C & $1.0 \mathrm{ng} / \mathrm{mL}$ & 1 vial \\
\hline 6 & Standard D & $2.5 \mathrm{ng} / \mathrm{mL}$ & 1 vial \\
\hline 7 & Standard E & $5.0 \mathrm{ng} / \mathrm{mL}$ & 1 vial \\
\hline 8 & Standard F & $10 \mathrm{ng} / \mathrm{mL}$ & 1 vial \\
\hline 9 & Substrate A & $6 \mathrm{~mL}$ & 1 vial \\
\hline 10 & Substrate B & $6 \mathrm{~mL}$ & 1 vial \\
\hline 11 & Stop Solution & $6 \mathrm{~mL}$ & 1 vial \\
\hline 12 & Wash Solution $(25 \times)$ & $50 \mathrm{~mL}$ & 1 vial \\
\hline 13 & Balance Solution & $3 \mathrm{~mL}$ & 1 vial \\
\hline
\end{tabular}

\section{GENERAL CONSIDERATIONS}

Samples should be handled following standard practices to minimize degradation or denaturation. Avoid multiple stoezage, maintain samples at temperatures that minimize

\section{never}

8. Subtract the mean blank value from each sample or standard value and calculate the mean for duplicate (or

Construct the standard curve using graph paper or

degradation or denaturation.
Without prior knowledge of the analyze concentration, determining the amount of sample required for robust enough sample be collected to allow for multiple dilutions to be assayed.

3. Experimental variation between wells is to be expected. We recommend assays be performed using at least two be averaged.

Two blank wells containing PBS or water should be included to determine background.

REAGENT PREPARATION

1. Bring all kit components and samples to room temperature before use. Remove the desired number of well strips and Dispense $10 \mu \mathrm{L}$ of Balance Solution into $100 \mu \mathrm{L}$ experimental samples.

NOTE: This step is required only when the sample is cell culture supernatant body fluid or tissue homogenate.

4. Dilute $40 \mathrm{~mL}$ of Wash Solution concentrate (25x) with $960 \mathrm{~mL}$ of deionized or distilled water. If crystals have formed in the concentrate warm to room temperature and mix to dissolve.

1. Add $100 \mu \mathrm{L}$ of sample or standard to the appropriate number of wells in the supplied Neoplate. Note that wells have been pre-blocked and no additional blocking steps well.

well) in the supplied NeoPlate and mix well Cover and incubate 1 hour at $370^{\circ} \mathrm{C}$ in a humid chamber. Wash each well 5 times with $300-400 \mu \mathrm{L} 1 \mathrm{X}$ Wash blot dry by tapping on absorbent paper. Note: Hold the sides of the plate frame firmly when washing to assure

that all strips remain securely in the frame. Complete
removal of the liquid at each step is essential for good

5. Add $50 \mu \mathrm{L}$ Substrate $A$ to each well followed by addition of $50 \mu \mathrm{L}$ Substrate B. Cover and incubate 10-15 minuses at room temperature. Substrate is light sensitive. Kee

.

6. Add $50 \mu \mathrm{L}$ of Stop Solution to each well and mix well.
7 . Immediately read the optical density $[0 . D$. at $450 \mathrm{~nm}$ Note: Blank well must NOT have Enzyme Solution.

SENSITIVITY AND SPECIFICITY

1. The sensitivity of this assay should be approximately the detection of PICP. No significant cross-reactivity or interference between $\mathrm{NeP}$ and any homologous protein not been specifically det

ADDITIONAL SUGGESTIONS

When not in use, kit components should be refrigerate

Samples should be collected inpyrogen/endotoxin-free

When possible, avoid use of hemolyzed or lipemic sera Centrifuge or filter samples if particulate matter is

4. It is recommended that all standards, controls, and samples be run at least in duplicate.

To hsure equal incubation times maintain a consistent

6. Cover or cap all reagents when not in use.
$7 . \quad$ Do not mix or interchange different reagent lots from various kit lots

Determine absorbance within 2 hours of

10. Substrate $B$ is light sensitive. Avoid prolonged exposure light. Substrate B will discolor metals so contapst

11. Incomplete washing will adversely affect the test
outcome. All washing must be performed with the

12. Washing can be performed using a squirt bottle and fillin

13. Dill wells to the top. duplicate. Standards and samples must be assayed at the same time.
2. This assay has high sensitivity and excellent specificity for

reagents from different lots. It is 


\section{SAFETY NOTES}

1. This kit contains $3,3^{\prime}, 5,5^{\prime}$-Tetramethylbenzidine (TMB) in Substrate B. TMB, present at levels greater than or potential carcinogen by OSHA. TMB may cause irritation to skin and eyes. Please wear appropriate personal protective equipment, including gloves, safety glasses, and lab coats when handling.

the kit is an acidic solution. Please wear appropriate personal protective equipment all kit components.

3. All blood components and biological materials should be handled as potentially hazardous. Follow universal precutions as established by the Centers for Disease and Health Administration when handling and disposing of infectious agents.

4. All waste must be disposed of in accordance with all applicable local, state, and federal regulation

Index
Calculation of competitive ELISA results

Original data (example)
\begin{tabular}{|l|l|}
\hline OD & Concentration of standards \\
\hline 2.1515 & 0 \\
\hline 1.4933 & 0.5 \\
\hline 1.1893 & 1.0 \\
\hline 0.8247 & 2.5 \\
\hline 0.5132 & 5.0 \\
\hline 0.2124 & 10 \\
\hline
\end{tabular}

2. Data processing Standard 0 , then multiplied by 100 ;

Y: log(base 10 or other) of (concentration of standards)

\begin{tabular}{|l|l|}
\hline$X$ & $Y$ \\
\hline 100 & 0 \\
\hline 69.407 & 1.698970004100 \\
\hline 55.277 & 2 \\
\hline 38.331 & 2.397940009 \\
\hline 23.853 & 2.698970004 \\
\hline 9.872 & 3 \\
\hline
\end{tabular}

3. The standard curve is generated using some curve 4. The formula:$$
\text { Linear Fit: } y=a+b x \quad \text { CoefficientData: } 0.998
$$

5. Calculation of results $a=3$ $=3.22 \mathrm{E}+00 \quad \mathrm{~b}=-2.19 \mathrm{E}-02$

1) To process the sample O.D.: 0.D.of samples divided by 2) To get $Y$ value using the above formulation
3) To get the concentration of samples: 10 to the power of

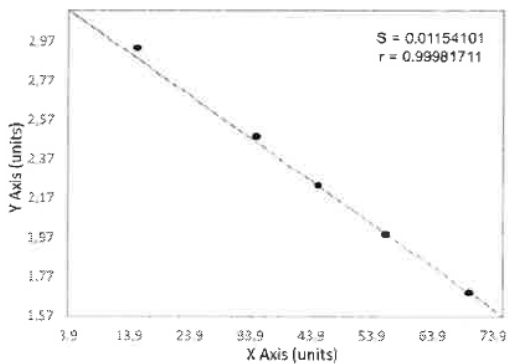

\section{Featured Products;}

Species: Human, Mouse, Rat, Rabbit, Guinea Pig, Goat, Porcine

Canine, Bovine, Anserine, etc.
subcategories: Cytokine, Globulins, CD \& AM, Innate Immune, Immunodulator, Transplantation, Autoimmunity, Apoptosis, umor Immune, Hypersensitivity. Immunity, Infectious Disease ar, Respiratory, Digestive, Urinary System, Aristogenesis, Endocrine, Metabolism, Enzyme, Kinase, Hormone, etc.

roteins and Antibodies $(>5,000)$

Cytokines, Growth Factors, Chemokines, Hormones, Enzymes

Technicals

Technical Services

Neoscientific is your premier partner in ELISA. We can make various high-quality ELISA Kits for you based on your request. rapid use. This serve esigned for minimal manipulation and your research rather than of the arduous work of designing and building ELISA assays.

Custom antibody service

Antibodies are critical research reagents. Neoscientific has extensive experience generating high quality monoclonal an polyclonal antisera to native and recombinant proteins as well
as synthetic peptides. Using immunization proptocols we have had reat success high-titer, high-affinity custom antibodies against a diverse se of antigens from numerous species.

\section{Peptide Synthesis}

NeoPeptide offers a comprehensive range of Peptide Synthesis modifications. Our emphasis is on providing high peptides at a competitive price. All peptides synthesized are provided with a complete quality control package, which includes HPLC chromatograms to ensure purity and MS analysi

Custom Protein Expression and Purification

Neoscientific's custom recombinant protein services provide comprehensive portfolio of protein expression systems, including bacteria, yeast, baculovirus infected insect cells, and the expression level can be significantly increased We also offer a full spectrum of protein purification methods to achieve the ideal level of protein purity. We work in partnership with our clients to ensure efficient and high quality reagent protein and proprietary technologies. We can also provide process
development and scale-up production of biologics for research purposes.

\section{Innovative Technology}

We offer our customers a novel technology platform for development of Post Translationally Modified (PTM) peptides for diagnostics, epitope mapping, companion drug biomarkers, and monitoring immune signatures. Our patent portfolio covers enzymes \& methods for production or hese glycosylated PTMcustom made glycosylated peptides to meet their research needs.

MassA $\mathrm{b}^{\text {my: }}$ Low Cost-High Quality Monoclonal Antibodies your proten of terest on highly ing 6 peptides speciff

This system has been used in over thousands projects delivering
high quality monoclonal antibodies at the lowest cost available.

Promotion: 12 Custom Monoclonal Antibodies for \$2,999

: A set of 12 independent custom mAbs

- Customer gets $0.5 \mathrm{mg}$ of each antibody

ELISA titer guarantee

More antibodiesavailable at additional charge

Tel: +1(888) 754-5670 (Toll Free) or +1(857) 259-4898 Fax: +1(888) 754-5670 Email:info@Neobiolab.com NEO Group Inc, 86 Cummings Park, Woburn, Massachusetts, US 01801 


\section{Carboxy-Terminal Telopeptide of Type 1 Collagen (CTX)}

\section{Human CTx1 ELISA KIT}

C terminal Telopeptides of type $l$ collagen ELISA K

Compatible samples: Cell culture fluid, body fluid, tissue homogenate, serum or blood plasma

Store all reagents at $2-8^{\circ} \mathrm{C}$

FOR RESEARCH USE ONLY. NOT FOR THERAPEUTIC OR DIAGNOSTIC APPLICATIONS. READ THROUGH ALL PROCEDURES BEFORE USE.

ASSAY PRINCIPLE

This CTx1 ELISA is a quantitative competitive immunoassay. The Neoplate provided is coated with a CTx1 specific antibody, Standards or experimental samples are co-incubated in wells
along with a CTX1 conjugate. CTx 1 in standards or samples competes with CTx1-HRP conjugate for binding to the plate bound antibody. Higher levels of CTx1 from standards or samples leads to decreased CTx1-HRP conjugate binding and reduced signal. Captured CTx1-HRP is quantitatively detected of the CT 1 1-HRP is visulized by production of colorimetric reaction products that can be quantitatively measured by absorbance at $450 \mathrm{~nm}$.

MATERIALS

its must be stored at $2-8^{\circ} \mathrm{C}$. Refer to the expiration date on the label.

\begin{tabular}{|l|l|l|l|}
\hline 1 & NeoPlate & $96 \mathrm{strip}$ wells & \\
\hline 2 & Enzyme Solution & $6.0 \mathrm{~mL}$ & 1 vial \\
\hline 3 & Standard A & $0 \mathrm{ng} / \mathrm{mL}$ & 1 vial \\
\hline 4 & Standard B & $0.5 \mathrm{ng} / \mathrm{mL}$ & 1 vial \\
\hline 5 & Standard C & $1.0 \mathrm{ng} / \mathrm{mL}$ & 1 vial \\
\hline 6 & Standard D & $2.5 \mathrm{ng} / \mathrm{mL}$ & 1 vial \\
\hline 7 & Standard E & $5.0 \mathrm{ng} / \mathrm{mL}$ & 1 vial \\
\hline 8 & Standard F & $10 \mathrm{ng} / \mathrm{mL}$ & 1 vial \\
\hline 9 & Substrate A & $6 \mathrm{~mL}$ & 1 vial \\
\hline 10 & Substrate B & $6 \mathrm{~mL}$ & 1 vial \\
\hline 11 & Stop Solution & $6 \mathrm{~mL}$ & 1 vial \\
\hline 12 & Wash Solution $(25 \times)$ & $50 \mathrm{~mL}$ & 1 vial \\
\hline 13 & Balance Solution & $3 \mathrm{~mL}$ & 1 vial \\
\hline
\end{tabular}

GENERAL CONSIDERATIONS

Samples should be handied following standard practices to minimize degradation or denaturation. Avoid multiple storage, maintain samples tet temperatureses that minimize
2. Without prior knowledge of

We detection is difficult. Therefore we quired for robus 列

to be assayed.

3. Experimental variation between wells is to be expected Wells for every sample or standard. Readings of duplicate wells should be averaged.

4. Two blank wells containing PBS or water should be

REAGENT PREPARATION

1. Bring all kit components and samples to roo

(a) sired number of well strips an immediately reseal and store at 2-8 $8^{\circ} \mathrm{C}$. Dispense $10 \mu \mathrm{L}$ of
experimental samples.

NOTE: This step is required only when the sample is cell culture supernatant, body fluid or tissue homogenate

4. Dilute $40 \mathrm{~mL}$ of Wash Solution concentrate (25x) with Drmed in the concentrate warm to room temperatu and mix to dissolve.

\section{SSAY PROCEDUR}

le or standard to the appropria (a) have been pre-blocked and no additional bloch are required.Add 100 L of PBS (pH 7.0-7.2) to the blank well.

Add $50 \mu \mathrm{L}$ of Enzyme Solutiontoeach well(NOT blank well) in the supplied NeoPlate and mix wel

Cover and incubate 1 hour at $37^{\circ} \mathrm{C}$ in a humid chamber Wash each well 5 times with 300-400 $\mu \mathrm{L}$ 1X Wash Solutionper well. After the last wash invert the plate and sides of the plate frame firmly when washing to assure that all strips remain securely in the frame. Complete removal of the liquid at each step is essential for good

Add $50 \mu \mathrm{L}$ Substrate $A$ to each well followed by addition at room temperature. Substrate is light sensitive. Keep out of direct sunlight or cover with foil.

6. Add $50 \mu \mathrm{LL}$ of Stop Solution to each well and mix well. 8. Subtract the mean blank value from each sample or
standard value and calculate the mean for duplicate (or greater) wells.

9. Construct the standard curve using graph paper or Cotstical sofware.

作

$0.1 \mathrm{ng} / \mathrm{mL}$.

This assay has high sensitivity and excellent specificity for interference between CTx1 and any homologous proteins assayed has been observed. Species cross-reactivity has not been specifically det

ADDITIONAL SUGGESTION

ponents should be refrigerated. All reagents should be warmed to room temperature

before use.

3. When possible, avoid use of hemolyzed or lipemic sera. Centrifuge or filter samples if particulate matter is

present.
4t is recommended that all standards, controls, and order of addition from well-to-well when reagents.

.

8. Do not use reagents after the kit expiration date. Determine absorbance within 2 hours of assay

Substrate B is light sensitive. Avoid prolonged exposure rate B will discolor metals so contact shoul Incomplete outcome. All washing must be performed with the

erformed using a squirt bottle and filling all wells to the top.

3. Do not mix reagents from different lots. It is recommended that assays be performed at least in 


\section{neenter}

\section{(A)}

1. This kit contains $3,3^{\prime}, 5,5^{\prime}$-Tetramethylbenzidine (TMB) in Substrate B. TMB, present at levels greater than or
equal to $0.1 \%$ is NOT identified as a carcinogen or potential carcinogen by OSHA. TMB may cause irritation to skin and eyes. Please wear appropriate persona and lab coats when handling.

2. The Stop Solution provided in the kit is an acidic solution Please wear appropriate personal protective equipment
(gloves, safety glasses, lab coat) when handling this and (gloves, safety glass

3. All blood components and biological materials should be handled as potentially hazardous. Follow universal precautions as established by the Centers for Diseas Control and Prevention and by the Occupational Safety of infectious agents. All waste must be

applicable local, state, and federal regulations.

Index

of competitive ELISA results

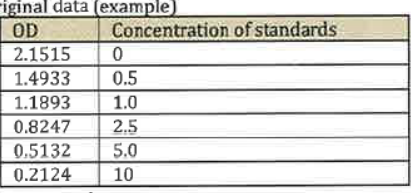

ards divided by that of

$Y: \log ($ base 10 or other) of (concentration of standards)

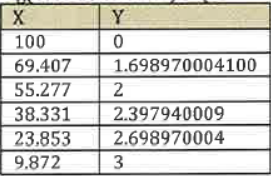

The standard curve is generated using some curve

software. (standard 0 is not used)

Linear Fit: $y=a+b x \quad$ CoefficientData: 0.99

$a=3.22 \mathrm{E}+00 \quad b=-2.19 \mathrm{E}-02$

5. Calculation of results

To process the sample O.D.: O.D.of samples divided by 2) To get $Y$ value using the above formulatio
3) To get the concentration of samples: 10 to the power of

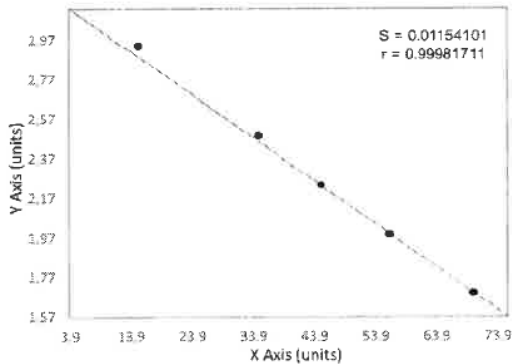

\section{Featured Products}

ppecies: Human, Mouse, Rat, Rabbit, Guinea Pig, Goat, Porcine, Canine, Bovine, Anserine, etc.

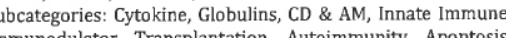
Tumor Immune, Hypersensitivity, Autoimmunity, Apoptosis, Hematology, Vascular, Signal Transduction, Neuroscience, Eye \&

Proteins and Antibodies $[>5,000)$ : Cytokines, Growth
and Viral Antigens

\section{Technical Services}

Neoscientific is your premier partner in ELISA. We can make various high-quality ELISA Kits for you based on your request. Our ELISA assays are designed for minimal manipulation and rapid use. This service from Neoscientifc allows you to focus on

Antibodies are critical research reagents. Neoscientific has extensive experience generating high quality monoclonal and as synthetic peptides. Using our reliable and tested immunization protocols we have had great success generating high-titer, high-affinity custom antibodies against a diverse se of antigens from numerous specles.
Peptide Synthesi

NeoPeptide offers a comprehensive range of Peptide Synthesis services from peptide sequence design advice to peptide modiffcations. Our emphasis is on providing high quality peptides at a compenphe prite. includes HPLC chromatograms to ensure purity and MS analysis to confirm identity.

Custom Protein Expression and Purification

services provide a including bacteria, yeast, baculovirus infected insect cells, and mammalian cells. With our proprietary optimization technology, the expression level can be significantly increased. We also offer ideal level of protein purity. We work in partsership with our clients to ensure efficient and high quality reagent protein production with customized solutions, flexible production scale, and proprietary technologies. We can also provide process purposes.

\section{Innovative Technology}

We offer our customers a novel technology platform for development of Post Translationally Modified (PTM) peptides and monitoring immune signatures, Our patent portfolio covers enzymes \& methods for production of these glycosylated PTMpeptides and biomarkers. We can provide our customers with ustom made glycosyla

MassAb ${ }^{m}$ : Low Cost-High Quality Monoclonal Antibodies We utilize a novel technology to display 6 peptides specific to your protein of interest on a highly immunogenic vector. This system has been used in over thousands projects delivering

Promotion: 12 Custom Monoclonal Antibodies for \$2,999

- A set of 12 independent custom $m A b s$

- Mice immunized with12 unique peptide antigens

- ELISA titer guarantee

More antibodiesavailable at additional ch

- Cells lines of your choice available at additional charge
Tel: $+1(888) 754-5670$ (Toll Free) or $+1(857) 259-4898$ Fax: $+1(888) 754-5670$ NEO Group Inc, 86 Cummings Park, Wobum, Massachuselts, US 0180
Email:info@Neobiolab.com http://www.Neobiolab.com 